\title{
WestVirginiaUniversity
}

THE RESEARCH REPOSITORY @ WVU

Graduate Theses, Dissertations, and Problem Reports

2004

\section{Reduction of natural gas engine emissions using a novel aftertreatment system}

Timothy S. Burlingame

West Virginia University

Follow this and additional works at: https://researchrepository.wvu.edu/etd

\section{Recommended Citation}

Burlingame, Timothy S., "Reduction of natural gas engine emissions using a novel aftertreatment system" (2004). Graduate Theses, Dissertations, and Problem Reports. 1482.

https://researchrepository.wvu.edu/etd/1482

This Thesis is protected by copyright and/or related rights. It has been brought to you by the The Research Repository @ WVU with permission from the rights-holder(s). You are free to use this Thesis in any way that is permitted by the copyright and related rights legislation that applies to your use. For other uses you must obtain permission from the rights-holder(s) directly, unless additional rights are indicated by a Creative Commons license in the record and/ or on the work itself. This Thesis has been accepted for inclusion in WVU Graduate Theses, Dissertations, and Problem Reports collection by an authorized administrator of The Research Repository @ WVU. For more information, please contact researchrepository@mail.wvu.edu. 


\title{
Reduction of Natural Gas Engine Emissions Using a Novel Aftertreatment System
}

\author{
Timothy S. Burlingame \\ Thesis submitted to the \\ College of Engineering and Mineral Resources \\ At West Virginia University \\ In partial fulfillment of the requirements \\ For the degree of \\ Master of Science \\ In \\ Mechanical Engineering \\ Mridul Gautam, Ph.D., Chair \\ Gregory Thompson, Ph.D. \\ W. Scott Wayne, Ph.D. \\ Department of Mechanical and Aerospace Engineering \\ Morgantown, WV \\ 2004
}

Keywords: Aftertreatment, Oxidation Catalyst, Emissions, Particulate Trap, Particulate Matter 


\section{ABSTRACT \\ Reduction of Natural Gas Engine Emissions Using a Novel Aftertreatment System}

\section{Timothy S. Burlingame}

The global objective of this study was to develop an exhaust aftertreatment system to reduce gaseous and particulate matter emissions from natural gas fueled vehicles. Specific objectives of this study were to evaluate and characterize emissions from a natural gas fueled vehicle powered by a Cummins C $8.3 \mathrm{G}+$ engine with and without the particulate matter (PM) filter and oxidation catalyst (OC) combination, which was designed and developed by West Virginia University in collaboration with LubrizolECS. Central Business District (CBD) Cycle tests were performed on West Virginia University's Transportable Emissions Testing Laboratory. A heavy-duty transportable chassis dynamometer and a dedicated "clean" dilution tunnel were used to sample emissions from the vehicle. Past studies indicate that the use of a clean dilution tunnel omits the possibility of background emission concentrations being higher than actual vehicle-out emissions. Therefore, a clean primary dilution tunnel was designed, fabricated, and implemented for use during this study to avoid contamination from tunnel history.

Three vehicle configurations were tested: 1) Baseline, 2) OEM Catalyst, and 3) WVU-Lubrizol particulate trap and oxidation catalyst system. Baseline emissions are sampled without any type of aftertreatment installed on the vehicle, and are the actual engine out emissions. Baseline emission levels were collected to aid in the determination 
of the effect of aftertreatment systems implemented during this study. Regulated emissions such as carbon monoxide $(\mathrm{CO})$, oxides of nitrogen $\left(\mathrm{NO}_{\mathrm{x}}\right)$, total hydrocarbons (THC), and particulate matter (PM) were sampled and analyzed during this study. Unregulated emissions such as polycyclic aromatic hydrocarbons (PAH), nitro-PAH, carbonyls, elemental metals, and volatile organic compounds (VOC) were also sampled and analyzed during this study.

Research has proven that nano-particulates are generated in both diesel and natural gas engines; with natural gas engine particulate number counts typically being higher than diesel engine particulate counts. Previous research has shown that the higher nano-particle emissions might be explained by the composition of natural gas exhaust in the vehicle stack. Being that carbonaceous particles are virtually absent in natural gas exhaust, lubrication oils are commonly accepted as the precursors to nano-particles. This indicates that lubrication oil precursors undergo nucleation in the exhaust system to form these nano-particles. Thus, the need to examine the chemical composition of natural gas exhaust, and more importantly develop aftertreatment systems that target toxic chemical species. Exhaust chemical speciation is the key to examining the chemical constituents in natural gas exhaust.

This study shows that with a particulate trap and an oxidation catalyst in series, baseline engine out emissions can be greatly reduced. Regulated PM emissions were reduced from $0.0388 \mathrm{~g} / \mathrm{mile}$ to $0.0007 \mathrm{~g} /$ mile indicating a reduction of over $98 \%$ when the WVU-Lubrizol Aftertreatment system was implemented. $\mathrm{NO}_{\mathrm{x}}$ was lowered from $37.7 \mathrm{~g} / \mathrm{mile}$ to $21.0 \mathrm{~g} / \mathrm{mile}$, which indicates a $44 \%$ reduction from baseline emission levels using the WVU-Lubrizol system. CO was lowered from $13.2 \mathrm{~g} / \mathrm{mile}$ to $0.13 \mathrm{~g} / \mathrm{mile}$ 
indicating a 99\% reduction from baseline levels via the WVU-Lubrizol system, and THC was lowered from $21.9 \mathrm{~g} / \mathrm{mile}$ to $11.8 \mathrm{~g}$ /mile indicating a $46 \%$ reduction from baseline levels. 


\section{Acknowledgements}

"If $\mathrm{A}$ is success in life, then A equals x plus y plus $\mathrm{z}$. Work is $\mathrm{x}$; $\mathrm{y}$ is play; and $\mathrm{z}$ is keeping your mouth shut." Albert Einstein (1879 - 1955)

First and foremost, I would like to give thanks to Dr. Mridul Gautam for affording me the opportunity to work with him during my graduate career. Dr. Gautam, your dedication, success, and ability to cope with the everyday nuisances have given me a sense of direction during my career here at WVU. All of the lessons you have taught me will be long remembered and never forgotten. Thank you for your guidance, faith, wisdom, and support.

Dr. W. Scott Wayne, I would like to thank you for your dedication, knowledge, and guidance throughout my graduate career at WVU. You have given me a strong foundation in what it takes to be successful. You have taught me lessons, albeit through humiliation and defeat, that I will never forget. Thank you for your guidance, faith, and support.

Dr. Gregory Thompson, I would like to thank you for your guidance throughout my graduate career. Your dedication and ability to pay attention to detail have taught me many lessons. Thank you for taking the time to guide me through the media labeling and tracking mine field that exists through the nature of the work. I will always remember to keep things I.P. Dr. Thompson, the greatest thing you have taught me is the ability to have fun and keep a good sense of humor while working. Again, thank you for your guidance, faith, humor, and support.

Mr. Ralph Nine, I would like to thank you for your guidance during my graduate career. Without your help, I would still be determining C's and H's. Thank you for your 
intuitive and intellectually stimulating conversations regarding data reduction methods. Your help will not be forgotten.

Dan Carder, Wesley Riddle, Richard Atkinson, Ryan Barnett, and many others thank you for your wisdom and intellectual input during my graduate career. Thank you for your teachings and your intuition. Without all of you, many things could not be achieved. I wish you all the best in the future.

Siram thank you for your support, teaching ability, and intellect. But most importantly, thank you for your Friendship. I wish you success and well being throughout life.

Katy, your support through life has given me a reason to work hard and give my career all that I have. Without you none of this would be possible or worthwhile. You give me strength, guidance, patience, support, hope, and faith. But most importantly, you have shown me that the path to success lies within. Thank you for all of your love, dedication, support, and faith.

Mom and Dad, without you I would never have been afforded the chance to gain the success I have gained. You have made sacrifices in life to provide for me and support me in all that I do, and for that I am extremely grateful. Words cannot express my gratitude to the both of you. Thanks and Love.

Chad, Heather, Mia, Curt, Darya, Dustin, Jessie, Granny, Pat, Jim, Gina, and Aaron, thank you for your support and love. I greatly appreciate all of the support you have given me over the years, and will continue to give in the future. Thank you.

Aaron W. Smith, from golf to drinks all I can say is, we never had a dull moment. Thanks for helping keep me sane and most of all thanks for your friendship. To anyone I 
may have forgotten to mention, you are only forgotten due to my cluttered mind and not my cold heart. Thank You. 


\section{Table of Contents}

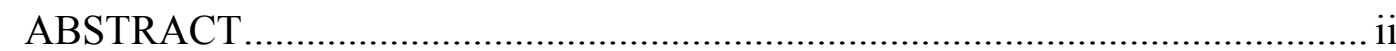

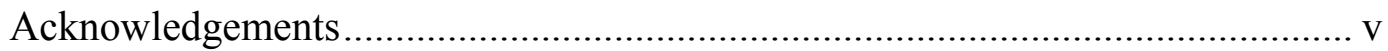

Table of Contents ............................................................................................

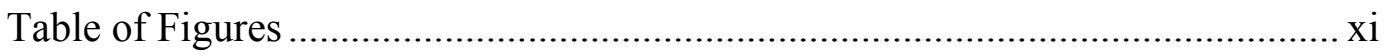

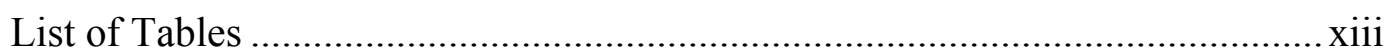

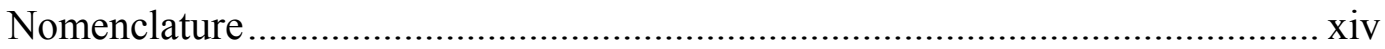

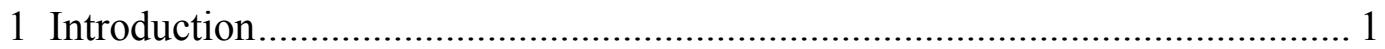

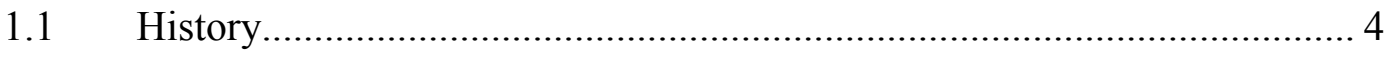

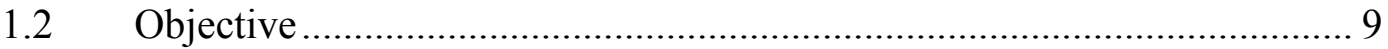

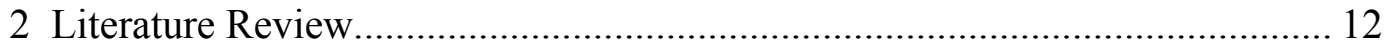

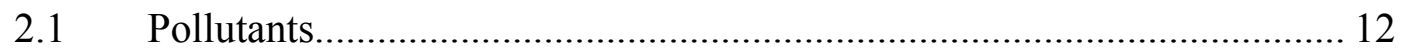

2.2 Engine Certification and Emissions Standards ......................................... 19



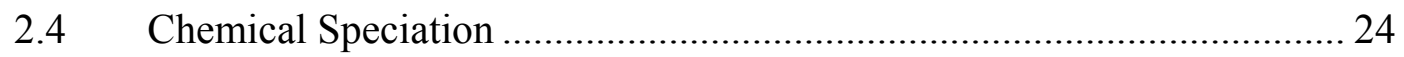

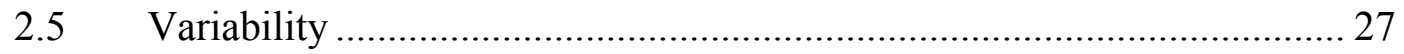

$2.6 \quad$ Aftertreatment Devices ....................................................................... 31

2.6.1 Oxidation Catalysts ............................................................................ 31

2.6.2 Diesel Particulate Filters ........................................................................ 34

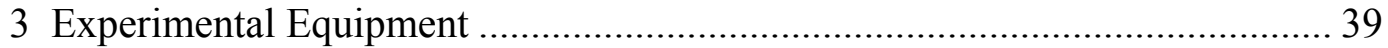

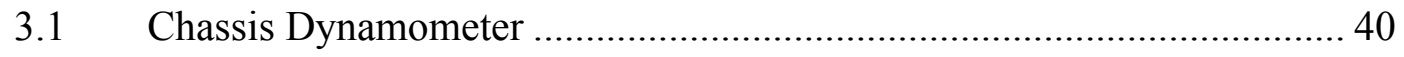

3.2 Dilution Air Filtration System ............................................................. 43

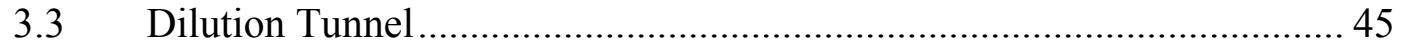

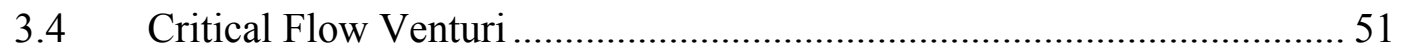

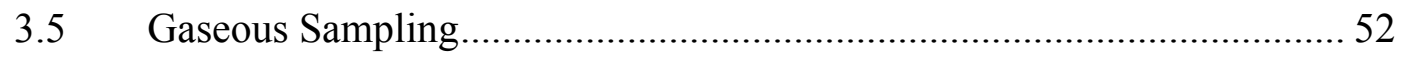

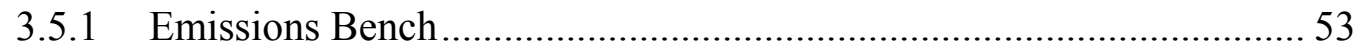

3.5.2 Regulated Emissions Sampling Trains ……………………………..... 56

3.5.2.1 Carbon Monoxide and Carbon Dioxide............................................ 57

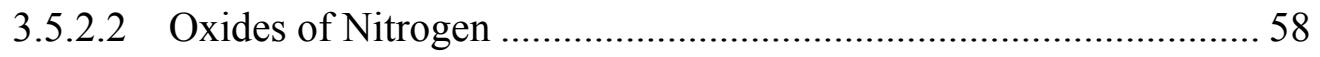

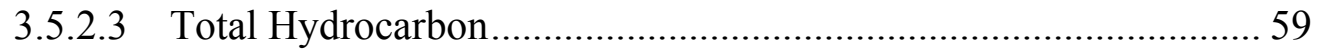






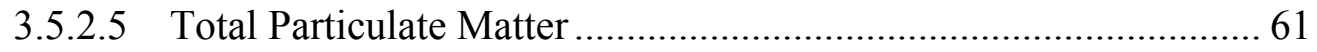

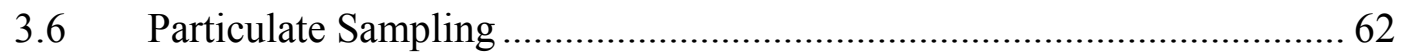

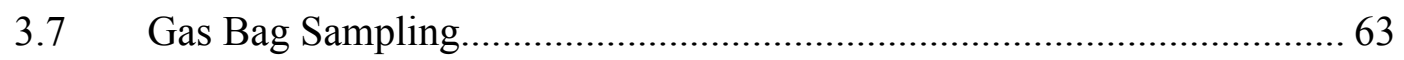

3.8 Temperature Control Module .................................................................. 63

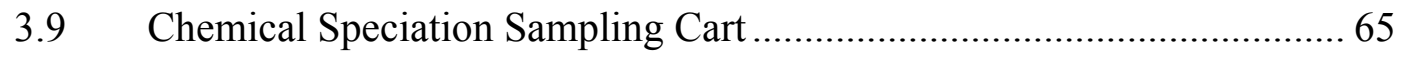

3.9.1 Volatile Compound Bag Sampling System ............................................ 65

3.9.2 Semi-Volatile Organic Compound Sampling System ............................. 66

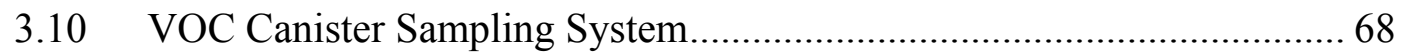

3.11 Instrumentation Control and Data Acquisition ......................................... 69

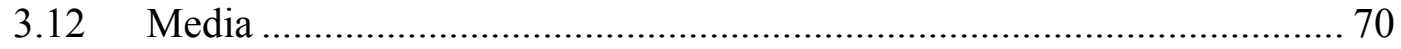

3.12.1 Media Conditioning and Weighing ................................................... 71

3.12.2 Media Labeling .......................................................................... 72

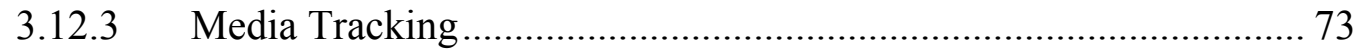

3.12.3.1 Media Arrival..................................................................... 73

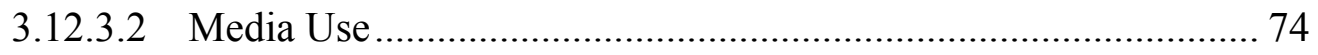

3.12.3.3 Media Departure ...................................................................... 74

4 Emissions Testing Process ............................................................................ 76

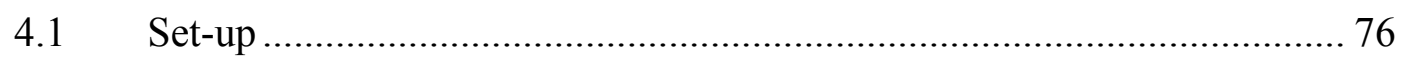

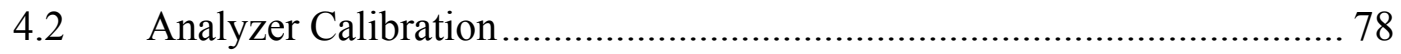

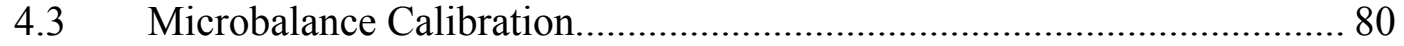

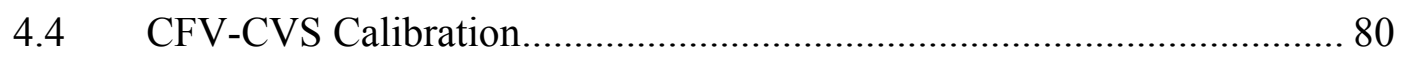

4.4.1 CFV-CVS Calibration Verification .................................................... 82

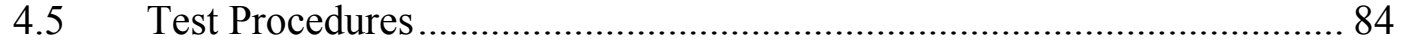

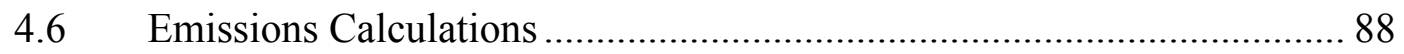

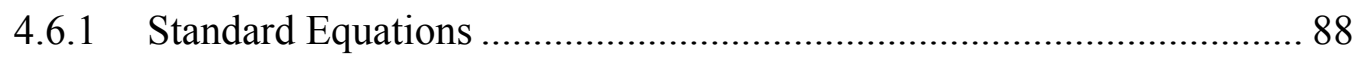

4.6.2 Equations for Calculating Regulated Emission Masses......................... 90

4.6.3 Equations for Calculating Unregulated Emission Levels ...................... 92

4.6.3.1 Elemental Metals Equations ....................................................... 94

4.6.3.2 Elemental Carbon and Organic Carbon Equations .......................... 95

4.6.3.3 Semivolatile and Particle-bound Organic Speciation ....................... 96 
4.6.3.4 Methane and Non-Methane Hydrocarbon Analysis 97

4.6.3.5 1,3-butadiene and BTEX On-Site Analysis................................. 99

4.6.4 Gravimetric Analysis of Particulate Matter ........................................ 99

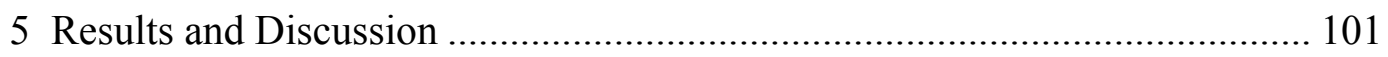

5.1 Background Emission Levels ............................................................. 102

5.2 Round 1: Vehicle Emission Levels..................................................... 105

5.2.1 Round 1: Regulated Emissions ................................................... 106

5.2.2 Round 1: Unregulated Emissions................................................. 108

5.3 Round 2: WVU-Lubrizol Aftertreatment System Emission Levels ....... 118

5.3.1 WVU-Lubrizol Aftertreatment System: Formulation and Protection 118

5.3.2 WVU-Lubrizol Aftertreatment System: Emission Reductions........... 121

5.3.2.1 Round 2: Regulated Emissions ........................................... 121

6 Conclusions and Recommendations ................................................ 125

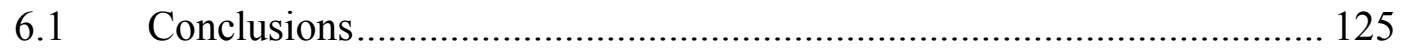

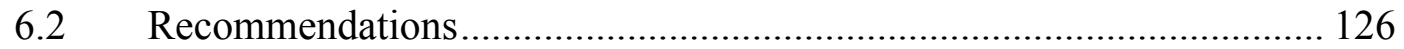

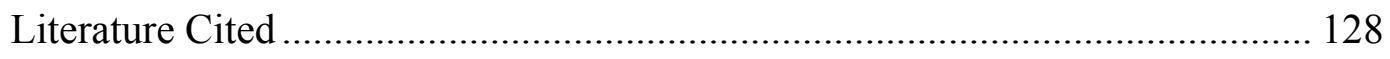

Appendix A: Vehicle and Engine Specifications......................................... 132

Appendix B: Vehicle Configurations and Test Matrix .................................. 133

Appendix C: WVU-Lubrizol Aftertreatment Specifications .......................... 134

Appendix D: VOC Sampling System Operation ........................................ 135

Appendix E: Lubrication Oil Analysis ........................................................ 137

Appendix F: Round 1 Speciation Results .................................................. 138 


\section{Table of Figures}

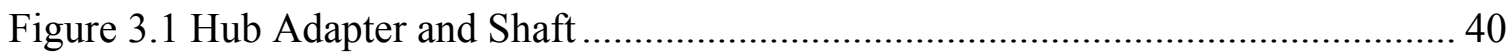

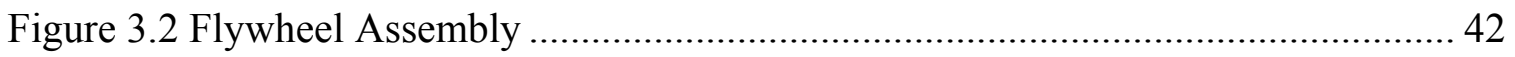

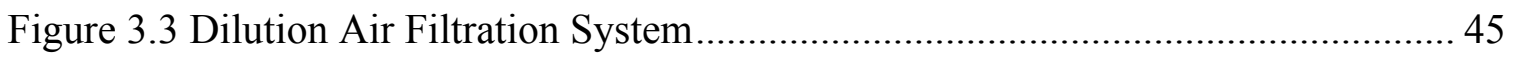

Figure 3.4 Sections 1 and 2 with Exhaust Transfer Tube and HEPA Dilution Air .......... 48

Figure 3.5 Regulated Emissions Sampling Zone with Secondary Dilution Tunnel ......... 49

Figure 3.6 Unregulated Emissions Sampling Zone ..................................................... 50

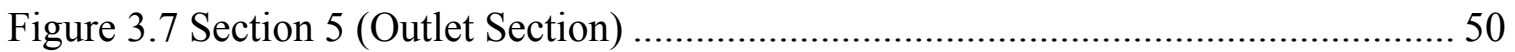

Figure 3.8 Particulate Matter Cyclonic Separator (URG, 2003) ........................................ 63

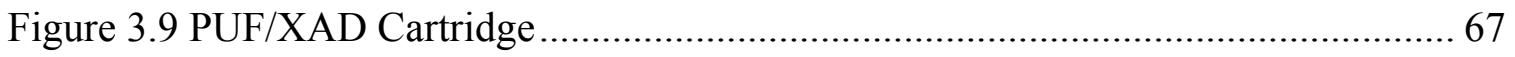

Figure 3.10 Chemical Speciation Cart without PUF/XAD Installed ................................. 68

Figure 3.11 VOC Sampling System Supplied by Environment Canada .......................... 69

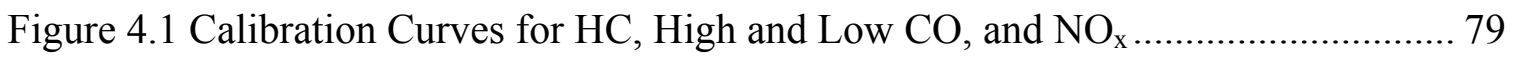

Figure 4.2 Test Vehicle Mounted on Chassis Dynamometer ........................................... 85

Figure 4.3 Exhaust Transfer Tube Connection ............................................................... 85

Figure 5.1 XRF Metal Background Levels from Round 1 .......................................... 103

Figure 5.2 1,3-butadiene and BTEX Background Levels from Round 1 ....................... 104

Figure 5.3 Background and Test Uncorrected Gravimetric Filter Mass Values............. 105

Figure 5.4 OEM Oxidation Catalyst Regulated Emission Reductions ........................... 107

Figure 5.5 OEM Oxidation Catalyst HC Emission Reductions...................................... 108

Figure 5.6 OEM Oxidation Catalyst Engine Wear Metal Emission Reductions............ 109

Figure 5.7 Lubrication Oil Emission Reductions Due to the OEM Catalyst.................. 111

Figure 5.8 PAH Reduction Due to OEM Catalyst....................................................... 112

Figure 5.9 Nitro-PAH Reductions Due to OEM Catalyst.............................................. 113

Figure 5.10 BTEX Reductions due to OEM Catalyst..................................................... 114

Figure 5.11 Aldehyde Reductions Due to the OEM Catalyst......................................... 116

Figure 5.12 PM Reductions Due to the OEM Catalyst................................................ 117

Figure 5.13 WVU-Lubrizol Aftertreatment Regulated Emission Reductions................ 122

Figure 5.14 WVU-Lubrizol Aftertreatment System HC Reductions............................... 123

Figure 5.15 WVU-Lubrizol Aftertreatment System PM Reductions ............................. 124 
Figure F.1 PAH Results With Background Values ...................................................... 138

Figure F.2 Carbonyl Results With Background Values................................................ 138

Figure F.3 Engine Wear Metal Results With Background Values ................................. 139

Figure F.4 Lubrication Oil Results With Background Values....................................... 139

Figure F.5 Hopane Results..................................................................................... 140

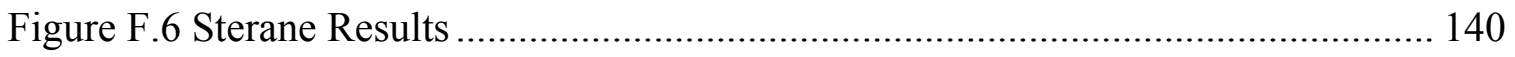

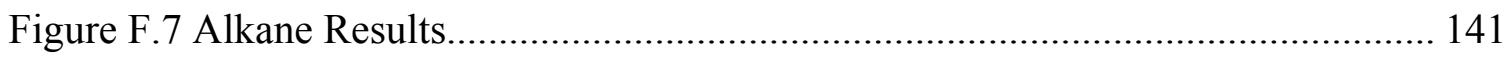

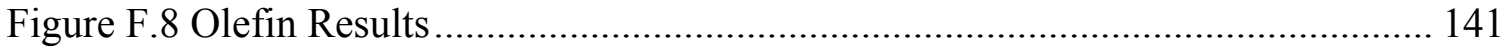

Figure F.9 C6 and Heavier Alkanes..................................................................... 142

Figure F.10 C6 and Heavier Olefins ....................................................................... 142

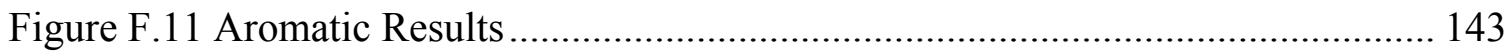

Figure F.12 Elemental Metal Analysis with Uncertainty .............................................. 143

Figure F.13 PAH Results with Uncertainty ................................................................ 144

Figure F.14 Nitro-PAH with Uncertainty ………………...................................... 144 


\section{List of Tables}

Table 1.1 EPA Emissions Standards for Heavy-duty Truck and Bus Engines

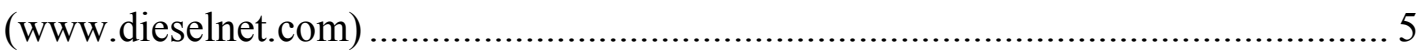

Table 1.2 California Emissions Standards For Heavy-duty Truck and Bus Engines



Table 1.3 Emission Standards Changed for 2007 and Later Model Year Engines

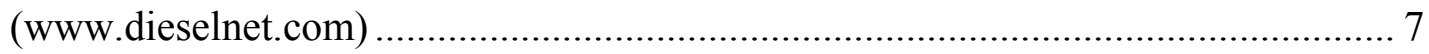

Table 1.4 Regulated and Unregulated Emissions Sampled ....................................... 10

Table 2.1 Volatile Organic Compound Classifications (Lev-On, 2002) ......................... 18

Table 2.2 Federal and California GVWR Classifications (www.dieselnet.com) ............ 19

Table 3.1 Venturi Sleeve Diameter and Flow Rates................................................. 52

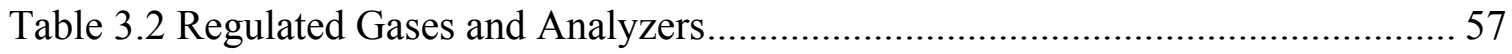

Table 3.3 Chemical Species and Collection Media .................................................... 70



Table 5.1 15 PAH Contributors Collected During Round 1 ....................................... 113

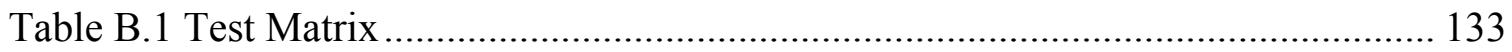




\section{Nomenclature}

BTEX - Benzene, Toluene, Ethyl Benzene, m\&p-Xylene, O-xylene

CAA - Clean Air Act

CARB - California Air Resources Board

CBD - Central Business District

CFR - Code of Federal Regulations

CFV - Critical Flow Venturi

$\mathrm{CO}$ - Carbon Monoxide

$\mathrm{CO}_{\text {mass }}-$ Mass of carbon monoxide

$\mathrm{CO}_{2}-$ Carbon Dioxide

$\mathrm{CO}_{2 \text { Mass }}-$ Mass of carbon dioxide

CVS - Constant Volume Sampler

Density $_{\mathrm{co}}$ - Density of carbon monoxide

Density $\mathrm{CO}_{2}$ - Density of carbon dioxide

Density ${ }_{\mathrm{HC}}$ - Density of hydrocarbons

Density $_{\mathrm{NO} 2}$ - Density of oxides of nitrogen

DNPH - 2,4-dinitrophenylhydrazine

DPF - Diesel Particulate Filter

EPA - Environmental Protection Agency

GC - Gas Chromatography

$\mathrm{HC}-$ Hydrocarbon

$\mathrm{H}$ - Absolute humidity of the engine intake air

$\mathrm{HC}_{\mathrm{d}}-$ Hydrocarbon concentration of the dilution air

$\left(\mathrm{HC}_{\mathrm{e}}\right)_{\mathrm{i}}$ - Instantaneous hydrocarbon concentration

$\mathrm{HC}_{\text {mass }}$ - Hydrocarbon emissions mass

HD - Heavy Duty

HEPA - High Efficiency Particulate Air

HFID - Heated Flame Ionization Detector

$\mathrm{K}_{\mathrm{H}}-$ Humidity correction factor

lpm - liters per minute

NDIR - Non-dispersive Infrared

NIST - National Institute of Standards and Technology

NMHC - Non-Methane Hydrocarbon

$\mathrm{NO}$ - Nitric Oxide

$\mathrm{NO}_{2}$ - Nitrogen Dioxide

$\mathrm{NO}_{\mathrm{x}}$ - Oxides of Nitrogen

$\mathrm{NOx}_{\text {mass }}$ - Oxides of nitrogen emissions mass

$\mathrm{O}_{2}$ - Oxygen

$\mathrm{O}_{3}$ - Ozone

OEM - Original Equipment Manufacturer

$\mathrm{P}_{\mathrm{B}}$ - Barometric pressure

$\mathrm{P}_{\mathrm{d}}-$ Saturated vapor pressure

Pd - Palladium

PM - Particulate Matter

ppm - Parts Per Million 
Pt - Platinum

PUF - Polyurethane Foam

$\mathrm{R}_{\mathrm{i}}$ - Relative humidity of the engine intake air, percent

SCAQMD - South Coast Air Quality Management District

scfm - Standard Cubic Feet per Minute

SMPS - Scanning Mobility Particle Sizer

SOF - Soluble Organic Fraction

SVOC - Semi-Volatile Organic Compounds

$\mathrm{t}$ - Test Time

TCM - Temperature Control Module

THC - Total Hydrocarbon

$\mathrm{V}_{\text {tunnel }}$ - Total Tunnel Flow without samples removed

$\mathrm{V}_{\text {full flow }}=$ Full Flow Tunnel Flow (lpm)

$\mathrm{V}_{\text {mini }}$ - Mini-dilution tunnel flow (lpm)

$\mathrm{V}_{\mathrm{pm} 1}$ - PM1 gravimetric sample flow rate (lpm)

$\mathrm{V}_{\mathrm{pm} 2.5}$ - PM2.5 gravimetric sample flow rate (lpm)

$\mathrm{V}_{\mathrm{pm} 2.5}$ - PM2.5 Elemental sample flow rate (lpm)

$\mathrm{V}_{\mathrm{pm} 2.5}$ - PM2.5 EC/OC sample flow rate (lpm)

$\mathrm{V}_{\mathrm{pm} 10}$ - PM10 gravimetric sample flow rate (lpm)

$\mathrm{V}_{\text {tpm }}$ - TPM sample flow rate (lpm)

$\mathrm{V}_{\text {puf } / \mathrm{xad}}-\mathrm{PUF} / \mathrm{XAD}$ sample flow rate (lpm)

VOC - Volatile Organic Compounds

WVU - West Virginia University

Translab - West Virginia University Transportable Heavy-Duty Vehicle Emissions Laboratory 


\section{Introduction}

The study presented in this work encompasses emissions testing of a Cummins C8.3G+ engine equipped with a catalyst and certified for ULEV emission levels by the California Air Resources Board (CARB). This study focuses on performing emission tests using a chassis dynamometer and emissions sampling system to evaluate emissions from said vehicle. Recent studies by WVU have been performed which include chemical characterization, bioassays, size-distribution of PM, and measurements of regulated and unregulated emissions. During the aforementioned studies, WVU and affiliates learned valuable lessons pertaining to tunnel history. High tunnel background levels are very detrimental to test results when testing Ultra-Low Emitting Vehicle (ULEVs). In 2001, a study was performed by Lev-On et al. (2002) to evaluate emissions from diesel vehicles operated on various fuels and equipped with diesel particulate filters. During this study chemical speciation was performed to chemically characterize exhaust emissions from trucks and buses. Chemical speciation plays a vital role in researching the relationship between chemical constituents and nano-particle formation. Research has proven that nano-particulates are generated in both diesel and natural gas vehicles, with natural gas engine number counts typically being higher than diesel engine counts. Nanoparticle emissions might be explained by the composition of natural gas engine exhaust in the vehicle stack. Being that carbonaceous particles are virtually absent in natural gas exhaust, lubrication oils are commonly accepted as the precursors to nanoparticles. This indicates that lubrication oil precursors undergo nucleation in the exhaust system to form these nanoparticles. Thus, arises the need to examine the chemical composition of natural gas exhaust, and most importantly develop aftertreatment systems that target toxic 
chemical species. Exhaust chemical speciation is the key to examining the chemical constituents in natural gas exhaust.

During Lev-On's (2002) study, emissions were sampled and evaluated on a mass per driving distance basis, and an extensive background emissions study was performed to determine the effects of background levels on the calculated emissions. Results from the background studies indicate that tunnel history and ambient background can severely compromise speciation results from exhaust samples collected from ULEVs, thus indicating the need for a sampling system without extensive tunnel history. A detailed review of previous studies has been performed and is presented in Chapter 2 of this work, and tunnel background analysis for this study is presented in Chapter 5 .

A trend to make ULEVs the norm in the heavy-duty vehicle industry demonstrates the need for more advanced emission sampling systems. In order to facilitate testing of ULEVs in the future, WVU has designed and implemented a "clean" dilution tunnel to be used in the evaluation of CNG fueled vehicle emissions. The "clean" tunnel will aid in reducing high background levels commonly associated with sampling systems that have extensive tunnel history, as has been shown by Lev-On et al. (2002).

The work herein is designed to concentrate on the characterization of CNG engine emissions, and not on engine development. The test procedure implemented in this study started with baseline emissions testing during Round 1 of the study. Baseline emission samples are the actual engine out emissions of the vehicle with no aftertreatment device installed. Baseline characterization provided a means for evaluating the performance of aftertreatment devices installed in the exhaust of the vehicle. After baseline emissions were sampled, the original equipment manufacturer (OEM) catalyst was installed and the 
vehicle was tested again to determine the effects of the OEM oxidation catalyst. A detailed analysis of baseline and OEM emission levels was performed and is discussed in Chapter 5 of this work. After Round 1 emission level evaluations, it was decided that an advanced aftertreatment system was in order. Engine Control Systems, WVU, and Lubrizol collaborated and designed a novel aftertreatment system that further reduced emission levels from said vehicle. The design of the novel aftertreatment system and its reduction characteristics are discussed in Chapter 5 of this work.

Epidemiological studies suggest that increases in air particulate levels may be associated with an increase in mortality and morbidity (Gautam, 2002). Areas of particular concern include the characterization and control of genotoxic respirable PM from heavy-duty engines; detailed chemical speciation and control of toxic emissions in engine exhaust streams with particular emphasis on carbonyl and polycyclic aromatic hydrocarbons; particulate size distribution and concentration from natural gas and diesel fueled vehicles; impact of lubrication oils on PM emissions, and design of appropriate exhaust sampling systems.

In past studies, WVU has played the lead role in evaluating PM emissions from heavy-duty engines. WVU has participated in and evaluated the characterization of regulated and unregulated emissions from natural gas and diesel fueled engines. WVU employs state-of-the-art testing facilities for performing in-use chassis dynamometer vehicle tests. Exhaust sampling systems designed according to CFR 40 accurately sample and analyze emissions from diesel and natural gas fueled vehicles. A chassis dynamometer and dilute exhaust sampling system designed and operated by WVU were 
used during this study, and are discussed in Chapter 3 of this work. This work will encompass the aforementioned procedures, goals, and outcomes of the study performed.

\subsection{History}

The Clean Air Act (CAA) of 1963 was established to enhance air quality and promote research and development in clean air technology. The CAA was implemented to reduce the emissions from an increasing industrial society, but an overlooked source of pollution soon became evident, automobiles. Thus, in 1970 automobile regulations were set by an amendment to the CAA that required vehicles to reduce their emissions by $70 \%$ to $90 \%$. In 1977 , the CAA was amended to include the regulation of exhaust particulate emissions from various vehicles manufactured during or after model year 1981. In 1990, the CAA was amended again to include regulations on heavy-duty diesel-fueled vehicles. The effort to lower emissions from vehicles aids in the enforcement of the CAA, which aims to reduce the overall amount of pollutants emitted to the environment.

Heavy-duty vehicles in use today, such as buses and tractors, are being subjected to the pressures of the ever-demanding need to convert to lower emissions internal combustion engine systems. Current combustion engineering technology incorporates the use of various clean fuels and exhaust aftertreatment devices to lower emissions from heavy-duty on-road vehicles. Fuels that are being considered clean fuels are low-sulfur diesel $(<15 \mathrm{ppmS})$, biodiesel, compressed natural gas $(\mathrm{CNG})$, and liquefied natural gas (LNG). Through the use of cleaner fuels and aftertreatment devices, toxic products of combustion will be reduced.

Pollutants formed during the combustion process include carbon monoxide $(\mathrm{CO})$, carbon dioxide $\left(\mathrm{CO}_{2}\right)$, volatile organic compounds (VOC), oxides of nitrogen $\left(\mathrm{NO}_{\mathrm{x}}\right.$, 
includes nitric oxide, $\mathrm{NO}$, and nitrogen dioxide, $\mathrm{NO}_{2}$ ), and Particulate Matter (PM).

These pollutants also contribute to the formation of other pollutants such as

photochemical smog and ozone $\left(\mathrm{O}_{3}\right)$, when they come into contact with sunlight and the atmosphere. To create a healthy environment for humans, plants, and animals, emissions standards are updated continuously by industrial and governmental agencies to increase air quality. Table 1.1 lists emission standards set by the EPA for heavy-duty trucks and buses.

Table 1.1 EPA Emissions Standards for Heavy-duty Truck and Bus Engines (www.dieselnet.com)

\begin{tabular}{|c|c|c|c|c|}
\hline \multicolumn{5}{|c|}{ Heavy-d u ty T ruck Engines } \\
\hline Y e a r & N O x & P M & C O & H C \\
\hline & $(\mathrm{g} / \mathrm{bh} \mathrm{h}-\mathrm{hr})$ & $(\mathrm{g} / \mathrm{bh} \mathrm{p}-\mathrm{hr})$ & $(\mathrm{g} / \mathrm{b} \mathrm{h}-\mathrm{hr})$ & $(\mathrm{g} / \mathrm{bh} \mathrm{p}-\mathrm{hr})$ \\
\hline 1988 & 10.7 & 0.60 & 15.5 & 1.3 \\
\hline 1990 & 6.0 & 0.60 & 15.5 & 1.3 \\
\hline 1991 & 5.0 & 0.25 & 15.5 & 1.3 \\
\hline 1994 & 5.0 & 0.10 & 15.5 & 1.3 \\
\hline 1998 & 4.0 & 0.10 & 15.5 & 1.3 \\
\hline
\end{tabular}

\begin{tabular}{|c|c|c|c|c|}
\hline \multicolumn{5}{|c|}{ Urban B us Engines } \\
\hline Year & N O x & P M & C O & H C \\
\hline & $(\mathrm{g} / \mathrm{bhp}-\mathrm{hr})$ & $(\mathrm{g} / \mathrm{bh}-\mathrm{hr})$ & $(\mathrm{g} / \mathrm{b} \mathrm{h}-\mathrm{hr})$ & $(\mathrm{g} / \mathrm{bh} \mathrm{p}-\mathrm{hr})$ \\
\hline 1991 & 5.0 & 0.25 & 15.5 & 1.3 \\
\hline 1993 & 5.0 & 0.1 & 15.5 & 1.3 \\
\hline 1994 & 5.0 & 0.07 & 15.5 & 1.3 \\
\hline 1996 & 5.0 & 0.05 & 15.5 & 1.3 \\
\hline 1998 & 4.0 & 0.05 & 15.5 & 1.3 \\
\hline
\end{tabular}

Emissions Standards for the State of California are set by the California Air Resources Board (CARB), and are listed in Table 1.2 (www.dieselnet.com). Generally, CARB specifications are more stringent than those of the EPA, due to the high emissions present in some California cities and counties. CARB indicate that diesel vehicles 
account for $4 \%$ of the vehicle population in California, but they contribute $38 \%$ of the oxides of nitrogen and about 50\% of the PM emissions (www.arb.ca.gov).

Table 1.2 California Emissions Standards For Heavy-duty Truck and Bus Engines (www.dieselnet.com)

\begin{tabular}{|c|c|c|c|c|c|}
\hline \multicolumn{7}{|c|}{ Heavy-duty Truck Engines } \\
\hline Year & NOx & PM & CO & HC & NMHC \\
\hline & (g/bhp-hr) & (g/bhp-hr) & (g/bhp-hr $)$ & (g/bhp-hr) & (g/bhp-hr) \\
\hline 1987 & 6.0 & 0.60 & 15.5 & 1.3 & $\mathrm{n} / \mathrm{a}$ \\
\hline 1991 & 5.0 & 0.25 & 15.5 & 1.3 & 1.2 \\
\hline 1994 & 5.0 & 0.10 & 15.5 & 1.3 & 1.2 \\
\hline
\end{tabular}

\begin{tabular}{|c|c|c|c|c|c|}
\hline \multicolumn{7}{|c|}{ Urban Bus Engines } \\
\hline Year & NOx & PM & CO & HC & NMHC \\
\hline & (g/bhp-hr) & (g/bhp-hr) & (g/bhp-hr) & (g/bhp-hr) & (g/bhp-hr) \\
\hline 1991 & 5.0 & 0.1 & 15.5 & 1.3 & 1.2 \\
\hline 1994 & 5.0 & 0.07 & 15.5 & 1.3 & 1.2 \\
\hline 1996 & 4.0 & 0.05 & 15.5 & 1.3 & 1.2 \\
\hline
\end{tabular}

The aforementioned emissions standards in Tables 1.1 and 1.2 are set for model year 1987 - 2003. More stringent regulations have been set for future heavy-duty engines depending upon model year and vehicle type. Model year 2004 and later emissions standards have changed for on-highway heavy-duty engines. $\mathrm{NO}_{\mathrm{x}}$ levels were lowered to $2.0 \mathrm{~g} / \mathrm{bhp}-\mathrm{hr}$ and manufacturers have the flexibility of certifying their engines using one of two options. Option 1 combines the $\mathrm{NO}_{\mathrm{x}}$ and $\mathrm{NMHC}$ values and the regulation is set at $2.4 \mathrm{~g} / \mathrm{bhp}$-hr. Option 2 separates the $\mathrm{NO}_{\mathrm{x}}$ and $\mathrm{NMHC}$ values and the regulations are set at 2.5g/bhp-hr $\mathrm{NO}_{\mathrm{x}}$ and 0.5g/bhp-hr NMHC. These changes take effect in 2004.

Standards were also revised for 2007 and later model year heavy-duty engines, and these changes are listed in Table 1.3. 
Table 1.3 Emission Standards Changed for 2007 and Later Model Year Engines (www.dieselnet.com)

\begin{tabular}{|c|c|}
\hline S p e cie s & 2007 L e ve \\
\hline & $(\mathrm{g} / \mathrm{b} \mathrm{h}-\mathrm{h} \mathrm{r})$ \\
\hline $\mathrm{P} \mathrm{M}$ & 0.01 \\
\hline $\mathrm{NO}_{\mathrm{x}}$ & 0.2 \\
\hline $\mathrm{N} \mathrm{M} \mathrm{H}$ & 0.14 \\
\hline
\end{tabular}

PM emission standards will be instituted in 2007 heavy-duty engine model year engines, while the $\mathrm{NO}_{\mathrm{x}}$ and $\mathrm{NMHC}$ will be phased in for engines between 2007 and 2010. Beginning in 2007, EPA and CARB will require in-field testing of in-use heavy-duty vehicles to determine emission levels in the Not-to-Exceed (NTE) zone. The results of the in-field testing will be used to develop cleaner running vehicles through the use of cleaner fuels, aftertreatment devices, and combinations of the two.

A majority of the heavy-duty vehicles in use today are operated using various grades of diesel fuel. But, combustion technology has enabled manufacturers to use compressed natural gas as an alternative to diesel. As with any fuel, CNG has it's pros and cons. Initially it was determined that $\mathrm{CNG}$ fueled vehicles emit less particulate matter than their diesel counterparts. This in fact is true, but further research has indicated that the particulate matter emitted from CNG fueled vehicles is of a much smaller size than that of diesel. The smaller size of the $\mathrm{CNG}$ particulate matter is more dangerous for humans due to its ability to be inhaled into the deep air sacs of the lungs where oxygen is transferred to the blood. This is an issue of great concern for researchers, and is still being investigated. Other negative aspects of $\mathrm{CNG}$ include the low availability of $\mathrm{CNG}$ fueling stations, poorer fuel economy, and cost of purchasing vehicles equipped with CNG 
engines. Southern California has increased the number of fueling stations for CNG fueled vehicles, but the availability in other states is much less.

Positive aspects of CNG include a lack of odor after combustion, safer storage, cleaner handling, and the lack of a wet spill occurrence. Employees at fueling stations have an easier time handling $\mathrm{CNG}$ and there is less likelihood of a spill during refueling. Risk of soil contamination due to underground storage is reduced because the fuel is in a gaseous state and maintained in a controlled environment, unlike diesel fuel, which is liquid and can spill into the soil in the case of a storage tank failure. Determining which fuel is better, diesel or CNG, is a losing battle and should be avoided. Instead, the testing of vehicles running on both fuels should continue, with fuel adaptations and aftertreatment devices being the main devices of investigation. These investigations will be best carried out using in-field testing procedures currently employed.

In-field testing must be performed using various fuels and aftertreatment devices to determine emission outputs of in-use heavy-duty vehicles, and ultimately determine the mass, size distribution, chemical characteristics, and physical (shape) characteristics of particulate matter (Gautam, 2002). In order to simulate on-road driving conditions during in-field testing, the heavy-duty vehicle must be tested using a transportable emissions laboratory capable of simulating actual vehicle driving conditions. West Virginia University's Heavy-Duty Vehicle Emissions Laboratory has been involved in countless studies involving heavy-duty vehicles, and has proven to be one of the top performing testing facilities in the United States. The laboratory is capable of sampling regulated and unregulated emissions, and is capable of performing emissions testing under transient and steady-state modes (Ferguson, 1993). West Virginia University's transportable 
laboratories include a chassis dynamometer and emissions trailer containing exhaust gas analyzers and dilution tunnels necessary for performing in-field testing. CFR 40 was used as a guideline when developing the transportable laboratory.

\subsection{Objective}

The global objective of this study was to develop an exhaust aftertreatment system to reduce gaseous and particulate matter emissions from natural gas fueled heavy-duty vehicles.

The specific objectives of this study were to evaluate and characterize emissions from a natural gas fueled vehicle powered by a Cummins $\mathrm{C} 8.3 \mathrm{G}+$ engine with and without a particulate matter trap and oxidation catalyst. To accomplish this objective a transit bus was tested using a multiple cycle Central Business District (CBD) testing procedure. Three vehicle configurations were implemented during this study. The three configurations include a baseline emissions test without a catalyst or trap installed, an emissions test with an OEM oxidation catalyst installed, and an emissions test with a WVU-Lubrizol-ECS formulated particulate trap and oxidation catalyst system installed.

Regulated emissions are sampled during any type of heavy-duty vehicle testing, but additional particulate matter and chemical speciation testing needs to be performed to quantify toxic pollutants. Although not regulated, many chemical species are toxic in high quantities, and contribute to the formation of nano-particles in natural gas engine exhaust streams. The collection and analysis of these unregulated chemical species will help to identify certain chemical compounds that are in abundance, and if necessary, help to implement strategies to reduce these species. The detection and quantification of chemical species will enable aftertreatment device specialists to design aftertreatment 
systems that can target and reduce the toxic chemical species, and reduce the nanoparticle count found in natural gas exhaust.

This study implemented the use of advanced systems to obtain results for regulated and unregulated emissions. Unregulated emissions samples were taken for a variety of chemical species and particulate matter. Chemical speciation helps to quantify the levels of harmful contaminants in the exhaust stream. These contaminants are not only harmful to living organisms, but also to the function of the vehicle. Certain species can contribute to the improper wear and aging of an engine. Thus, affecting the emission levels of the engine. Studies in this area are important to help quantify the contribution of these chemical species to the emission levels of in-use vehicles. Results from these studies can be used to develop cleaner fuels and oils, and aid in the advancement of aftertreatment systems.

Table 1.4 Regulated and Unregulated Emissions Sampled

\begin{tabular}{|c|c|}
\hline Regulated & Unregulated \\
\hline $\mathrm{CO}$ & VOC \\
\hline $\mathrm{NO}_{\mathrm{x}}$ & $\mathrm{PAH}$ \\
\hline $\mathrm{THC}$ & $\mathrm{n}$-PAH \\
\hline $\mathrm{TPM}$ & Carbonyls \\
\hline $\mathrm{CO}_{2}$ & $\mathrm{PM}_{10}$ Gravimetric \\
\hline $\mathrm{CH}_{4}$ & $\mathrm{PM}_{2.5}$ Gravimetric \\
\hline $\mathrm{NMHC}$ & $\mathrm{PM}_{2.5}$ EC/OC \\
\hline & $\mathrm{PM}_{2.5}$ Elemental \\
\hline & $\mathrm{PM}_{1.0}$ Gravimetric \\
\hline
\end{tabular}

Table 1.4 lists regulated and unregulated emissions sampled during this study. Regulated emissions were sampled using heated sampling trains discussed in 
Chapter 3. Unregulated emissions were sampled using a variety of sampling systems including cyclonic separators, canister sampling, PUF/XAD mass flow controlled system, and an aldehyde sampling train similar to that of the regulated systems. All of the unregulated sampling systems are discussed in Chapter 3.

The results of this study focus on the effects of a factory installed oxidation catalyst and a novel aftertreatment system developed by WVU and Lubrizol-ECS. Variations in $\mathrm{PM}, \mathrm{NO}_{\mathrm{x}}, \mathrm{CO}$, and THC due to the catalysts have been analyzed and reported. Chemical speciation data has been analyzed and reported as well.

In order to give the reader insight into the depth of emissions research and to validate practices performed by WVU, a literature review has been performed, and is presented in Chapter 2. Chapter 3 will discuss the experimental equipment. Chapter 4 discusses the set-up and operation of the laboratory and emissions calculations. Chapter 5 discusses the results of the study, and Chapter 6 yields conclusions about the study and recommendations for future research. 


\section{Literature Review}

West Virginia University's Transportable Heavy Duty Vehicle Emissions Testing Laboratory (Translab) has successfully preformed countless emission tests. These tests have pushed the limits of emissions testing and have combined various engines, fuel types, and aftertreatment devices to determine the best configuration for reducing emissions from in-use heavy-duty vehicles. Since the creation of the Translab, the amount of literature on the subject has increased dramatically. Many different teams around the world have conducted emissions testing and numerous papers have been published. Due to the vast amounts of literature, only those selected as relevant to the study at hand have been reviewed. This Chapter will summarize works that encompass the areas of pollutants, engine certification and emissions standards, sampling systems, emissions testing, and aftertreatment devices.

\subsection{Pollutants}

Emission levels from heavy-duty vehicles are continually being analyzed to establish what chemical compounds and constituents are responsible for the pollution of our environment. Evaluating chemical species in heavy-duty vehicle exhaust is critical in determining which species are carcinogenic, and which species contribute to the formation of nano-particles. Determination of these toxic species aids in the development of control strategies and regulations to limit these species. Most are familiar with the common pollutants, which include carbon monoxide (CO), oxides of nitrogen $\left(\mathrm{NO}_{\mathrm{x}}\right)$, hydrocarbons, and particulate matter. These pollutants are referred to as regulated pollutants in the scientific community, because they are regulated by federal and state agencies. But, these pollutants only summarize a small part of the pollutants 
found in vehicle emissions, particularly diesel and natural gas vehicles. Diesel and natural gas engine emissions are comprised of an amalgam of chemical species, which are considered toxic at high levels. These pollutants include, but are not limited to the following: 1) Volatile Organic Compounds (VOC), 2) Carbonyls, 3) Elemental metals, 4) Hopanes and Steranes, and 5) Methane. In this section, the regulated pollutants and the recently mentioned unregulated pollutants will be discussed and a relationship will be formed between each of the pollutants and their subcategories to help the reader understand how each contributes to pollution in our environment.

Carbon monoxide (CO) is an odorless, colorless gas released into the atmosphere primarily through incomplete combustion of carbon-based fuels (CASA, 2002). Vehicles are common emitters of $\mathrm{CO}$, but other sources include fireplaces, industry, aircrafts, and from the combustion of natural gas (CASA, 2002). Carbon monoxide is most commonly formed during oxygen deficient combustion of carbonaceous materials (Eastwood, 2000). Eastwood states, that it is primarily the air-to-fuel ratio that controls the formation of carbon monoxide; it is found that when there is not sufficient oxygen to burn the fuel, partial reaction products are formed. Localized oxygen deficient regions in the cylinder cause typically higher levels of $\mathrm{CO}$ in diesel engines. Other factors that influence $\mathrm{CO}$ formation include cold starting, high power during driving, acceleration, deceleration, and gear changes (Eastwood, 2000). The main environmental implication with carbon monoxide is seen through excessive human exposure. $\mathrm{CO}$ combines with the blood to form carboxyhemoglobin, which keeps the blood from delivering oxygen to the body (U.S.E.P.A., July 2003). High levels of CO can lead to heart attacks and strokes due to 
the lack of oxygen being delivered to the body and the brain. For these reasons, carbon monoxide levels in the environment must be monitored and reduced.

Oxides of nitrogen $\left(\mathrm{NO}_{\mathrm{x}}\right)$ are the combination of nitric oxide $(\mathrm{NO})$ and nitrogen dioxide $\left(\mathrm{NO}_{2}\right)$. Eastwood (2000) suggests that it is more convenient to group these oxides together because reactions in the atmosphere convert $\mathrm{NO}$ to $\mathrm{NO}_{2}$. Aside from the combustion of fossil fuels, oxides of nitrogen are emitted from welding, steel making, glass making, and the chemical industry (Eastwood, 2000). The formation of $\mathrm{NO}_{\mathrm{x}}$ occurs through a chain of high temperature reactions, indicating that $\mathrm{NO}_{\mathrm{x}}$ is not a direct product of combustion, but rather a secondary reaction. The formation of oxides of nitrogen is quickly quenched during the expansion stroke, but this only halts the formation of more $\mathrm{NO}_{\mathrm{x}}$. Thus the $\mathrm{NO}_{\mathrm{x}}$ generated during the combustion stroke remains in the cylinder. Health effects include respiratory irritation, decreased breathing capacity, and lung tissue damage. $\mathrm{NO}_{\mathrm{x}}$ may be labeled as a pollutant, but researchers have found that the oxidation of $\mathrm{NO}$ to $\mathrm{NO}_{2}$ aids in the oxidation process of carbon. When platinum catalysts are used, $\mathrm{NO}$ is converted to $\mathrm{NO}_{2}$ and certain reactions take place that facilitate in the combustion of particulate (Eastwood, 2000). Eastwood notes, that the most interesting outcome of the process is that no direct physical contact is necessary between the platinum and carbon for the oxidation to take place. This indicates that aftertreatment devices with platinum coating will facilitate in the $\mathrm{NO}_{\mathrm{x}}$ conversion process, and ultimately reduce particulates.

Particulate matter (PM) includes liquid and solid particles emitted during the combustion process. In the technical sense, PM does not refer to the visible black, blue, or white smoke typically associated with diesel engines, but rather refers to the 
microscopic particles present when the exhaust appears clear (Eastwood, 2000). The particulate matter that is regulated by governmental agencies is the Total Particulate Matter emitted during the combustion process. Particulates span a wide range of sizes, typically from the nano-particle to the micro-particle. The upper size limit according to Eastwood is normally 10 micrometers, designated as PM10, but the majority of the particles fall within the 100-200 nanometer size range. The formation of particulate matter is very intricate in nature because it involves many different unregulated pollutants found in the exhaust stream that tend to condense onto and nucleate with solid carbon particulate. Nano-particles have been found to form through nucleation processes in the exhaust stream. The formation and three different components responsible for PM will be discussed here, but the reader is encouraged to investigate the detailed formation characteristics found later in the author's writing and cited sources.

Eastwood (2000) best describes the formation of PM. He says that PM is conceived as soot nuclei in the highly oxygen-deficient core of fuel sprays, with the first recognizable particles being less than 2 nanometers in diameter (Eastwood, 2000). Eastwood says that initial particles are formed from fuel molecules by fragmentation, condensation and polymerization, and dehydrogenation. After their formation, the particles grow through several processes. Surface growth is a process in which particles change size due to the incorporation of gas phase molecules in the spray mixture. The combination of particles is another method through which particles are formed. The formation of these particles continues until they eventually form clusters or chains consisting of thousands of particles. Eastwood states, "Not all of the particles are emitted from the engine, and in fact a large fraction of them are removed through heterogeneous 
oxidation reactions when the spray core subsequently mixes with the rest of the charge." PM continues to form even after the combustion process has taken place. Ambient cooling and dilution of exhaust gases causes particulate matter to "take-up" gaseous organic compounds and sulphates (Eastwood, 2000).

Scientists and researchers typically classify PM in three categories, which stem from chemical methods used in compositional analysis. Eastwood (2000) lists the three categories as the insoluble fraction, sulphates, and the soluble fraction. The insoluble fraction is the PM originally emitted by the engine. It is solid and composed primarily of carbon, but does contain small amounts of incombustible ash. The ash found in the insoluble fraction is typically derived from lubricants. Natural gas emissions typically have low levels of carbonaceous materials, indicating smaller insoluble fractions. Sulphates are derived from fossil fuels and lubrication oils. According to Eastwood, sulphur is emitted from the engine as sulphur dioxide and sulphur trioxide. Sulphates are formed by reactions between sulphur trioxide and water. Sulphur dioxide is not a problem alone, but due to the ease of its oxidation to sulphur trioxide, it can easily contribute to the PM. If sulfuric acid in the exhaust stack were to nucleate, the nuclei would serve as absorption sites for the semi-volatile and heavier hydrocarbons. This nucleation and absorption would significantly increase the concentration of nanoparticles in the exhaust. The soluble fraction of PM is typically referred to as the Soluble Organic Fraction (SOF). The SOF is a highly complex combination of high molecular weight compounds derived from the fuel and lubricant (Eastwood, 2000). The SOF is comprised of three major groupings. These groupings all belong to a group of compounds classified as Volatile Organic Compounds (VOC), and are the unburned 
hydrocarbons, oxygenated hydrocarbons, and Polycyclic Aromatic Hydrocarbons. Volatiles in PM are classified as the SOF and sulphates due to the fact that they are only formed when temperatures have fallen sufficiently low enough to allow condensation and adsorption to occur (Eastwood, 2000). Eastwood states that it is essential to realize that PM is not stable, and that it can change dramatically depending on operating conditions, fuel, ambient conditions, etc... Again, the author encourages the reader to further investigate the formation and complexity of PM to gain a better understanding of its nature.

Eastwood (2000) defines the Volatile Organic Compounds (VOC) as being, "carboncontaining compounds present in the gaseous state at ambient temperatures." This definition leads to the complexity of chemical species found under the heading of VOC. Typically, VOCs are associated with hydrocarbon compounds. While this is not untrue, it should be understood that the hydrocarbons are divided into four major subgroups, and that there are non-hydrocarbon compounds listed under the VOC heading. The hydrocarbon subgroups include alkynes, alkenes, alkanes, and aromatics. Alkanes are molecules with single hydrogen-carbon bonds. Alkene molecules contain single and double bonds, and alkynes contain single, double, and triple bonds. To further separate the organic species, Lev-On et al. (2002) created a matrix that divided the VOC's into five categories. These categories make it easier to collate the chemical species once they have been identified, and can be found in Table 2.1. 
Table 2.1 Volatile Organic Compound Classifications (Lev-On, 2002)

\begin{tabular}{|c|c|}
\hline Compound & Description \\
\hline C2-C5 Alkanes & $\begin{array}{c}\text { Light Saturated } \\
\text { Hydrocarbons }\end{array}$ \\
\hline $\begin{array}{c}\text { C6 and Higher } \\
\text { Alkanes }\end{array}$ & $\begin{array}{c}\text { Remaining Saturated } \\
\text { Hydrocarbons }\end{array}$ \\
\hline C2-C5 Olefins & $\begin{array}{c}\text { Light Olefin compounds } \\
\text { with one or more } \\
\text { unsaturated bonds }\end{array}$ \\
\hline $\begin{array}{c}\text { C6 and Higher } \\
\text { Olefins }\end{array}$ & $\begin{array}{c}\text { Remaining Olefin } \\
\text { Compounds }\end{array}$ \\
\hline Aromatics & $\begin{array}{c}\text { All Compounds (up to } \\
\text { C10) with at least one } \\
\text { benzene ring }\end{array}$ \\
\hline
\end{tabular}

The non-hydrocarbon VOC constituents include ketones and aldehydes. The most common aldehydes include formaldehyde, acrolein, and acetaldehyde. According to Eastwood, normally organic compounds are low in conventional fuels, but alternative fuels can have high levels of these compounds such as methyl tertiary butyl ether (MTBE) in gasoline, and formaldehyde in methanol and natural gas.

VOCs of major concern are the aromatics and the aldehydes. Benzene is toxic and is a carcinogen, and studies show that around $80 \%$ of the benzene in the atmosphere is emitted from automobiles. Since benzene is the life source of aromatic compounds, alleviating it from the products of combustion would be a start to reducing the aromatic levels. According to Eastwood, "Automobiles make a large contribution to the formaldehyde found in urban areas," but this statement is difficult to quantify due to the potential of aldehydes to form from secondary reaction in the atmosphere (2000).

Lev-On et al. (2002) have performed chemical speciation studies on diesel engine equipped vehicles with various diesel fuels and aftertreatment devices, and on CNG 
fueled buses. These studies help to support the need for further investigation into the realm of unregulated emissions and nano-particle formation. These studies are used as a quantitative analysis of unregulated chemical species and are discussed later in this Chapter. These papers have been used as a basis for continuing research into the field of unregulated emissions. It is important to remember that lubricating oil plays a vital role in the emissions of unregulated species, and that these species play a vital role in the formation of not only particulate matter, but specifically nano-particulates.

\subsection{Engine Certification and Emissions Standards}

Heavy-duty highway vehicles are classified depending upon their GVW (Gross Vehicle Weight). The GVWR (Gross Vehicle Weight Rating) classifies heavy-duty vehicles in three categories, light HD (heavy-duty) diesel vehicles, medium HD diesel vehicles, and heavy HD diesel vehicles (Table 2.2).

Table 2.2 Federal and California GVWR Classifications (www.dieselnet.com)

\begin{tabular}{|c|c|c|c|c|}
\hline \multirow{2}{*}{$\begin{array}{c}\text { Engine } \\
\text { Classification }\end{array}$} & \multicolumn{2}{|c|}{ GVWR Federal } & \multicolumn{2}{c|}{ GVWR California } \\
\cline { 2 - 5 } & Low (lbs) & High (lbs) & Low (lbs) & High (lbs) \\
\hline Light Heavy-Duty Diesel Engines & 8500 & 19500 & 14000 & 19500 \\
\hline Medium Heavy-Duty Diesel Engines & 19500 & 33000 & NA & NA \\
\hline Heavy Heavy-Duty Diesel Engines & 33000 & $>33000$ & NA & NA \\
\hline
\end{tabular}

Vehicles that are below 10,000 pounds and are used for personal transportation are classified as medium-duty passenger vehicles. The classification as a medium-duty passenger vehicle makes them fall under light-duty emissions classifications. Therefore, the same engine may be used in two different vehicles, but depending on the use of the vehicle, the legislation enacted upon the emissions of the vehicle will vary (www.dieselnet.com). 
Emissions testing for heavy-duty vehicles can be tested using a chassis dynamometer, an engine dynamometer, or in-use testing equipment. Federal regulations do not require that heavy-duty vehicles be chassis tested and certified, only that the engines are certified (www.dieselnet.com). The Federal Test Procedure (FTP) is the primary test for certifying engines. The Supplemental Emissions Tests (SET) and the Not-To-Exceed (NTE) are other tests used in the United States for on highway engine certification. The SET is a 13-mode steady-state test that represents the performance of a heavy-duty vehicle on the freeway, and the NTE is a set of limits that have been introduced to make sure that the engine emissions are controlled over the full range of the vehicles speed and load. The NTE sets limits that the emissions levels from the engine must not exceed (www.dieselnet.com). As stated in the introduction to this work, emissions standards are set by the federal and state agencies. State agencies can set their own standards as long as the standards meet or exceed those set forth by the Environmental Protection Agency. Information regarding these standards can be found in Tables 1.1, 1.2, and 1.3 of this work.

\subsection{Emissions Testing}

Many different methods of experimentally determining emission outputs of in-use heavy-duty vehicles have been performed. Current experimental technologies include engine dynamometer testing, chassis dynamometer testing, on-road actual emissions testing, and predictive emissions modeling/testing. The engine dynamometer and chassis dynamometer testing methods use analyzers housed in a stationary analytical bench, whereas the on-road testing uses analyzers that are housed in the cab of the test vehicle. 
Experiments using the aforementioned testing methods will be the discussion of this section.

Lev-On et al. (2002) performed a multi-year study that implemented a chassis dynamometer testing facility to perform chemical characterization studies. The chassis dynamometer testing facility was supplied and operated by West Virginia University. Sampling considerations typically not implemented, included a speciation cart for proportional sample collections, heated sampling for organic speciation, heated carbonyl (DNPH) sampling system, $\mathrm{PM}_{2.5}$ cyclone for $\mathrm{EC} / \mathrm{OC}$ sample collection, $\mathrm{PM}_{10}$ cyclone for SOF analysis, and a separate sampling for dioxins and furans. The sampling system effectively collected sample media for the analysis of $\mathrm{CO}, \mathrm{NO}_{\mathrm{x}}, \mathrm{THC}, \mathrm{PM}$, particle bound and semi-volatile organic species, NMHC, inorganic ions, inorganic elements, carbonyls, elemental and organic carbon, gravimetric PM, dioxins, and furans. Results obtained and lessons learned during this study are discussed in Section 4 of the current Chapter.

A project conducted by the Coordinating Research Council (2003) and several other organizations made use of the WVU transportable laboratory to conduct studies on regulated and unregulated gaseous and PM emissions from vehicles in California's South Coast Basin. The study was referred to as the E-55/E-59 study. The study implemented sampling trains to sample VOCs, methane, SVOCs, PAH, Nitro-PAH, carbonyls, nitrosamines, $\mathrm{PM}$ SOF, elemental species, ammonium, $\mathrm{EC} / \mathrm{OC}$, and $\mathrm{PM}_{2.5}$ for gravimetric analysis. The laboratory successfully tested numerous vehicles and aided in the quantification and evaluation of emissions for diesel fueled vehicles.

Clark et al. (1984) discussed various applications of diesel transient testing. They placed an emphasis on the Federal Heavy-Duty Truck exhaust emissions test procedure, 
and identified the key element of transient testing as the dynamometer. According to Federal Test Procedures, simulation of vehicle operation by a dynamometer requires both absorbing and motoring capabilities. Torque and speed control were other issues in the testing of vehicles on a dynamometer. If the dynamometer is fast enough, it can control the speed of the vehicle, but the torque is left to the control of engine fueling. A direct current (DC) dynamometer was chosen along with electrical solenoid actuators. Although the facility was capable of simulating actual transient cycles recorded from vehicles, only the Federal Test Procedure (FTP) cycle was employed. During a test procedure engine exhaust was directed into a double dilution constant volume sampler (CVS) system. Preconditioned dilution air was drawn into the system by two variable speed positive displacement pumps (PDP). Both continuous and bag samples were collected for the analysis of regulated emissions. Double dilution methods were employed for the sampling of particulate matter. The objective of this study was to determine the appropriate testing equipment for transient testing of diesel engines. The paper focused on the need for accurate and quick control of load and speed during the test procedure. Little emphasis was placed on the testing equipment since the same equipment can be used for transient testing as is used for steady state testing as long as the response times are adequate.

CFR 40 describes heavy-duty engine certification using the EPA heavy-duty engine transient cycle. These tests were performed on engines and not on the actual vehicle, thus creating question about the validity of the emissions factors obtained during a test. Dietzmann and Warner-Selph (1985) used an equivalent vehicle distance for the engine transient cycle of 6.18 miles for the average vehicle. Using this equivalent distance it 
was possible to estimate emissions factors. This study attempted to correlate the transient engine test cycle with a chassis version. Gaseous and particulate emissions were obtained from three tandem-axle tractors and a city bus operating over the chassis version of the EPA transient cycle. The engines were then removed from the vehicles and tested over the EPA heavy-duty diesel engine transient procedure. Emissions results were compared in $\mathrm{g} / \mathrm{mile}$ and $\mathrm{g} / \mathrm{kg}_{\text {fuel }}$. Correlation of engine and chassis transient tests depends on many factors, namely the assumptions made in vehicle frontal area, gross vehicle weight of the test vehicle, as well as the specific engine to chassis match. Tires, transmission, and other vehicle components also affect the results obtained during testing. The testing performed demonstrated poor correlation between the chassis test and the engine dynamometer testing, and it was recommended that further research be performed to investigate the differences in the testing methods.

Rideout (1991) presented emissions data from a number of urban buses powered by various engines and fuels. The data were used to evaluate the effects of driving cycles on emissions. The selected vehicles were tested on a heavy-duty chassis dynamometer, which simulated the inertia weight and road load forces that a vehicle typically experiences during in-use operation. Exhaust from the vehicles was diluted using a large single dilution CVS. Total hydrocarbons were determined on a continuous basis using a heated flame ionization detector (HFID). Emission rates of $\mathrm{CO}$ and $\mathrm{CO}_{2}$ were determined by collecting a proportional sample of dilute exhaust in tedlar bags, and analyzing the bag contents using nondispersive infrared (NDIR) instruments. $\mathrm{NO}_{\mathrm{x}}$ emissions rates were determined also by collecting a proportional sample of the dilute exhaust in tedlar bags, but a chemiluminescent analyzer was used to analyze the sample. 
Carbonyls were collected using 2,4-dinitrophenylhydrazine (DNPH) coated silica gel cartridges for subsequent measurement of the derivatives using high performance liquid chromatography. Hydrocarbon speciation was conducted by drawing a sample from the tedlar bags, and analyzing the contents using gas chromatography. Vehicles operated on diesel, gasoline, liquid petroleum gas, and compressed natural gas fuels were evaluated over the EPA Heavy Duty Chassis Transient Cycle, the Central Business District Cycle, the New York Bus Cycle, and the New York Composite Bus Cycle. Emission rates have been collected and reported over the various tests.

\subsection{Chemical Speciation}

Chemical speciation plays an important role in quantifying toxic and carcinogenic chemical compounds emitted from vehicles. Lev-On et al. (2002) performed one of the initial chemical characterization studies in the spring of 2001 to compare the exhaust emissions of several trucks and buses equipped with and without aftertreatment devices using various fuels. The chemical speciation was performed to quantify volatile organic hydrocarbons (VOC), polycyclic aromatic hydrocarbons (PAH), nitro-PAH, carbonyls, polychlorodibenzo-p-dioxins (PCDD) and polychlorodibenzo-p-furans (PCDF), inorganic ions, elements, $\mathrm{PM}_{10}$, and $\mathrm{PM}_{2.5}$ in diesel exhaust. Tests were performed using four diesel vehicles and two compressed natural gas vehicles. A school bus and two grocery trucks were operated over the City Suburban Heavy Vehicle Route (CSHVR) and three city buses were operated over the Central Business District (CBD) cycle. The school bus and grocery trucks were tested with their original exhaust systems and subsequently fitted with DPFs. The transit buses were equipped with dedicated CNG engines without particle filters or oxidation catalysts. All tests were performed on the chassis 
dynamometer described in Section 3 of this Chapter. Details of the testing methodology and set-up are left as research for the reader. The vehicle exhaust was diluted with HEPA filtered ambient air in a total exhaust double-dilution CVS. Tests were performed using one set of filter media over multiple test cycles to collect adequate samples for analysis. Results indicated that elemental emissions from all vehicles were reduced when a diesel particulate filter was used, ionic species from all fuel/vehicle/filter combinations were very low, fuel and aftertreatment combinations gave different results depending on the vehicle type and the results indicated a decrease in the levels of PM, BTEX, and elemental emissions. On a per mile basis, vehicles retrofitted with DPFs and fueled with ECD emitted $91 \%$ to $99 \%$ less PM, CO, and THC when compared to CARB diesel (control group) vehicles with their original exhaust systems. DPF reductions were shown to be in the range of $70-90 \%$, with variability due to individual vehicles and test days. NMHC and aldehyde levels were both greatly reduced for diesel-fueled vehicles equipped with DPF's. PAH levels were similar for DPF equipped diesel vehicles and CNG fueled vehicles, with some variability.

During Lev-On's study, valuable lessons regarding background emission levels were learned. The authors emphasized that great care needs to be taken when performing this type of testing, especially when emissions levels are expected to be near, or at the background levels. Background levels proved to be extremely close to the dilute emission levels sampled, indicating that tunnel history played a vital role in the quantification of engine emissions. Not only do background levels from the ambient air source become a factor, but levels inside of the tunnel also contribute to the background emissions. During vehicle operation, the high temperature dilute exhaust causes 
chemical species trapped on the tunnel wall to outgas and reenter the flow stream. This outgassing adds to the error inherent in this type of testing. This information was taken from SAE Papers 2002-01-0432 and 2002-01-2873. The papers give suggestions for future testing and state conclusions about the effects of fuel and aftertreatment devices.

LeTavec et al. (2002) performed a yearlong evaluation of trucks and buses equipped with passive diesel particulate filters. Vehicles were retrofitted with two types of catalyzed DPFs and operated on ultra-low sulfur diesel fuel for over one year. Seven vehicle fleets were used in this study, which included heavy-duty trucks, light-duty trucks, buses, and tram vehicles. Five fleets of vehicles were discussed in the paper, with each fleet containing vehicles fueled with California diesel fuel (control vehicles) and vehicles operated on ultra-low sulfur diesel fuel with or without a DPF (test vehicles). Three different test fuels were used and three different exhaust aftertreatment systems were used. The vehicles were initially tested after installation and tested again after one year of operation. The study aimed to determine if various aftertreatment devices' reduction of emissions deteriorated over time. Testing was performed on a heavy-duty chassis dynamometer. Grocery trucks, tanker trucks, and school buses were operated over the CSHVR cycle, while the transit buses and refuse haulers were operated over the CBD cycle. Engine emissions were diluted with HEPA filtered air in a full flow dilution tunnel. The HEPA filtered air helps to eliminate atmospheric PM from entering the dilution area of the dilution tunnel. Particulate matter was collected on Teflon filters and analyzed for soot, volatile organic fraction, and sulfate. $\mathrm{NO}_{\mathrm{x}}$ levels were determined using two chemiluminescent analyzers to estimate the $\mathrm{NO}$ and $\mathrm{NO}_{2}$ split for vehicles equipped with DPFs. Multiple runs were performed on a single set of media to ensure 
that sufficient emissions levels were obtained. Results indicated that test vehicles retrofitted with catalyzed DPFs and fueled with ultra-low sulfur diesel fuels had over $90 \%$ lower particulate emissions than control vehicles without aftertreatment. No significant deterioration of particulate matter emissions was evident from retrofitted vehicles after one year. $\mathrm{CO}, \mathrm{NO}_{\mathrm{x}}$, and $\mathrm{PM}$ levels were lower in retrofitted test vehicles than in control vehicles. Other variables were also considered, such as fuel economy and cost of operation. Details on aftertreatment devices can be found in Chapter 2, Section 6.2.

\subsection{Variability}

Kittelson and Johnson (1991) studied the sources of variability in particulate measurements using the heavy-duty transient test. The study included an examination of the test procedures, visits to various testing facilities to compare and contrast facility design and procedure, and a development of a simplified model of the procedures and systems used in the heavy-duty transient testing. Sources of variability studied include particle deposition and reentrainment, outgassing, cycle matching, combustion and dilution air conditioning, tunnel/sampling system design, and filtration errors.

Particle deposition and reentrainment are very exhaustive issues in performing emissions testing using dilution tunnels. During the testing process particles attach themselves to the walls of the tunnel. There are many different methods in which a particle may become attached to the tunnel; such methods include, but are not limited to, mechanical processes, phoretic losses, and electrostatic effects. Mechanical processes include inertial effects and diffusion through the boundary layer. Phoretic losses include diffusiophoresis, Stephan Flow, and thermophoresis. Diffusiophoresis is due to an 
imbalance of momentum transfer to the particle that results from a concentration gradient in the gas phase. Stephan Flow phenomenon is the hydrodynamic flow of a gas-vapor mixture normal to the surface of a condensing or evaporating liquid, which compensates for gas diffusion away from or toward the surface. Thermophoresis is the entrainment of a particle to the wall due to a temperature gradient. Many times thermophoretic forces are created when dilution systems are improperly insulated, or dilution ratios are incorrect. In order to eliminate thermophoretic effects, proper tunnel insulation is recommended and temperature control where needed. Electrostatic effects are those in which the dilution tunnel or any subsystem that is collecting a particulate sample becomes statically charged, and the particulate itself is also charged. The static electricity in the components can cause particulates to adhere to these surfaces and not to the filter. Static charges can be eliminated from the tunnel and subsystems through the use of proper tunnel grounding techniques. Reentrainment and outgassing may occur anywhere in the sampling system. Reentrainment is the process by which solid particles deposited in the sample system release and become entrained into the sample stream, thus increasing the amount of particulate in the sample. Reentrainment is a problem because the amount of particulate released and the time at which the particulate was released is not definable. During testing the effects of reentrainment can be seen when filter weights are compared and several tests have corresponding values, but one test exhibits a higher value. Outgassing is the process by which the vapor from deposits is released into the sample stream, thus increasing the amount of soluble organic fraction (SOF). Outgassing has the same effect on vapor levels as reentrainment has on particulate levels. Reentrainment and outgassing are very unpredictable processes and require further 
review to determine methods best suited for eliminating these causes of variability. Today, the best methods for reducing these effects include: proper insulation and grounding.

Cycle matching is a controllable source of variability if the proper equipment is used and attention is paid to the driving cycle. Speed response of the engine may have an effect on how well the driving cycle is matched. Vehicle response is mainly the concern of the route driver, thus human error is added as a factor of variability. A determination of how well a cycle is matched to a reference cycle and reductions in the tolerances that are allowed is a plausible method for reducing cycle variability. Also recommended is the continuous measurement of $\mathrm{CO}_{2}$ during the transient cycle, which would give a direct measure of the engine fuel-air ratio.

Combustion and dilution air conditioning plays a vital role in the amount of particulate collected during a transient test. The study shows that there is no consistent pattern among testing facilities for combustion air conditioning, but temperature control and humidity control are suggested. The control of combustion air humidity will help to eliminate some variability associated with high humidity levels. Dilution air and combustion air filtration will greatly reduce the variability due to high particles in the ambient air. Tunnel design variability is primarily due to bends, flexible joints, and tunnel flow rates.

Filtration errors are another source of variability and errors are induced due to sampling conditions, weighing and handling errors, filter conditioning and filter media. Sampling conditions primarily refers to the filter face velocity, which is important because the face velocity is responsible for determining a pressure drop across the filter 
and the efficiency of the filter. Kittelson and Johnson (1991) state that for vehicles with lower emissions levels, it may be necessary to increase the filter face velocity to ensure that filter pressure drops are sufficient for particle collection.

Weighing and handling errors are becoming a major source of variability due to cleaner running engines, which produce fewer particles. Typical errors associated with filters include particulate mass lost from the filter during weighing, actual filter material being lost, contaminants in the air attaching to the filter, electrostatic charges on the filter, and outgassing from filter storage containers. Improper filter conditioning and improper use of media also add to the variability of particulate measurements. With the increased use of clean fuels, the issue of filter media efficiency is an area of study that needs to be investigated further to determine new materials and methods for particulate sampling. Improvement of the aforementioned variables during the test procedure along with proper engine and tunnel conditioning procedures will reduce the testing variability and lead to more accurate results.

Parker et al. (1999) performed a study that included emissions test variability. The variability study was concerned with vehicle-to-vehicle and test-to-test variability. Five vehicles of similar weight, body style, engine, odometer readings, and evaporative systems were selected for the vehicle-to-vehicle variability test. The vehicle-to-vehicle variability results indicate that an average of 0.046 grams per vehicle variability was noticed. Test-to-test variability studies used the same test facility and crew. Twenty-five test sets were conducted, totaling 56 tests in various facilities. Results indicated that there is some test-to-test variability, but the variability would be difficult to eliminate. 


\subsection{Aftertreatment Devices}

Fuel and engine improvements have resulted in a substantial decrease in the emission levels from heavy-duty vehicles. Diesel fuel sulfur content has been curtailed, alternate fuels, such as natural gas, have been implemented. Advanced aftertreatment devices have been developed to reduce emission levels. Aftertreatment devices to reduce exhaust emissions levels from vehicles are being studied around the world. Different designs and strategies have been implemented to aid in the reduction of regulated emissions and particulates emitted by vehicles. There are numerous types of aftertreatment devices, such as, diesel oxidation catalysts (DOC), lean $\mathrm{NO}_{\mathrm{x}}$ catalyst, diesel particulate filters (DPF), etc.

Aftertreatment devices cause backpressure fluctuations on the engine. These backpressures are responsible for the proper operation of aftertreatment devices in that the increase in backpressure causes an increase in in-cylinder temperatures, which in turn causes an increase of the exhaust temperature which is the heat source for the aftertreatment device. This section will contain information pertaining to the development, strategies, and formulation of oxidation catalysts and diesel particulate filters.

\subsubsection{Oxidation Catalysts}

The function of an oxidation catalytic converter is to oxidize carbon monoxide and hydrocarbons to carbon dioxide and water in an exhaust gas stream (Heywood, 1988). The principle $\mathrm{CO}$ oxidation reaction in a hydrocarbon-air flame is:

$$
\mathrm{CO}+\mathrm{OH} \rightarrow \mathrm{CO}_{2}+\mathrm{H} \text { Equation } 2.1
$$


Oxidation catalysts oxidize (burn) carbon monoxide and hydrocarbons in order to reduce them to $\mathrm{CO}_{2}$ and water. Precious metals such as platinum and palladium are commonly used as the catalytic materials on oxidation catalysts. Precious metals are preferred due to their activity, resistance to deactivation, and their ability to be regenerated. According to Heck et al. (1995), a platinum catalyst is preferred for the catalysis of saturated hydrocarbons and higher molecular weight species. A palladium catalyst is preferred for methane and low molecular weight olefins. The catalytic materials are distributed over a large surface area so that there is a $100 \%$ conversion of CO and $\mathrm{HC}$. NO in the exhaust stream is not removed, but instead is reduced via adsorption and desorption. Typically $\mathrm{CO}$ and hydrocarbons are used to aid in the process of reducing NO. Chemical reactions take place between the $\mathrm{CO}$, hydrocarbons, and $\mathrm{NO}$ that help to reduce the amount of actual NO released. The type of system that helps to eliminate all three constituents is commonly referred to as a three-way catalyst (Heywood, 1988). Typical precious metals used as catalysts include: Ruthenium, Rhodium, Palladium, and Platinum.

Harayama et al. (1992) tested various types of oxidation catalyst materials using repeated particulate emission measurements over the USHDD transient test procedure on a direct injection diesel engine. The authors note that regulations set forth by the USEPA on emission levels cannot be met by engine modification alone. Therefore, some type of aftertreatment device must be used to help reduce the amount of SOF emitted. Test results indicated that sulfate formation must stabilize before SOF catalyst performance can be evaluated. Stabilization of sulfates can be achieved by operating engines, with the catalyst installed, under appropriate steady state conditions prior to the transient test procedure. Results indicate that an increase in sulfate formation causes an increase in 
bound water and SOF, thus resulting in an increase of particulate. This indicates that a reduction in the amount of sulfate formed on the oxidation catalyst is of high importance when trying to lower the amount of particulate emitted. No effects on carbon monoxide or hydrocarbon emissions were noticed when using the various catalyst materials. With the minimum amount of sulfate formation and the optimum catalyst material, the ability to reduce particulates over the USHDD transient cycle is feasible.

Gulati (1992) performed a study on large frontal area honeycomb ceramic converters that investigated the physical durability of the catalysts. Mechanical and thermal durability are the main two constituents in the physical durability. Gulati stated that catalytic durability can be optimized by using appropriate catalyst formulation that maximizes oxidation of organic particulates while minimizing oxidation of $\mathrm{SO}_{2}$, controlling the operating temperature window to facilitate physical adsorption and oxidation of organic particulates without adsorbing and oxidizing $\mathrm{SO}_{2}$, and selecting a catalyst support material that minimizes storage and release of sulfur during temperature transients. The study showed that durability requirements can be met by optimizing the mechanical durability through high strength cell geometry, a compatible washcoat system, and a rugged packaging design. Optimization of converter size and cell geometry within space constraints can achieve low backpressure and high total surface area. Gulati's final conclusion was that the large frontal area ceramic converter is the most viable solution for aftertreatment of diesel emissions. 


\subsubsection{Diesel Particulate Filters}

Many diesel vehicles use particulate filters, also known as particulate traps, with regeneration technologies to aid in the reduction of particulate emissions. Diesel particulate filters (DPF) are aftertreatment devices that use open-pore, wall-flow systems to collect particulate material from the exhaust gas. The pores in the DPF trap the particulate. The filter is then cleaned via oxidation of the accumulated particles. Particulate traps are typically impregnated with catalytic materials that aid in the process of oxidizing hydrocarbons, carbon monoxide, and in the regeneration process of the DPF. DPFs typically operate using either passive or active regeneration. Passive regeneration is the process by which the aftertreatment device uses a catalyst to remove and lower chemical compounds in the exhaust stream. The advantage of passive, unlike active regeneration, is that passive regeneration does not require advanced and sometimes troublesome sensing and control systems to monitor the performance of the device.

The conversion of $\mathrm{NO}$ to $\mathrm{NO}_{2}$ helps in the regeneration process of the DPF. The following reaction equations are for the conversion of $\mathrm{NO}$ and the oxidation of diesel particulate matter.

$$
\begin{gathered}
\mathrm{NO}+\frac{1}{2} \mathrm{NO}_{2} \leftrightarrow \mathrm{NO}_{2} \quad \text { Equation 2.2 } \\
\mathrm{NO}_{2}+\mathrm{C} \rightarrow \mathrm{NO}+\mathrm{CO} \quad \text { Equation 2.3 } \\
\mathrm{NO}_{2}+\mathrm{C} \rightarrow \frac{1}{2} \mathrm{~N}_{2}+\mathrm{CO}_{2} \quad \text { Equation 2.4 }
\end{gathered}
$$

The Johnson-Matthey continuously regenerating diesel particulate filters $\left(\mathrm{CRT}^{\circledR}\right)$ contain combinations of an oxidation catalyst and an uncatalyzed filter. The catalyzed 
filter requires the use of low sulphur fuel to limit the sulphur poisoning associated with catalyzed particulate filters.

Heywood (1988) stated that several issues that arise with the use of these systems include: (1) increased backpressures in the exhaust system; (2) under normal diesel engine operating conditions the particulate material will not oxidize; (3) once the oxidation process is initiated, the temperatures must be controlled so that the filter in the particulate trap is not damaged or destroyed. Some different particulate filter materials include: ceramic monoliths, alumina-coated wire mesh, ceramic foam, ceramic fiber mate, woven silica-fiber rope wound on a porous tube (Heywood, 1988).

Nagendran (2003) performed a study to evaluate the effects of ultra low sulphur diesel fuel on an off-road heavy-duty engine retrofitted with catalyzed traps. An 8cylinder Caterpillar 3408 Series engine was used for the study. The study involved the use of three diesel fuels and two diesel particulate filters. The fuels used included a CARB off-road diesel, Fischer-Tropsch diesel, and ECD-1. ECD-1 is an ultra-low sulfur ( $>15 \mathrm{ppm}$ sulfur) diesel fuel formulated by ARCO BP. The DPFs studied were a Johnson-Matthey CRT ${ }^{\circledR}$ and an Engelhard DPX ${ }^{\circledR}$. Results indicated that extraordinary reductions in PM, hydrocarbons, and $\mathrm{CO}$ were found using all combinations of fuel and aftertreatment devices. PM emissions were as low as $0.01 \mathrm{~g} / \mathrm{bhp}$-hr using both fuels and both filters, which amounted to a $98 \%$ reduction in PM from baseline levels. CO emissions were reduced by $96 \%$, and $\mathrm{HC}$ emissions were $0.02 \mathrm{~g} / \mathrm{bhp}-\mathrm{hr}$ using both fuels and the $\mathrm{CRT}^{\circledR}$; using the ECD-1 fuel and the DPX ${ }^{\circledR}, \mathrm{HC}$ emissions were $0.06 \mathrm{~g} / \mathrm{bhp}-\mathrm{hr}$. All results indicated that DPFs are able to reduce emissions to levels considered acceptable by CARB and the EPA. 
LaTavec et al. (2002) performed a yearlong study to evaluate ultra-low sulphur diesel fuels and passive particulate filters in truck and bus fleets. The test involved using three different fuels and three different exhaust configurations. Fuels used included a CARB fuel, ECD, and ECD-1. CARB fuel was a fuel similar to that of the typical diesel fuel for everyday use, while the ECD fuels were ultra-low sulfur ( $>15 \mathrm{ppm}$ sulfur) diesel fuels. The exhaust configurations are with a factor muffler, with a DPX ${ }^{\circledR}$ filter, and with a CRT ${ }^{\circledR}$. The DPX ${ }^{\circledR}$ was and Engelhard catalytic soot filter and the $\mathrm{CRT}^{\circledR}$ was a Johnson-Matthey continuously regenerating trap. The DPX ${ }^{\circledR}$ was a catalyzed wall-flow ceramic filter, which utilized a dual function platinum catalyst in combination with a base metal oxide catalyst. The $\mathrm{CRT}^{\circledR}$ was a two-stage system that featured a platinum loaded oxidation catalyst and an uncoated ceramic wall-flow filter. The catalyst in the $\mathrm{CRT}^{\circledR}$ was used to continuously oxidize the $\mathrm{NO}$ to $\mathrm{NO}_{2}$, and thus generate temperatures needed for the regeneration of carbonaceous materials on the filter element. Results indicated a 90\% reduction in PM emissions when a DPF was installed, and no deterioration of emissions was witnessed. Emissions deterioration is actually the opposite that one would assume. The deterioration is actually the increase of emission levels. A variability analysis indicated that there is greater than $95 \%$ certainty that $\mathrm{CO}, \mathrm{HC}$, and $\mathrm{PM}$ are reduced due to the DPFs installed.

A study performed by Horiuchi et al. (1990) indicated that catalysts used in their study reduced the soluble organic fraction (SOF) by $40-90 \%$ at exhaust temperatures between $100^{\circ} \mathrm{C}$ and $500^{\circ} \mathrm{C}$. The study indicated that collecting the SOF at low temperatures on the catalyst surface and then oxidizing them at higher temperatures achieved these reductions. When a platinum only catalyst was used in the study, a low 
total particulate reduction was noticed and was attributed to the fact that high sulfate formation occurred at higher temperatures. The root cause for the high sulfate formation was due to platinum's high $\mathrm{SO}_{2}$ oxidation ability. Therefore, more plausible reductions in SOF can be achieved in the range of $50-60 \%$ and particulate reductions in the range of $40-50 \%$ when an oxidation catalyst with low sulfate oxidation ability is used.

Clark et al. (2000) performed an in-field study using 20 tractors equipped with Detroit Diesel 60 Series engines and operated on a chassis dynamometer. The trucks were tested while operating on various fuels and aftertreatment devices. Five trucks were operated on CARB fuel and fifteen of the trucks were operated on ECD fuel. Of the fifteen trucks operated on ECD, five were equipped with a Johnson-Matthey CRT ${ }^{\circledR}$ and five were equipped with an Engelhard DPX ${ }^{\circledR}$. The other five vehicles operated solely on ECD and had no aftertreatment devices installed. The DPX ${ }^{\circledR}$ filter was a platinum-coated ceramic wall-flow filter, with the catalyst coating impregnated into the porous filter walls of the element. The $\mathrm{CRT}^{\circledR}$ filter was a two-stage filter with a platinum-loaded oxidation catalyst followed by an uncoated ceramic wall-flow filter. Results indicated that ECD without aftertreatment produced no reduction in PM emissions over CARB fuel. However, PM was virtually eliminated when the ECD fuel was used in conjunction with the aftertreatment devices. The trap systems also aided in the reduction of carbon monoxide and hydrocarbon levels. The paper concluded in saying that employing particulate filters with clean diesel may reduce oxides of nitrogen and eliminate most of the regulated emission masses.

Mayer et al. (2000) conducted a study on diesel fueled city transit buses in Switzerland. The study investigated the effects of over 200 particulate trap systems, and 
concluded that a continuously regenerated trap was the best type of trap. Bench tests and field tests were performed using a continuously regenerating trap. Bench tests showed a $90 \%$ reduction in particulate matter, excellent carbon monoxide conversion, and low hydrocarbon and $\mathrm{NO}_{\mathrm{x}}$ reduction. Reasons for low $\mathrm{NO}_{\mathrm{x}}$ conversion may be due to exhaust backpressure effects of the trap, mileage, and store-and-release phenomena. The reduction in particulate matter throughout the whole size range demonstrated that the ability of the modern trap to reduce combustion particles can aid in achieving relatively clean air after dilutions of 1:100 to 1:1000 are encountered. The authors also mentioned that the cost of trap systems is relatively high and that implementation of traps into the emissions reduction process may be limited.

Through the analysis of diesel fueled and compressed natural gas fueled vehicles, it can be determined that using aftertreatment devices to aid in the reduction of emissions is a viable alternative. Studies that employ methods approved by the governing bodies are excellent methods for determining the in-use emissions of vehicles, and are a great method of analyzing aftertreatment device effects on emissions. The rest of this work will be concerned with the equipment, procedure, and analysis of the study performed. 


\section{Experimental Equipment}

The West Virginia University Transportable Heavy-duty Vehicle Emissions Testing Laboratory (Translab) is comprised of a chassis dynamometer and instrument trailer that houses the total exhaust double dilution tunnel, gaseous sampling train, particulate sampling train, temperature control modules, data acquisition and control systems, and several other sampling trains for unregulated emissions.

The Translab is comprised of three main components: a critical flow venturi constant volume sampler (CFV-CVS), a chassis dynamometer, and an instrumentation trailer. The CFV-CVS allows the desired mass flow rate of diluted exhaust through the primary dilution tunnel. The dilution air aids in the simulation of emission levels typically encountered in the environment, and maintains a dew point temperature low enough to prevent condensation. The chassis dynamometer simulates actual in-use driving conditions. A vehicle's raw exhaust is transferred to the primary dilution tunnel via an insulated transfer line. The raw exhaust is then mixed with HEPA filtered air at the inlet section of the primary dilution tunnel and drawn to the sampling section down stream. Gaseous and particulate samples are collected in the sampling zones, which are equipped with probes for determining regulated and unregulated emissions, and a secondary dilution tunnel is used for the collection of Total Particulate Matter (TPM). The gaseous samples are drawn to an analyzer bench in the instrumentation trailer where they are conditioned and analyzed.

The aforementioned components are the backbone of the testing facility, but many other components are used to achieve the desired result. Additional components include 
gas analyzers, particulate sampling cyclones, a temperature control module, and media.

All of the aforementioned components will be discussed in this section.

\subsection{Chassis Dynamometer}

The West Virginia University Transportable Heavy-Duty Vehicle Emissions Testing Laboratory chassis dynamometer is built into a semi-trailer that houses the frame, jacks, rollers, and vehicle loading components necessary for simulating on-road driving conditions (Ferguson, 1993). The transportable laboratory is designed to be a rugged piece of equipment capable of enduring transportation from one test site to another. The operation process, components, and limits of the chassis dynamometer are discussed in this section.

The operation of the chassis dynamometer is a detailed process. The process starts with a set of hub adapters connected to the vehicle. The hub adapters are comprised of a wheel rim of $1.8 \mathrm{ft}$ diameter $(0.55 \mathrm{~m})$ and a $0.5 \mathrm{in}(13 \mathrm{~mm})$ thick aluminum face plate (Figure 3.1).

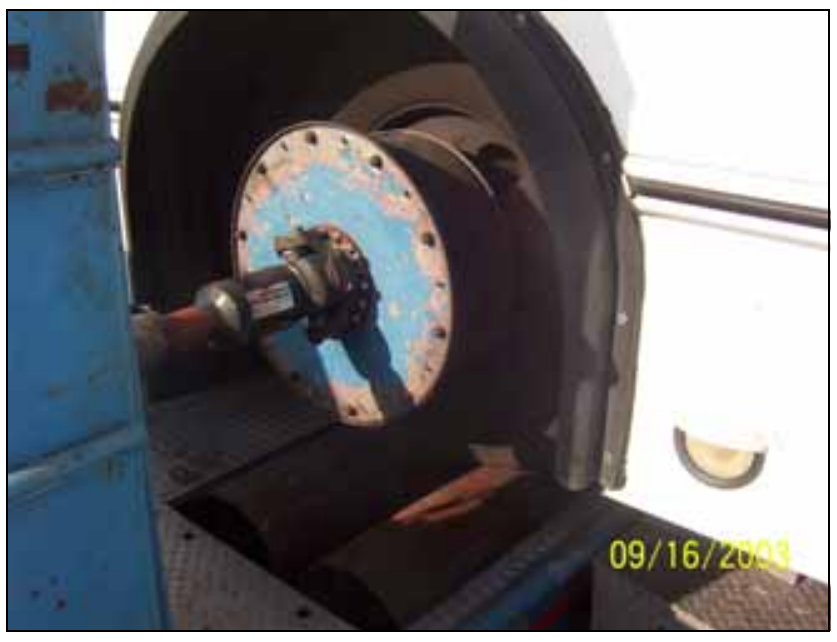

Figure 3.1 Hub Adapter and Shaft 
The hub adapter is connected to 24 in $(61 \mathrm{~mm})$ long shaft running in a pillow block. The shaft is connected through a spline and companion flange to a torque and speed transducer. The torque and speed transducer is a $16,665 \mathrm{lb}-\mathrm{ft}(22,595 \mathrm{~N}-\mathrm{m})$ Lebow, which is capable of providing a data-logging computer with time varying output torque at a rate of $10 \mathrm{~Hz}$ (Ferguson, 1993). The Lebow transducer drives a shaft that is also connected via a companion flange. This shaft then transmits power to a right-angle speed increasing drive. The right-angle speed increasing drive is a double reduction differential with a ratio of 1:3.65. This differential transmits power to the flywheel assembly and to a second differential. The second differential is similar to the first, the only difference being that it has only one output shaft. This output shaft drives the power absorber.

To simulate load due to rolling friction of the tires and wind resistance, eddy current power absorbers are used. The power absorbers used are capable of continuously absorbing $300 \mathrm{hp} \mathrm{(224kW)} \mathrm{and} \mathrm{intermittently} \mathrm{absorbing} 1000 \mathrm{hp}(746 \mathrm{~kW})$ during peak operation. Supplying direct current to the coils of the power absorber controls the dynamometer load at any speed. The energy absorbed is then dissipated to the disk rotors, which incorporate vanes for air-cooling (Ferguson, 1993). The road load is simulated using a flywheel assembly.

The flywheel assembly (Figure 3.2) is designed to simulate from 20,000 lb to 66,000 $\mathrm{lb}$ depending on the diameter of the tire. The upper limit starts at around 40,000 lbs. $40,000 \mathrm{lb}$ vehicle inertia occurs at a tire diameter of $4 \mathrm{ft}$, and the $60,000 \mathrm{lb}$ load occurs at a tire diameter of $3.25 \mathrm{ft}$ (Ferguson, 1993). The flywheel assemblies are comprised of a drive shaft housed in two pillow blocks with four drive rotors. Each drive shaft houses eight flywheels with bearings resting on the shaft. Flywheel assembly inertia can be 
changed in $250 \mathrm{lb}(113 \mathrm{~kg})$ increments. Increasing the inertia involves fixing the flywheel to the driver shaft. Allowing the additional flywheel to spin increases the inertia generated by the flywheel assembly, thus increasing the simulated load.

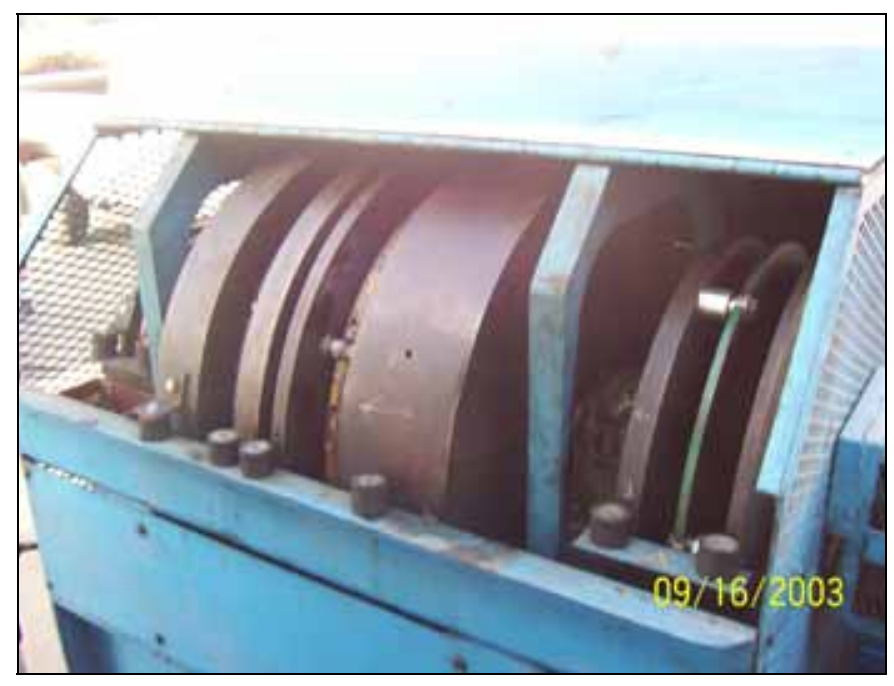

Figure 3.2 Flywheel Assembly

Monitoring speed and torque during a test allows control of the aforementioned variables. The driver of the vehicle controls speed during the test, but the transient torque must be controlled via an automated system. A Dyne-Systems Dyn-Loc IV controller controls the power absorbers, which simulate the load due to rolling friction and wind resistance. The controller is a Proportional Integral Differential (PID) controller. Proportional indicates that the controller receives a signal and calculates an error between that signal and the desired signal, and multiplies by a gain to correct the error. The Integral finds a running average of the errors and multiplies them by a gain to dampen out the system error, while the Differential takes the previous error and current error and uses a gain to determine what action to perform. The PID effectively creates a smooth running transient system by minimizing the error associated with transient systems. The controller receives the setpoint value from a computer and sends the correct setpoint 
value to the power absorber. The setpoint sent to the power absorber is equal to the road load. The road load power is calculated using Equation 3.1.

$$
P_{r}=\left(C_{r} M g+0.5 \rho_{a} C_{D} A V^{2}\right) V \quad \text { Equation 3.1 }
$$

Where

$$
\begin{aligned}
& P_{r}=\text { Road Load Power } \\
& C_{r}=\text { Coefficient of Rolling Resistance } \\
& M=\text { Vehicle Gravitational Mass } \\
& \rho_{\mathrm{a}}=\text { Air Density } \\
& A=\text { Frontal Area of Vehicle } \\
& C_{D}=\text { Drag Coefficient } \\
& V=\text { Vehicle Speed }
\end{aligned}
$$

The setpoint value is updated every 100 milliseconds, and both speed and torque are logged at a frequency of $10 \mathrm{~Hz}$ to insure the test has been performed properly.

The most common failures occur in bearings and power distribution shafts. Bearings typically fail for common reasons such as excess temperatures, point loading, wear life exceeded, and lubrication problems. Shafts typically fail due to sudden stops encountered during testing. Usually these stops are a part of the test procedure, and the repeated sudden stopping induces large amounts of torque in the shaft. These large and repetitive torques cause failure over time.

\subsection{Dilution Air Filtration System}

When exhaust gas comes in contact with ambient air, the temperature of the exhaust quickly drops causing PM, THC, and NOx to transform. Some of the transformations that occur are that of $\mathrm{NO}$ combining with oxygen to form $\mathrm{NO}_{2}$, and the self-nucleation of vapor particulates into PM. In order to simulate these transformations and more accurately represent real world emission levels in the environment, the exhaust gas must be diluted with ambient air. Dilution of raw exhaust with ambient air is achieved by 
mixing the raw exhaust from the test vehicle with dilution air in the primary dilution tunnel. According to CFR 40, primary dilution air should be filtered using a filtration element that has a particle removal efficiency of no less than $98 \%$, and secondary dilution air should be filtered using a High Efficiency Particulate Air (HEPA) filter that is rated at 99.97\% particulate removal efficiency (CFR, 2001). The air filtration system employed with the Translab uses four HEPA filters housed in an intake manifold (Figure 3.3). Each HEPA filtration system houses a primary filter to remove large dust particles and debris from the ambient air. The primary filters are standard ASHRAE filters used in HVAC applications for everyday use. After entering the intake manifold through the primary filter, the air is then purified by passing through the HEPA filters. The HEPA filter is designed to remove particles, fumes, smoke, and gaseous molecules as small as 0.3 microns at an efficiency of $99.999 \%$ (Croom, 1995). HEPA filters are made of a fiberglass paper that is pleated to increase the surface area of the filter, and use methods such as Brownian Diffusion and direct interception to remove particles from the air. Using HEPA filtered air for primary dilution air insures that the air entering the dilution tunnel is virtually clean air and is not contaminated by outside background particulates. HEPA filtered air is transferred to the inlet section of the primary dilution tunnel via a 20 inch flexible tube where it is used to dilute the incoming raw exhaust. 


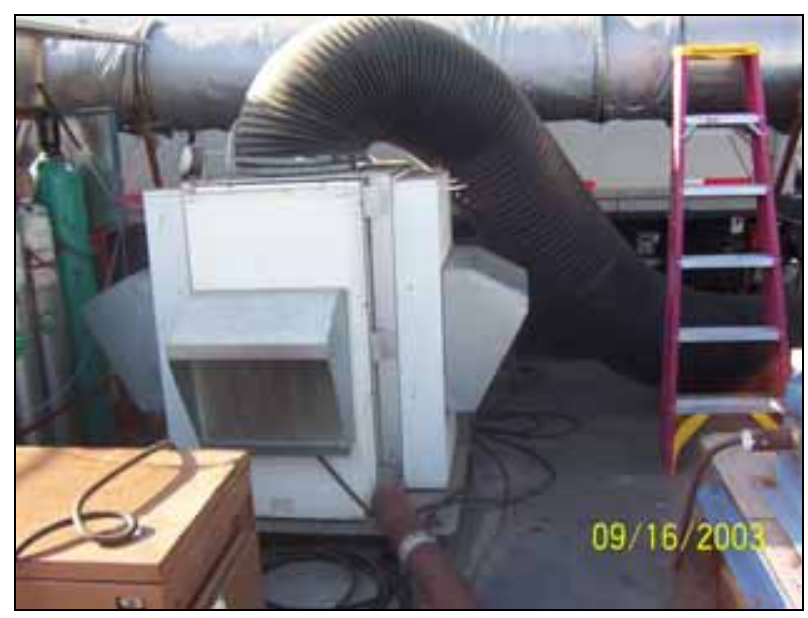

Figure 3.3 Dilution Air Filtration System

\subsection{Dilution Tunnel}

A clean dilution tunnel was used for this testing to reduce the amount of tunnel background concentrations. In this report, the term "clean" refers to a tunnel that has never been exposed to diesel engine exhaust. Diesel engine exhaust leaves behind high levels of soot that can be shed from the dilution tunnel walls and become entrained into the flow stream, causing excessively high background levels. High background levels can cause variability in emission studies. Past studies have shown that high levels of background PM can lead to incorrect gravimetric readings when testing ultra-low emissions vehicles. High background PM levels cause readings to be negative when the PM levels obtained during a test are lower than the background levels. An excessive amount of particulate matter is not the only factor that causes variability. The particulate matter that becomes attached to the walls of a dilution tunnel can adsorb chemical species during testing. This adsorption has two negative effects on emissions levels during the testing process. First, the adsorption can alter the levels of several unregulated species during testing and cause incorrect measurements. Second, the adsorption of these chemicals can lead to outgassing, or letting go, of these chemical species during later 
testing procedures. It should be noted that all engine tests require background levels to be determined in the dilution air at ambient conditions. However, during a test, the higher temperature of the diluted exhaust has a significant impact on the release of various species from the tunnel walls. Outgassing leads to higher levels of chemical species in a test and yields incorrect data. To eliminate high background levels during the testing procedure, a clean dilution tunnel was implemented for testing of compressed natural gas vehicles.

The clean dilution tunnel consisted of an inlet section, mixing zone, sampling zone, and outlet section. The clean tunnel was designed according to CFR 40 Part 86, Subpart N. The inlet section was connected to the HEPA filtered air manifold, and the outlet section was connected to a Critical Flow Venturi Constant Volume sampler (CFV-CVS). Raw exhaust was transferred from the test vehicle to the primary dilution tunnel via a stainless steel transfer tube. The raw exhaust entered into the inlet, mixing zone just upstream of an orifice plate used to create turbulence and aid in the mixing process. To reduce the possibility of thermophoretic effects in the exhaust transfer line, insulating blankets were used to reduce the temperature gradient typically present between the transfer tube surface and the ambient air.

After the raw exhaust and primary dilution air entered the mixing zone, they were drawn through an orifice plate, which created turbulence and facilitated in the mixing of the raw exhaust and dilution air. According to CFR 40, a dilution tunnel must be of a small enough diameter to create turbulent flow, and of sufficient length to allow for the complete mixing of the raw exhaust and dilution air (CFR 40, 2001). Sufficient length is defined as at least 10 diameters downstream of the mixing zone; this is referred to as the 
10-diameter rule in this literature. Therefore the dilution tunnel was designed accordingly. The inner diameter of the dilution tunnel was 18 inches, which makes the sufficient length for complete mixing around 180 inches, or 15 feet $(4.57 \mathrm{~m})$. Therefore, the sampling zone needed to be positioned at 15 feet $(4.57 \mathrm{~m})$ downstream of the mixing orifice to satisfy the 10-diameter rule. The tunnel diameter was selected based on CFR 40 regulations that when the single dilution technique for particulate sampling is used, the tunnel diameter must be at least 18 inches $(45 \mathrm{~cm})$. Since $\mathrm{PM}_{1}, \mathrm{PM}_{2.5}$, and $\mathrm{PM}_{10}$ are sampled using the single dilution method, this design parameter was incorporated. The "clean" tunnel was designed so that it was a stand-alone dilution tunnel that could be used with any of the transportable laboratories. This design required that the tunnel be comprised of several smaller sections instead of one large section. The tunnel is comprised of five sections, some sections having multiple parts. Section 1 is the inlet section for the dilution air, Section 2 is the inlet section for the raw exhaust, Section 3 is the mixture transfer/thorough mixing zone, Section 4 is the sampling zone, and Section 5 is the outlet section.

The tunnel sections were designed as follows. Section 1 was designed to be the inlet section that accepted the incoming HEPA filtered dilution air, which made this a necking section. The necking section changed from a 20 -inch diameter to a 24 -inch diameter where it was flanged to meet section 2. Section 2 was designed to accept the raw exhaust from the exhaust transfer tube and dilution air from Section 1. This section was made up of a 24 -inch diameter flanged section connected to an 18 -inch flanged section via ribs welded between the two sections. The difference in diameter creates an overflow for the tunnel so that the flow through the tunnel is not affected by the HEPA filter unit flows. 
The inlet for the raw exhaust transfer tube was located in Section 2 and was designed so that when the orifice plate was between section 2 and section 3, the raw exhaust entrance was as close as possible to the orifice, without touching the orifice. Figure 3.4 shows the insulated sections 1 and 2 with the exhaust transfer tube and HEPA filtered dilution air supply connected. Section 1 was not insulated because it only transfers dilution air and not a mixture of dilute air and raw exhaust, thus no thermophoretic effects would be seen if this section was not insulated.

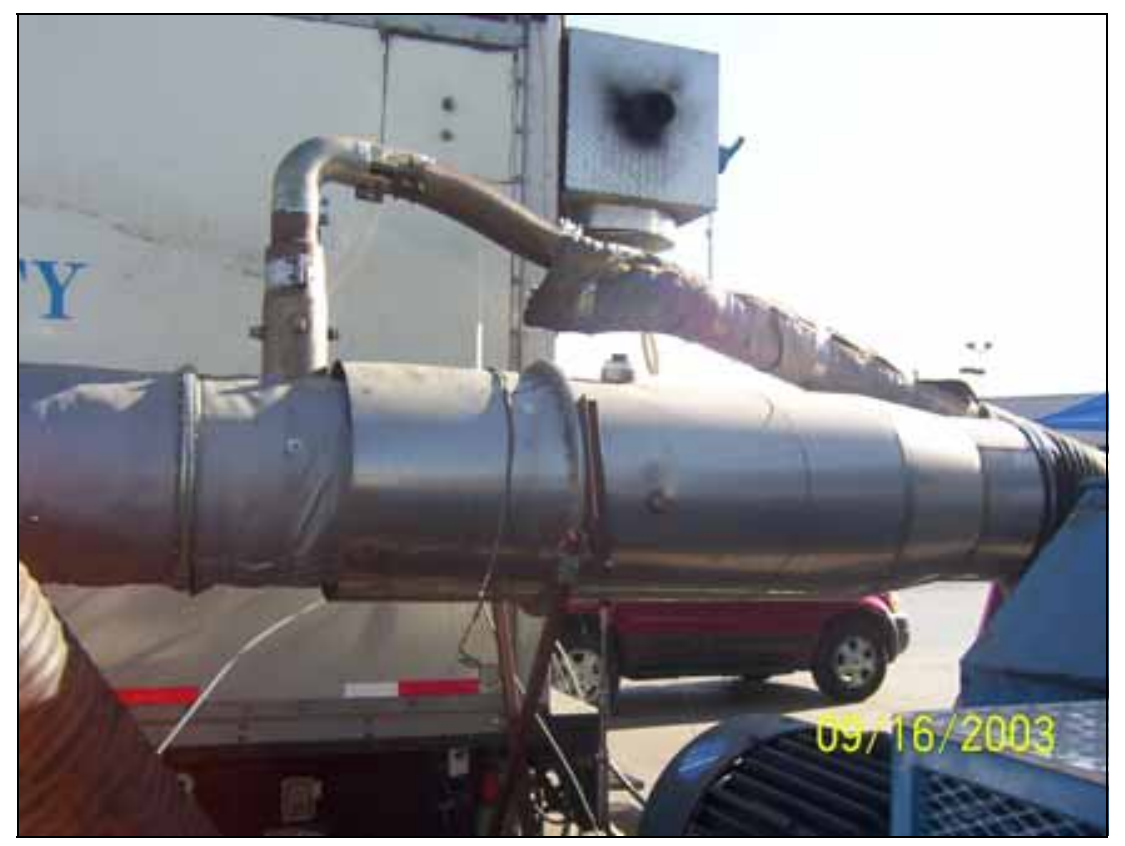

Figure 3.4 Sections 1 and 2 with Exhaust Transfer Tube and HEPA Dilution Air

The orifice plate was located between sections 2 and 3. Section 3 was comprised of two 18-inch diameter 7-foot long sections each containing two flanges. Section 3 was designed to facilitate in the mixing of the raw exhaust and dilute air before the sampling zone, or ultimately satisfy the 10-diameter rule. Section 4 was comprised of two 3-foot sections, with an extra three-foot section built for future use, but not installed during this testing. The sampling zone for regulated emissions was positioned half way down the 
first 3-foot section of section 4, and the sampling zone for unregulated emissions was positioned half way down the second 3 -foot section of section 4 . This puts the regulated emissions sampling zone at 15 feet 6 inches from the mixing orifice, which meets and exceeds the 10-diameter rule set forth by CFR 40 . The regulated and unregulated sampling zones were comprised of eight sampling ports each. The sampling ports in the regulated sampling zone of section 4 were comprised of ASME $150 \mathrm{lb}$ flanges of $4.25 \mathrm{inch}$ outer diameter. These flanges were radially located on the regulated emissions section. The sampling ports in the unregulated section and the additional section were designed in a similar fashion, but the flange sizes were different. The flanges were radially located, and they alternated from a 7 inch O.D. ASTM $150 \mathrm{lb}$ flange to the 4.25inch O.D. ASTM 150lb flange. Figure 3.5 shows the regulated emissions section with the secondary dilution tunnel attached, and Figure 3.6 shows the unregulated section.



Figure 3.5 Regulated Emissions Sampling Zone with Secondary Dilution Tunnel 


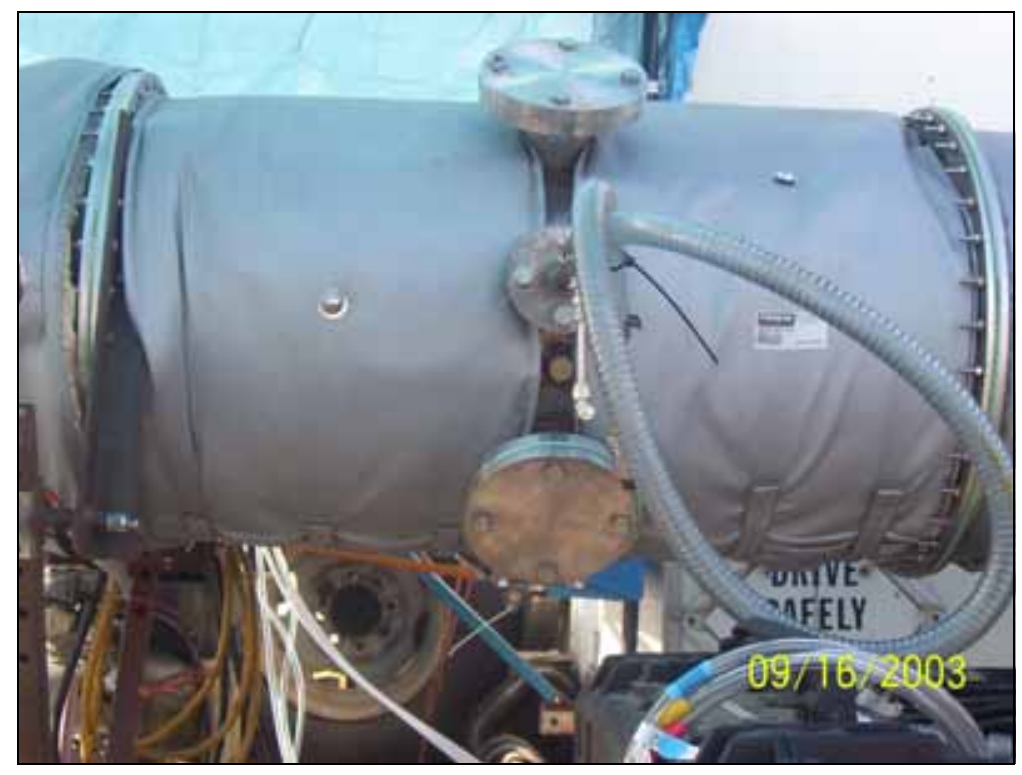

Figure 3.6 Unregulated Emissions Sampling Zone

Section 5 was a necking section that reduced from the 18 -inch flanged section to a 12 inch unflanged end, which connected to the CFV-CVS via a 12 inch flexible tube. Figure 3.7 illustrates section 5. The open hole seen in the secondary dilution tunnel was plugged before testing.

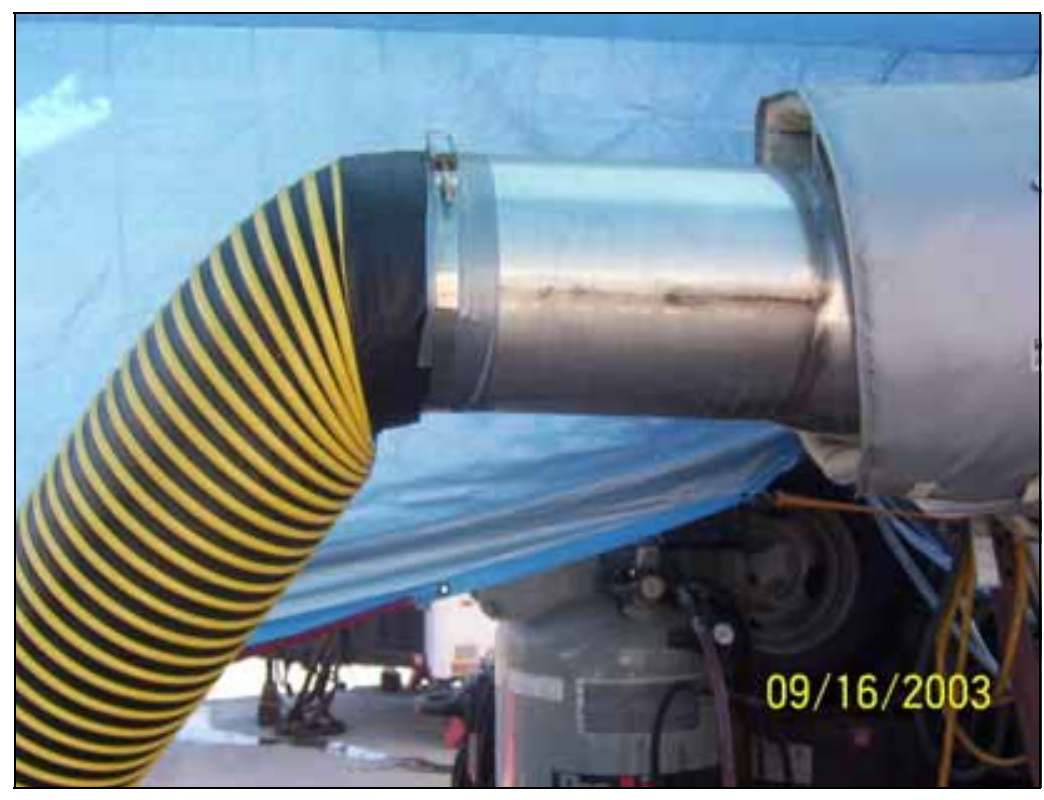

Figure 3.7 Section 5 (Outlet Section) 
The five sections were connected via flanges that have a bolt hole pattern located in the center of a flange and positioned every 10 degrees radially on the flange. A secure seal was created using a gasket at every flange joint. The gasket material selected had to be able to operate under high temperature conditions without outgassing, which occurs when a material is exposed to temperatures beyond its material ability. Outgassing occurs when a material starts to corrode and emits chemical compounds into the sample stream. These chemical compounds, usually hydrocarbons and PM, will make the results obtained from a test invalid because these compounds are not found in the exhaust, but are entrained into the sample flow in the dilution tunnel. Gaskets used were made from compressed non-asbestos, buna-nitrile material, which will prevent the material from outgassing during testing procedures. Injections of known concentrations of gases were used to verify that the fully connected dilution tunnel was leak free. These injections are discussed in Chapter 4.

\subsection{Critical Flow Venturi}

A critical flow venturi constant volume sampling system (CFV-CVS) was used to draw the exhaust and dilution air through the tunnel to the sampling zone. The CFV can operate at nominal flow rates of $1000,1500,2000,2500$, and $3000 \mathrm{scfm}$. The flow rate was determined by inserting a plug on a threaded fitting in the venturi throat. The plug changes the diameter of the venturi throat, thus changing the flow rate. The diameters and nominal flow rates for the venturi are listed below in Table 3.1. 


\section{Table 3.1 Venturi Sleeve Diameter and Flow Rates}

\begin{tabular}{|c|c|}
\hline Sleeve OD & Flow Rate \\
\hline inches & SCFM \\
\hline 3.696 & 1000 \\
\hline 3.424 & 1500 \\
\hline 3.128 & 2000 \\
\hline 2.801 & 2500 \\
\hline 2.431 & 3000 \\
\hline
\end{tabular}

\subsection{Gaseous Sampling}

Gaseous samples were taken in the regulated emissions zone of section 4. Heated probes and sample lines were used to draw diluted exhaust gas samples from the primary dilution tunnel to the exhaust gas analyzers. Four diluted exhaust gas samples were drawn from the tunnel and sent to the analytical bench. The samples collected were $\mathrm{CO}$, $\mathrm{CO}_{2}, \mathrm{NO}_{\mathrm{x}}, \mathrm{THC}$, and aldehydes. The heated lines and probes were manufactured by Unique Products, and were controlled by a Temperature Control Module (TCM) designed and built by the author. The TCM will be discussed later in Chapter 3 .

The heated sample probes were of the "span tip" type, which allowed for zero-span leak checks of the exhaust gas analysis sample train. The sample probes were equipped with two J Type thermocouples and a 6-foot 120 VAC power/control lead. Flange assemblies were used to mount the sample probes to the primary dilution tunnel. The flanges were of an ASME 150lb type flange of 4.25 O.D., which mated with flanges in the regulated emissions zone of section 4 . The thermocouples from the heated sample probes were sent to the TCM and to the data analysis bench where the temperatures were recorded for emissions calculations and verification. The probe temperatures were controlled by the TCM. After the probes were connected to the primary dilution tunnel, they were connected to the heated sample lines via Swagelok ${ }^{\circledR}$ fittings. 
The heated sample lines were selected depending upon their desired use, and all of the lines were of the recorable type. Recorable type sample lines have the capability of having the transfer line, located inside a heated line jacket, removed and replaced in the event of a transfer line failure. Sample line material selection depends on the type of gases that are to be analyzed by the analyzer to which that heated sample line is connected. Teflon coated lines are used for $\mathrm{CO}, \mathrm{CO}_{2}, \mathrm{NO}_{\mathrm{x}}$, and aldehydes, but a stainless steel line is used for THC due to the high temperatures that the line must maintain. Each sample line had two J Type and two K Type thermocouples, a control line, were 20-feet long, and ran off of $120 \mathrm{VAC}$ power supply. The heated sample lines were connected to the heated sample probes and their respective analyzers via Swagelok ${ }^{\circledR}$ fittings. The thermocouples were connected to the TCM and to the data analysis bench where temperature values were saved for emissions calculations and verification.

After the heated sample line and probe were connected to the primary dilution tunnel, they were connected to the emissions bench housed in the analytical trailer. Data for $\mathrm{NO}_{\mathrm{x}}, \mathrm{CO}, \mathrm{CO}_{2}$, and $\mathrm{THC}$ was obtained by integrating continuous readings of the dilute exhaust gas sample, and aldehyde samples were taken on DNPH sample media and analyzed by Environment Canada.

\subsubsection{Emissions Bench}

The emissions bench located in the analytical trailer of the Translab was used to house all of the analyzers and their respective systems. The bench was originally designed according to the following specifications (Ferguson, 1993):

a) Standby mode: Exhaust sample does not flow through the analyzers when the system is powered up. This has changed since the original design, and a continuous sample ran through the analyzers, but data was only taken during the test. The bag sampling system had both a stand-by and a fill mode. 
b) Sample mode: Dilute continuous exhaust sample was drawn through the analyzer bench via the three separate streams $\left(\mathrm{CO} / \mathrm{CO}_{2}, \mathrm{NO}_{\mathrm{x}}\right.$, and THC) and/or into the dilute exhaust bag over the test period and/or background bag over the test period.

c) Zero: Zero gas flowed through an individual or all analyzers.

d) Span: Span gas flowed through an individual or all analyzers.

e) Calibration: Calibration gas flowed through an individual or all analyzers.

f) Purge: Clean, dry air and $\mathrm{N}_{2}$ flowed through the entire system.

g) Backflush: Clean, dry air and $\mathrm{N}_{2}$ flowed through the entire system and out the probes.

h) Leak Check: Checked for leaks on the vacuum side of the pumps. The system was activated from the front of the panel and any leaks in the system are indicated at the emissions bench.

The emissions bench was designed to meet or exceed the requirements of the EPA and was built under the following specifications (Ferguson, 1993):

a) The analysis bench could not exceed 66 "W x 30"D x 72"H.

b) The zero/span calibration ports were located on the upper right side of the panel.

c) The $\mathrm{CO} / \mathrm{CO}_{2}$ sample stream included a single stream Refrigerator/Dryer with stainless internals and autotraps.

d) Both the $\mathrm{CO} / \mathrm{CO}_{2}$ and the $\mathrm{NO}_{\mathrm{x}}$ lines had their separate heated pumps, with a temperature display on the front of the panel.

e) Both the $\mathrm{CO} / \mathrm{CO}_{2}$ line and the $\mathrm{NO}_{\mathrm{x}}$ line had a heated and insulated filter before the heated pump, with a temperature display on the front of the panel.

f) Heated lines were used for regulated emissions.

g) Any valves in the heated lines were insulated and free from any cold spots which might lead to moisture condensation.

h) Temperature controllers for the heated pumps and heated lines were used. 
i) Differential pressure regulators were used.

j) Flow meters with internal needle valves were used. The optimum flows for the analyzers and bypass legs must be $50 \%$ of full scale on the flow meters.

k) Nupro guard filters were used before the inlet to the NDIR analyzers.

1) 3 and 5-way valves were used.

m) Backpressure regulators were used.

n) Filter regulators were used.

o) Magnehelic differential pressure gauges were used in series with flow meters in the NDIR streams.

p) In the unheated section, 316-stainless steel was used except where the flexibility for movement was required in which case Teflon tubing was used.

q) Swagelok ${ }^{\circledR}$ compression fittings were used when necessary.

r) The exhaust from each analyzer and bypass lines terminated in a PVC manifold and are expelled to the atmosphere through the top of the panel.

s) A circuit breaker, which consists of a breaker panel and breakers, was installed for power requirements. Each major component had a separate circuit breaker.

t) Analyzer output signal jacks and thermocouple jacks were to be located on the front panel.

u) Thermocouple jacks, in addition to temperature readout units were located on the front of the panel.

v) System was wired by NEC standards. All electrical wiring was 14 gauge and signal wiring was 22 gauge.

w) Power supply lines to the analyzers were isolated from power lines to auxiliary components.

x) Lighting on the inside of the bench for servicing.

y) AC utility-duplex outlet installed and accessible on the front of the bench.

z) Space was provided in the bench for future installation of analyzers. 
Specifications for bag sampling include:

a) Two bag sampling lines, one for the dilute exhaust sample and the other for the background sample, started with Swagelok ${ }^{\circledR}$ QC series quick connects at the front of the panel and terminate with Swagelok ${ }^{\circledR}$ QC series quick connects on the panel where the bags were connected.

b) The dilute bag sample line included a Balston filter with a 304 stainless steel body and a removable stainless steel bowl. The filter was accessible from the front of the panel. The filter was a glass fiber tube type filter.

c) The background bag sample line included a Balston filter with an anodized aluminum body and a removable polycarbonate bowl. The filter element was a glass fiber tube type filter.

d) The background sample and dilute exhaust sample pumps were diaphragm type and had a capacity of $.52 \mathrm{scfm}(14.7 \mathrm{lpm})$ at $10 \mathrm{psig}\left(68950 \mathrm{~N} / \mathrm{m}^{2}\right)$. The pumps featured $20 \mathrm{psi}\left(1.4 * 10^{5} \mathrm{~N} / \mathrm{m}^{2}\right)$ continuous rating and had stainless steel heads. The pumps were capable of handling both vacuum and pressure applications. The internals were made of stainless steel or teflon.

e) Both of the dilute bag and background sample lines consisted of flow meters for adjusting the flow rate to each sample bag. The flow meter had an internal needle valve with a stainless steel float. The flowmeter had a $65 \mathrm{~mm}$ scale calibrated from 2 to $18 \mathrm{cfh}$ (57 to $510 \mathrm{lpm}$ ) with an accuracy of $\pm 10 \%$.

f) Bag sampling lines from the tunnel to the bag were $3 / 8$ " $(.95 \mathrm{~cm})$ O.D. lines.

g) The oil-less rotary vane compressor for purging and evacuation of the bags was installed along with a vacuum gauge. The vacuum gauge indicated the vacuum applied to the bags during the evacuation cycle. The vacuum gauge was located on the front panel.

The specifications listed above were the original design specifications for the analytical systems. Since their development, modifications and improvements have been made, which make the laboratory more modern and efficient.

\subsubsection{Regulated Emissions Sampling Trains}

Sampling trains for regulated emissions consisted of sample probes, lines, and analyzers. Gas analyzers were used to collect data for $\mathrm{CO}, \mathrm{CO}_{2}, \mathrm{NO}_{\mathrm{x}}$, and total hydrocarbons (Table 3.1). All analyzers were housed in the analytical trailer in an 
analytical bench designed by engineers at West Virginia University. In this section, the regulated emissions sampling trains will be discussed, with an emphasis on the analyzers and their functions.

Table 3.2 Regulated Gases and Analyzers

\begin{tabular}{|c|c|}
\hline Gases & Analyzers \\
\hline Low CO & Horiba Model AIA-210 \\
\hline High CO & Rosemount Model 880A \\
\hline NOx & Rosemount Model 955 \\
\hline THC & Beckman Model 402 \\
\hline
\end{tabular}

\subsubsection{Carbon Monoxide and Carbon Dioxide}

CFR 40 does not require that $\mathrm{CO}$ and $\mathrm{CO}_{2}$ measurements be taken on a continuous basis, but the WVU emissions testing laboratory does continuously measure the carbon monoxide and carbon dioxide concentrations in the diluted exhaust gas mixture. Carbon dioxide measurements were taken for their use in the calculation of the dilution factor and to determine the fuel consumption of the test vehicle.

The $\mathrm{CO} / \mathrm{CO}_{2}$ sampling train consisted of a heated sample probe and heated line as described above. Both samples were drawn through the same sample probe and line, but two different analyzers were used to determine the concentrations of the gases. The heated probe and line were maintained at a temperature of $240^{\circ} \mathrm{F}\left(115.5^{\circ} \mathrm{C}\right)$ to prevent moisture condensation during the transfer process, and a refrigerator/dryer system was implemented into the stream to remove any water that may be mixed with the sample. Prevention of condensation in the transfer line was necessary because some of the species were water-soluble, and due to the fact that the analyzer response was affected by moisture. The removal and prevention of any condensation that may occur in the sample 
train qualifies the analysis as being performed on a dry basis. The samples were also passed through a heated filter element to remove any solid particulate matter in the line.

The carbon monoxide analyzer section consisted of two different analyzers, a high concentration analyzer and a low concentration analyzer. Both analyzers were nondispersive infrared analyzers (NDIR). NDIR analyzers operate using two infrared beams of equal energy directed through two optical cells. One cell contains a reference gas and the other cell contains a continuously flowing sample. A detector continuously measures the difference in the amount of infrared energy absorbed in each cell. The quantity of infrared energy absorbed is proportional to the component concentration. The detector converts the energy difference between the reference cell and the flowing sample, and displays the concentration. The high CO analyzer was a Rosemount Model 880A and the low CO analyzer was a Horiba AIA-210 IR. The high CO analyzer had an operating range of $0-1000 \mathrm{ppm}$ and $0-5000 \mathrm{ppm}$, while the low $\mathrm{CO}$ analyzer operating range was from $0-100 \mathrm{ppm}$ and $0-2500 \mathrm{ppm}$. The $\mathrm{CO}_{2}$ analyzer was also a Horiba Model AIA220 IR.

\subsubsection{Oxides of Nitrogen}

The $\mathrm{NO}_{\mathrm{x}}$ sampling train, including a heated probe and a heated line, was maintained at a temperature of $240^{\circ} \mathrm{F}\left(115.5^{\circ} \mathrm{C}\right)$ during testing. Temperature maintenance insures that water does not condense out in the line during sample transport to the analyzer. If water were to condense out during transport, water-soluble components such $\mathrm{NO}_{2}$ would be lost. Two $\mathrm{NO}_{\mathrm{x}}$ analyzers were used during testing, with both analyzers receiving their sample from the same heated line. One analyzed $\mathrm{NO}$ and the other analyzed $\mathrm{NO}_{\mathrm{x}}$. 
Both $\mathrm{NO}_{\mathrm{x}}$ analyzers, Rosemount Model 955, operated using a heated chemiluminescent method. The analyzers had a selectable full-scale range of 10, 25, 100, $250,1000,2500$, and $10000 \mathrm{ppm}$. The NO concentration was determined by quantitatively converting nitric oxide to nitrogen dioxide, which elevated the $\mathrm{NO}_{2}$ to an electrically excited state. The elevation was immediately followed by a reversion to the non-excited state. This reversion caused a release of photons, which impinged on a detector and generated a low DC current. This low current was amplified to drive a meter. An output signal was sent to the data-logging computer where values were recorded continuously.

The method for determining $\mathrm{NO}_{\mathrm{x}}$ was identical to that of $\mathrm{NO}$, but before the sample was allowed to enter the reaction chamber it was sent to a converter where $\mathrm{NO}_{2}$ was dissociated to form NO. The instrument response was proportional to the total NO in the converted sample. Total NO in the converted sample consisted of the NO originally in the sample and the NO produced by dissociation.

Periodically, $\mathrm{NO}_{\mathrm{x}}$ Efficiency tests were performed on the $\mathrm{NO}_{\mathrm{x}}$ analyzer. The $\mathrm{NOx}$ efficiency test was described in CFR 40, Part 86 Subpart N. The efficiency test was designed to determine the conversion efficiency of the analyzer. An efficiency of less than $90 \%$ was considered a failure, and the problem was identified and corrected.

\subsubsection{Total Hydrocarbon}

The total hydrocarbon (THC) sampling train, including a heated probe and heated line, was maintained at an operating temperature of $375^{\circ} \mathrm{F}\left(191^{\circ} \mathrm{C}\right)$. At temperatures below $375^{\circ} \mathrm{F}$ vapor phase organics in the exhaust condense out making the $\mathrm{THC}$ reading inaccurate. The THC analyzer was a Beckman Model 402, which operated as a heated 
flame ionization detector (HFID). An HFID analyzer uses a burner as a sensor through which a regulated flow of sample gas passes through a flame. The flame is sustained by a regulated flow of gas and air, generally $40 \%$ hydrogen and $60 \%$ helium. In the flame, hydrocarbons in the sample undergo a complex ionization, which produces electrons and positive ions. The ions are collected on a polarized electrode, which creates a current that flows through the analyzers electronic measuring circuit. The current is proportional to the rate at which carbon atoms enter the burner, thus giving a measure of the concentration of hydrocarbons in the original sample. The concentration is displayed on the analyzer and sent to the data-logging computer.

In order to optimize the performance of the THC analyzer, a burner peaking procedure was performed on the HFID analyzer. Performance optimization was defined by increasing the sensitivity of the analyzer. The response at the initial setting of the analyzer was determined from the difference between the zero-gas response and the spangas response. The first procedure consisted of setting the burner combustion air pressure at a constant, and incrementally adjusting the FID fuel pressure. The zero and span responses at these pressures were recorded and the difference was determined. The procedure was then repeated while leaving the FID fuel pressure at a constant, and adjusting the combustion air pressure. The zero and span responses were recorded and the difference was determined. The analyzer was then set at a pressure that yielded the best response. The typical fuel and air pressure values for analyzer optimization were 20 and 25 psi, respectively. 


\subsubsection{Carbonyls}

Although not a regulated emission, the carbonyl sampling train was similar to that of regulated emissions in that it consisted of a heated probe, heated line, and a vacuum pump. A sample was drawn through the probe and line at a rate of $11 \mathrm{pm}$ using the vacuum pump, and maintained at $240^{\circ} \mathrm{F}\left(115.5^{\circ} \mathrm{C}\right)$ to prevent water condensation. Flow was regulated using a standard needle type flowmeter. Cartridges packed with silica gel and coated with acidified 2,4-dinitrophenylhydrazine (DNPH) were used to collect carbonyl samples during each test sequence. The samples were then sent to a laboratory for analysis using high performance liquid chromatography (HPLC).

\subsubsection{Total Particulate Matter}

Total particulate matter (TPM) was a regulated emission sampled during chassis dynamometer testing. TPM was sampled using a secondary dilution tunnel attached to the primary dilution tunnel. A stainless steel transfer tube was attached via a port in the primary tunnel and a sample was removed to the secondary tunnel. In the secondary tunnel, the exhaust sample temperature was cooled to below $125^{\circ} \mathrm{F}\left(50^{\circ} \mathrm{C}\right)$, which allowed TPM to form as it would in the standard atmosphere. The cooled sample was then passed through a stainless steel filter housing containing two $70 \mathrm{~mm}$ Pallaflex fluorocarbon coated fiberglass filters on which the TPM collected. After testing was complete the filters were weighed and PM mass calculations were performed according to CFR 40.

The secondary dilution train for PM measurement used excess dilution air to decrease the temperature of the sample and cause the TPM to form. The exhaust was drawn through a $0.5 \mathrm{inch}(1.3 \mathrm{~cm})$ diameter transfer tube located at the sampling zone in 
the primary dilution tunnel. Sierra mass flow controllers and rotary vane pumps controlled flow through the secondary tunnel. The secondary tunnel was 3.0 inches $(7.62 \mathrm{~cm})$ in diameter and 30 inches $(76.2 \mathrm{~cm})$ long. The 10 -diameter rule was achieved during this mixing process to allow the sample to cool to $125^{\circ} \mathrm{F}\left(50^{\circ} \mathrm{C}\right)$ before entering the filter housing.

\subsection{Particulate Sampling}

Particulate matter is classified by particle diameter. Particulate matter sizes range from less than 2.5 micrometers diameter to 10 micrometers diameter, and are designated by $\mathrm{PM}_{2.5}$ and $\mathrm{PM}_{10}$ respectively (Environment Canada, Nov. 2002). Fine particles are classified as those of diameter less than or equal to $\mathrm{PM}_{2.5}$ micrometers, and coarse particles are those that range from $\mathrm{PM}_{2.5}$ to $\mathrm{PM}_{10}$.

Size selective particulate matter samples were taken using cyclonic separators to collect the desired size particle on a filter media. Cyclonic separators have size selective inlets that created a spinning motion, or vortex in the sample stream. This vortex created inertial forces that make heavier particulate matter in the sample fall out, while the desired particle size was drawn through a filter housing and collected on a filter. The heavier particles were collected in a reservoir that was emptied periodically. PM sampling was performed using Sierra 740 series mass flow controllers and Gast model 1032 rotary vane pumps. 


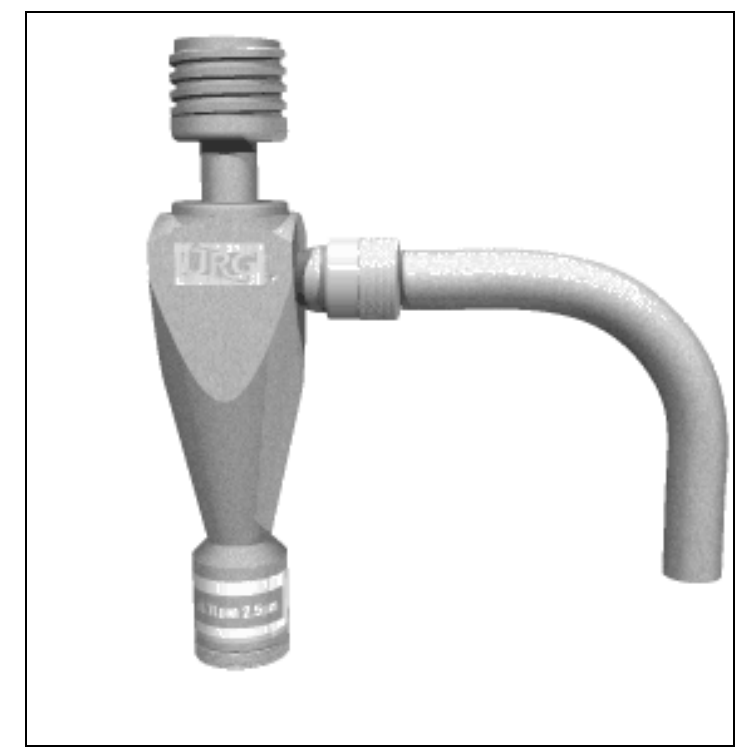

Figure 3.8 Particulate Matter Cyclonic Separator (URG, 2003)

\subsection{Gas Bag Sampling}

During the test procedure, a background bag and a diluted sample bag were filled. The background bag collected an ambient air sample used to determine the background levels during the testing procedure. The diluted sample bag collected a dilute exhaust sample from the primary dilution tunnel. After the test procedure, the bag samples were sent to the analyzers and the data from the bags was logged. The background bag values were used to correct emissions equations, and the dilute sample was a good comparison to the continuous data logged during the test. The values collected were used in the emissions equations discussed in Chapter 4.

\subsection{Temperature Control Module}

CFR 40 requires that regulated emissions samples be maintained at certain temperatures to prevent degradation of species during sampling. Insulating the primary dilution tunnel helped to prevent thermophoretic forces due to cold spots along the tunnel wall, but sampling trains must be maintained at specified temperatures. Maintaining the 
specified temperatures required the use of heated sample lines and probes as mentioned earlier and a system for controlling the temperatures. West Virginia University employed a temperature control module (TCM) to control the temperatures of the heated lines and probes and to send a data signal to a data-logging computer.

The TCM functioned as a closed loop control system to maintain the temperatures of heated components on the regulated emissions sampling train. The TCM received input signals from heated line and heated probe thermocouples. These input signals were sent to temperature controllers where the signal was detected and necessary action (output signal) was taken to maintain the temperature of the sample train. Omega model CNI-32 temperature controllers were used to control temperature. The temperature controllers used a set point temperature value to determine when to send an output signal to a solidstate relay. Output signals were sent to solid-state relays when the temperature of a heated line or heated probe droped below the set point value. The solid-state relay received a signal from the temperature controller and closed the relay connection so that power was supplied to the heated line or heated probe. A solid-state relay was activated only when the temperature of a heated line or heated probe droped below the set point value. Solid-state relays were Crydom Quad Relays and were normally open (NO). The relay load was sent to a Hubble twist lock connector, which connected to a heated probe or heated line power supply line. All thermocouples and thermocouple panel jacks were Omega type. $\mathrm{J}$ type thermocouples were used to control heated probes and both $\mathrm{J}$ and $\mathrm{K}$ type thermocouples were employed in the functioning of the heated lines. UPJ Series panel jacks by Omega were used to receive signals from the heated lines and probes. A 
thermocouple data signal port was located on the TCM, which allowed temperature readings to be sent to the data-logging computer.

\subsection{Chemical Speciation Sampling Cart}

Tedlar bag and PUF/XAD cartridge samples were collected using a chemical speciation cart designed by engineers at West Virginia University. The cart employs a vacuum bag sampling system for collecting volatile compound samples in tedlar bags and a mass flow system for collecting semi-volatile compound samples on 70mm Emfab filters and PUF/XAD cartridges. These two systems will be discussed in this section.

\subsubsection{Volatile Compound Bag Sampling System}

The volatile compound sampling system consisted of a vacuum chamber, diaphragm pump, and a flow metering system. The vacuum chamber was a $15 \mathrm{~L}^{\text {Pelican }}{ }^{\mathrm{TM}}$ case, model \#1450, with a vacuum release valve. Swagelok ${ }^{\circledR}$ quick connect fittings were installed in the vacuum chamber housing for easy connection of sample and evacuation lines. The vacuum chamber was fitted with a neoprene gasket and ABS latches to ensure a leak free environment. A dual filtration system was installed in line with the incoming sample to remove any particulate matter in the sample line. A Thomas Model 917 Teflon coated diaphragm pump was installed and used to create a vacuum in the vacuum chamber. A flow meter was used to control the rate at which air was removed from the vacuum chamber, thus controlling the rate at which the bag was filled.

The principle behind the system was similar to the function of human lungs. A reduction in the pressure inside of the box was compensated for by an exhaust sample flow into the tedlar bag. The pressure differential between the two environments allowed the bag to fill at the same rate that the vacuum chamber was being evacuated. The same 
is true when one exhales all of the air in their lungs. The atmospheric pressure becomes greater than the pressure in the lungs and inhalation occurs naturally if allowed. To achieve this in the vacuum sampling system, the sample line was connected to the primary dilution tunnel via a probe and also connected to a sampling port in the vacuum chamber. As the vacuum pump removed air from the vacuum chamber, the tedlar bag filled with an exhaust gas sample. The flow of the exhaust gas sample was regulated so that the bag did not overfill and burst.

\subsubsection{Semi-Volatile Organic Compound Sampling System}

Semi-volatile organic compounds were sampled using a mass flow system that removed an exhaust sample from the primary dilution tunnel and passed it across a filter and through a PUF/XAD canister. The system consisted of a Gast 1023 oil-free rotary vane pump, Swagelok ${ }^{\circledR}$ quick connect fittings, and a Sierra Series 840 mass flow controller. A probe and sample line were connected to the primary dilution tunnel. The sample line was a grounded line that was connected to the $70 \mathrm{~mm}$ filter holder. The pump pulled a sample from the tunnel flow stream and the mass flow controller controled the amount of sample drawn through the filter and PUF/XAD cartridge. Figure 3.9 shows the PUF/XAD cartridge housing with filter housing, and Figure 3.10 shows the chemical speciation cart which houses the PUF/XAD cartridges and Tedlar Bags. 


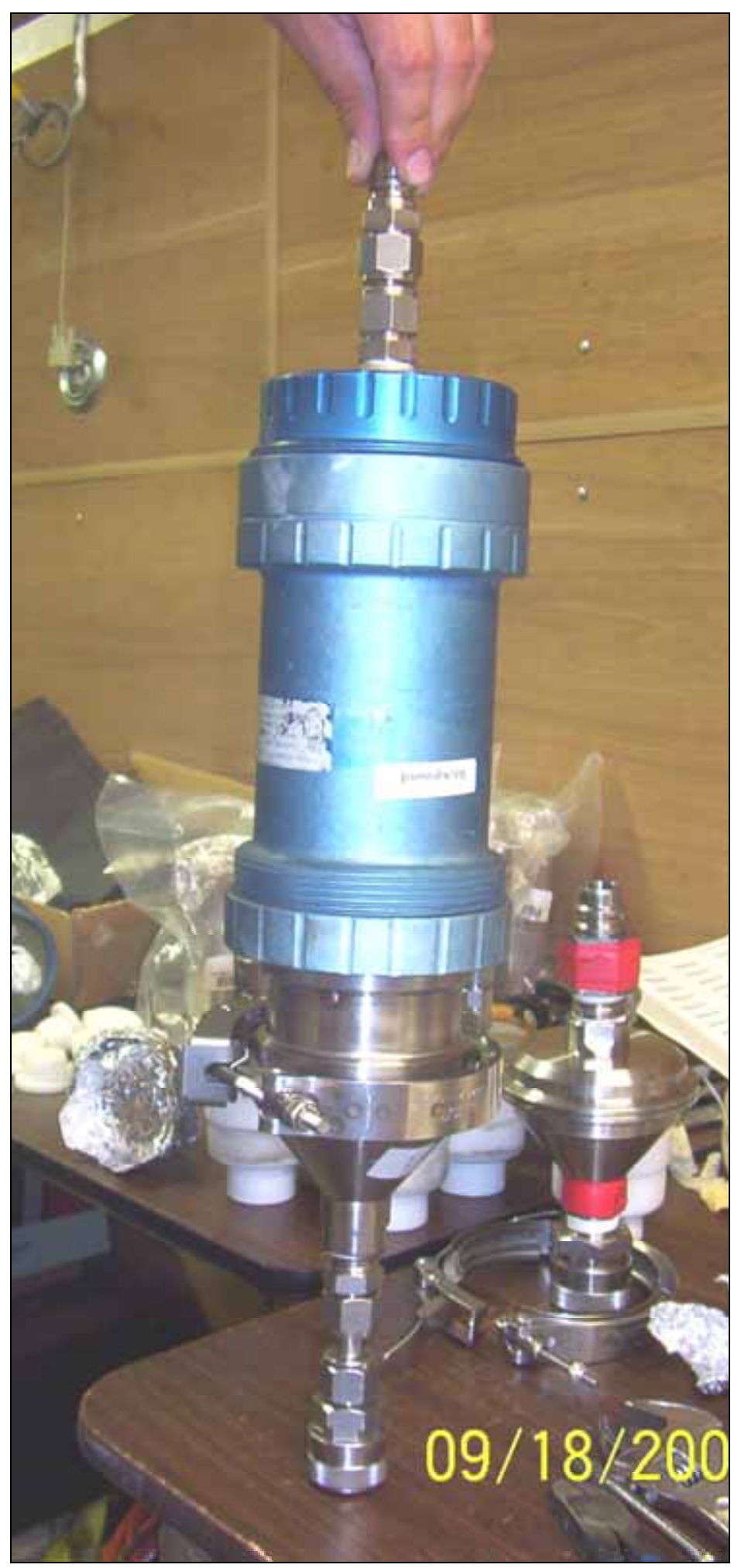

Figure 3.9 PUF/XAD Cartridge 


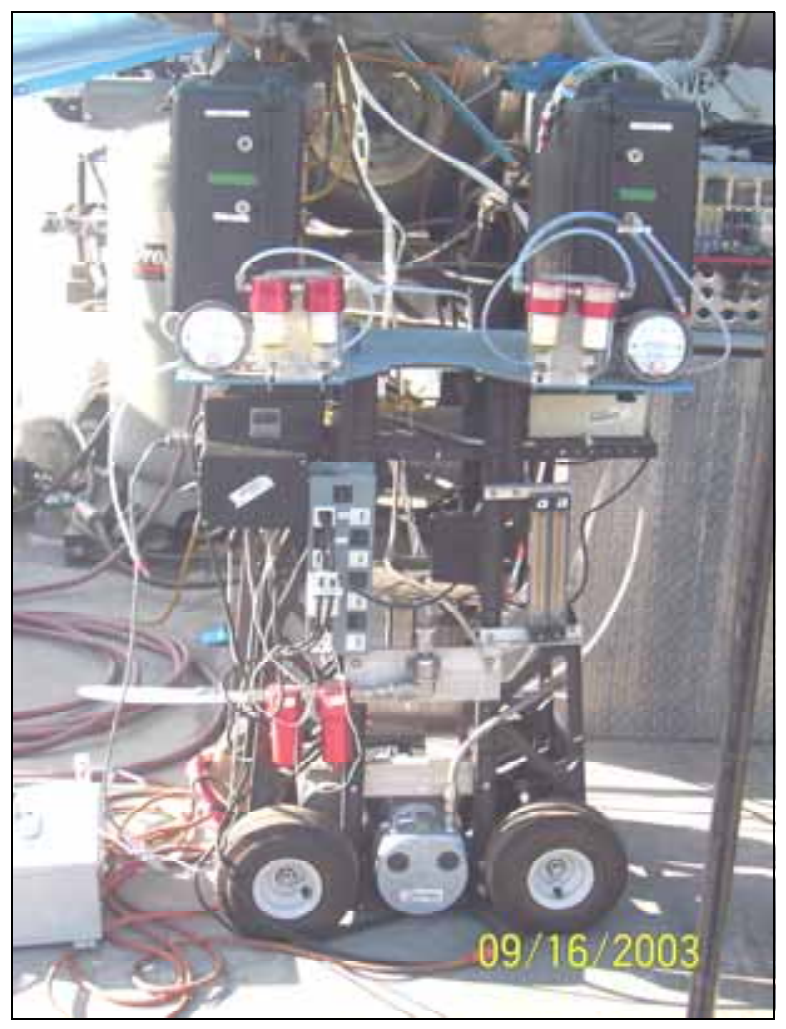

Figure 3.10 Chemical Speciation Cart without PUF/XAD Installed

\subsection{VOC Canister Sampling System}

A volatile organic compound canister sampling system was supplied by Environment Canada and implemented into the test procedure via engineers at the WVU testing facility. The sampling system consisted of one sample inlet port and three outlet ports. The outlet ports were: (1) sample canister filling port; (2) pump bypass port; (3) and a sample bypass port. The sample inlet port received a dilute exhaust sample directly from the primary dilution tunnel via a probe positioned in the tunnel with the probe opening opposing the tunnel flow. The sample bypass port was used in performing leak checks and when changing VOC canisters. The sample canister connection port was used to fill the canister during a test. A mass flow controller and a power supply/readout were 
integrated into the sampling system. Start-up and operating procedures for the VOC sampling system can be found in Appendix D.

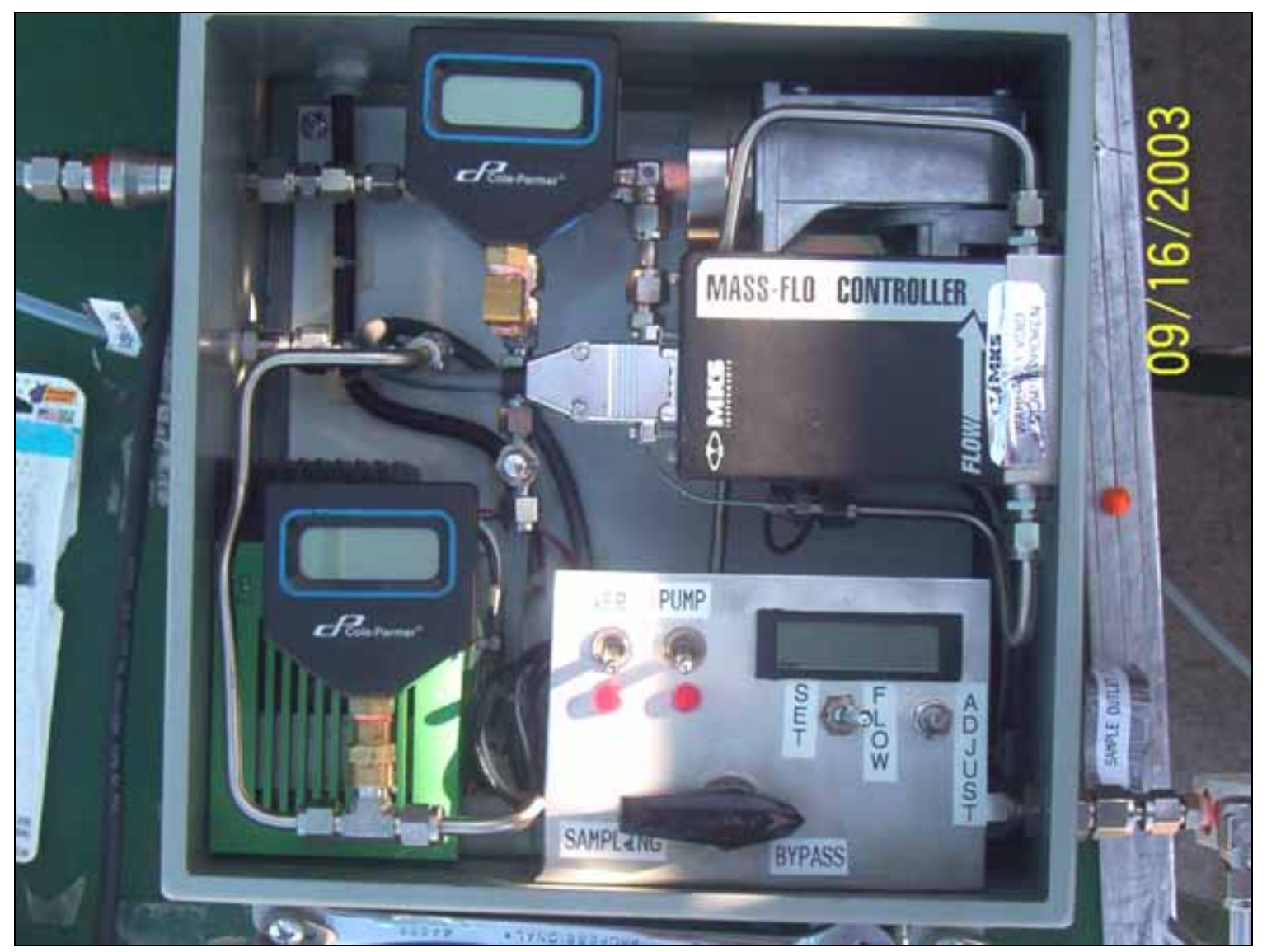

Figure 3.11 VOC Sampling System Supplied by Environment Canada

\subsection{Instrumentation Control and Data Acquisition}

The data acquisition and control originally consisted of six major components (Chasey, 1992). Those components included a:
a) Control system computer
b) Drivers interface computer
c) Data acquisition boards
d) Dyne-Loc controllers
e) Sensors, cabling, and interconnections 


\section{f) Calibration and test software}

These six components performed the functions of data sampling, archiving, processing, and system control (Ferguson, 1993). The driver interface computer is no longer needed because; the main data acquisition computer controls this function. The data was stored and used in emissions calculations and reduction.

\subsection{Media}

Media samples for chemical speciation and gravimetric analysis were collected during the testing procedure. CFR 40 outlines procedures for media handling and media quality. When collecting media for chemical speciation and gravimetric analysis, different types of media were used to collect different chemical samples for analysis. Table 3.3 lists the species collected during testing and the media used to collect the samples. Media conditioning, labeling, and tracking will be discussed in this section.

Table 3.3 Chemical Species and Collection Media

\begin{tabular}{|c|c|}
\hline Compound & Collection Media \\
\hline $\begin{array}{c}\text { Volatile Organic Compounds } \\
\text { (VOC), Methane, Non- } \\
\text { Methane }\end{array}$ & VOC Canisters \\
\hline $\begin{array}{c}\text { PAH, n-PAH, Hopanes, and } \\
\text { Steranes }\end{array}$ & $\begin{array}{c}\text { TX-40 (70mm) Filters + } \\
\text { PUF/XAD Cartridges }\end{array}$ \\
\hline Aldehydes & DNPH Cartridges \\
\hline $\mathrm{PM}_{2.5}$ (Elemental Analysis) & Teflon Filter $(47 \mathrm{~mm})$ \\
\hline $\mathrm{PM}_{2.5}$ (EC/OC) & Quartz Filters (47mm) \\
\hline 1,3 Butadiene/BTEX $_{10}$ (Gravimetric) & Tedlar Bag \\
\hline $\mathrm{PM}_{1.5}$ (Gravimetric) & T60-A20 (47mm) Filters \\
\hline $\mathrm{PM}_{2.5}$ (Gravm) Filters \\
\hline $\mathrm{PM}_{1}$ (Gravimetric) & T60-A20 (47mm) Filters \\
\hline Total PM (Gravimetric) & T60-A20 (70mm) Filters \\
\hline
\end{tabular}




\subsubsection{Media Conditioning and Weighing}

In order to maintain a level of consistency throughout the weighing of filter media, CFR 40 listed specifications that must be met when weighing filter media. The temperature of the weighing chamber and balance must be maintained at $22^{\circ} \mathrm{C} \pm 3^{\circ} \mathrm{C}$ $\left(71.6^{\circ} \mathrm{F} \pm 3^{\circ} \mathrm{F}\right)$ and a dew point of $9.5^{\circ} \mathrm{C} \pm 3^{\circ} \mathrm{C}\left(49.1^{\circ} \mathrm{F} \pm 3^{\circ} \mathrm{F}\right)(\mathrm{CFR} 40,2001)$. A relative humidity of $48 \% \pm 8 \%$ must also be maintained inside of the chamber and balance. This standard was set so that one testing facility cannot achieve better testing results than another facility by lowering the relative humidity or temperature of the room. The weighing chamber and microbalance at West Virginia University's Engine Emissions Research Center (WVUEERC) were maintained at $70^{\circ} \mathrm{F}$ and $50 \%$ relative humidity at all times, and this data was continuously recorded using a data logging computer.

Filter media must be conditioned for at least 8 hours but no more than 80 hours before weighing. Filter media was conditioned at WVUEERC for a period of 24 hours prior to weighing. Media conditioning was performed for the allotted time period to ensure that the media stabilizes to the temperature and relative humidity of the chamber. Reference filters were weighed to ensure that the microbalance was working properly and assure cleanliness of the air. Two reference filters remained in the chamber at all times. These filters were weighed before and after any media was weighed to assure that the microbalance was working properly.

After the twenty-four hour period, the filters were pre-weighed using a Cahn-32 Microbalance. Media weights were sent to a computer where they were logged for future use. Each individual piece of media was given a barcode, and the barcodes were used to 
$\log$ media weights into the database. After all of the media was weighed, it was conditioned for several hours and then placed in a refrigerator until it was required for use. After the media was used, it was again placed in the weighing chamber and conditioned before post-weighing.

\subsubsection{Media Labeling}

All media containers were labeled using barcodes and colors. Barcodes assigned to media were used only to aid in the tracking of the media from one location to another. These bar codes were placed on the petri dish containing a media, and an identical barcode was placed on a quality control and quality assurance (QC/QA) sheet. Media was arranged in packets so that when a set of media was being loaded for a test, one packet containing all of the media needed for that test was removed from the storage location. Color-coding was used to ease the process of changing media during multiple tests. Each individual type of media was assigned a color. Every place on the dilution tunnel that required media to be installed was color coded so that the correct media was installed in the correct location. Filter holders were color coded so that the correct filter was placed in the correct holder. The use of the color system made it virtually impossible to place media in the wrong location during the test procedure. 
Table 3.4 Media Color Coding

\begin{tabular}{|c|c|}
\hline Media & Color \\
\hline VOC Canisters & Black \\
\hline TX-40 (70mm) Filters & Salmon \\
\hline PUF/XAD Cartridges & Yellow-Neon \\
\hline DNPH Cartridges & Dark Blue \\
\hline Teflon filter (47mm) (Elemental) & Light Green \\
\hline Quartz Filters (47mm) (EC/OC) & Orange \\
\hline Tedlar Bag & White \\
\hline T60-A20 (47mm) Filters (PM1) & Red \\
\hline T60-A20 (47mm) Filters (PM2.5) & Yellow \\
\hline T60-A20 (47mm) Filters (PM10) & Light Blue \\
\hline T60-A20 (70mm) Filters (TPM) & Dark Green \\
\hline
\end{tabular}

After all media was color and bar coded, it was packaged and shipped to the test site.

\subsubsection{Media Tracking}

Media tracking was used as a quality assurance method to ensure that media was accounted for at all times and that the proper media was used during the test procedure. These practices were not required but are recommended by the author to aid in the proper distribution and use of the media. Media arrival, use, and departure will be discussed in this section.

\subsubsection{Media Arrival}

Media tracking software designed by engineers at West Virginia University allowed a user to catalog media arrival, media use, and media departure from the test site. The software used barcodes from the media storage containers to log information about the media into a database. When media shipments arrived at the test site, the carrier and tracking number were used to arrange the media in the database. All media in a shipment were cataloged under one tracking number. The media barcodes were scanned and the location, storage, and any damage to the media were input by the user. The media was 
then stored in the location input by the user until it was ready for use. All media that was shipped to the test site was stored in an air-conditioned room and refrigerators were available for media that required refrigeration.

\subsubsection{Media Use}

When the media was ready to be used for a test, it was removed from storage and logged into the database again as used media. Instead of being assorted by tracking number, the media was sorted according to the test sequence number provided by the field engineer. Media was arranged in the media use database by color and barcode. The color field aided in assuring the media handler that all media was present and accounted for during that test. All media used for a test sequence were logged at the same time and saved to the database under that same test sequence number. After the media was logged and saved, it was then placed at the proper location on the dilution tunnel. Filter holders were loaded inside of the trailer with their respective media, and all other media was loaded outside of the media trailer. Detailed analysis of media installation is discussed in Chapter 4 of this work. After the completion of a test, the media was returned to the trailer and stored until departure.

\subsubsection{Media Departure}

Media was shipped after testing to its respective analysis location. Tracking for media departure was similar to media arrival in that all media under one tracking number was logged into the database according to carrier and tracking number. The media barcodes were scanned and then placed into their respective shipping crates. After all media were logged for departure, the media were packaged and shipped. 
The components presented in this section make up the testing facility, and function together to obtain useable emissions data from heavy-duty vehicles. Chapter 4 discusses the emissions testing process and emissions calculations. 


\section{Emissions Testing Process}

In order to perform testing on a vehicle, some preparatory steps must be taken to ensure that all of the testing equipment is functioning properly. These steps include: installing the proper probes for media collection, calibrating equipment, and performing leak tests. After the aforementioned steps have been performed, the tests can be run and emissions calculations performed. In the following sections set-up, calibration, propane injection, test procedures, and emissions calculations will be discussed.

\subsection{Set-up}

The West Virginia University Transportable Heavy-Duty Vehicle Emissions Testing Laboratory was designed to be portable and available for testing at any location given proper notice. A set of tandem trailer wheels was fixed to the chassis dynamometer for moving the test bed from location to location. Upon arrival at a test site, the trailer holding the chassis dynamometer was positioned for testing. Four hydraulic jacks were built into the trailer frame. The jacks were used in the removal of the tandem trailer wheels and lowering the chassis dynamometer to the ground. The chassis dynamometer was leveled to ensure that no problems occurred when simulating vehicle inertia using the rotating flywheels. After the dynamometer was positioned and leveled, an analytical trailer was positioned in close proximity to the rear of the dynamometer as possible. The location of the analytical trailer helped to shorten the length of the exhaust transfer tube, which aids in the reduction of test variability. Next, the critical flow venturi was lowered via a crane into position. The CFV was positioned at the outlet section of the primary dilution tunnel. 
Typically a dilution tunnel located inside or on top of the analytical trailer was used during a test procedure, but this test procedure used a new, clean dilution tunnel to reduce the amount of tunnel background present during testing. The reduction in tunnel background eliminated a factor of variability in the testing procedure. The clean dilution tunnel was designed by the author and constructed by local manufacturers and in-house technicians. For ease of use, the dilution tunnel was positioned next to the analytical trailer on an adjustable height stand. The reader is encouraged to review Chapter 3 for details on the clean dilution tunnel.

After the dilution tunnel was erected, a transfer tube was connected from the CFV to the outlet section of the dilution tunnel. Next, the dilution air filtration system was placed near the inlet section of the primary dilution tunnel and an inlet hose was attached. After all equipment was in place for testing, the analytical trailer was prepared for testing.

Preparing the analytical trailer for use took little set-up time. The analyzer bench, environmental chamber, and dynamometer controls were all shock mounted in the trailer and required little preparation. The computer, pressure regulators, and calibration gas cylinders were set-up for testing. Typically, when using the dilution tunnel attached to the analytical trailer, sample lines, probes, and the secondary dilution tunnel were left attached during transport and are immediately ready for testing. Since a clean dilution tunnel was used for testing, heated lines, heated probes, and the secondary dilution tunnel were installed after the dilution tunnel was erected. Sample systems were leak checked and blown clean with high-pressure air. All equipment was inspected and fittings were tightened to assure that the laboratory was operational. 
In addition to the aforementioned procedures, there are several additional steps that were taken to start the analyzers and equipment. Power supply for the testing facility was not required at the test site, but when power was available on-site, it was used. If on-site power was not available, a $135 \mathrm{hp}(100 \mathrm{~kW})$ generator was available to provide power to the blower, power absorbers, and analytical trailer. Power was supplied to the necessary locations, and equipment such as an air compressor and the zero air generator were powered up and allowed time to store air before turning on the analyzers. Proper amounts of air were necessary because the $\mathrm{NO}_{\mathrm{x}}$ analyzer and the HFID required airflow to operate. After proper air requirements were attained, analyzers were turned on and allowed to stabilize. Stabilization usually occurred for twenty-four hours before equipment was ready for calibration. Once the equipment was stabilized temperatures were verified and thermocouples were attached where necessary, the laboratory was ready for calibration.

\subsection{Analyzer Calibration}

Analyzer calibration was performed using gas bottles with known concentrations and a gas divider that ranged from zero to one hundred percent of full scale. The gas divider had an accuracy of $0.5 \%$ of full scale, and operated by allowing a certain percentage of zero air and span gas into the analyzer. The calibration process was an 11-point calibration method in the calibration gas was divided from $0 \%$ to $100 \%$ in increments of 10. Analyzers were calibrated weekly or more often if necessary. The need to recalibrate would arise if a drift in excess of $3 \%$ for $\mathrm{THC}$ and $2 \%$ for $\mathrm{NO}_{\mathrm{x}}, \mathrm{CO}$, and $\mathrm{CO}_{2}$ occurred. Analyzer drift was determined using zero/span checks of the analyzers. A zero check sent zero air through the analyzer. A reading of zero should have been seen on the 
analyzer during the zero check. Span checks were performed using a concentration of span gas sent through the analyzer. If the analyzer was off by the given percentages, then the analyzer was recalibrated. Zero/span checks were performed after calibration and before and after each test run. If an analyzer drifted by more than the aforementioned percentages during a test, the test was considered void. In the event that a span gas concentration was changed due to a different bottle being used, the analyzer was recalibrated and the ranges for the analyzer changed if necessary. Figure 4.1 demonstrates typical calibration curves.
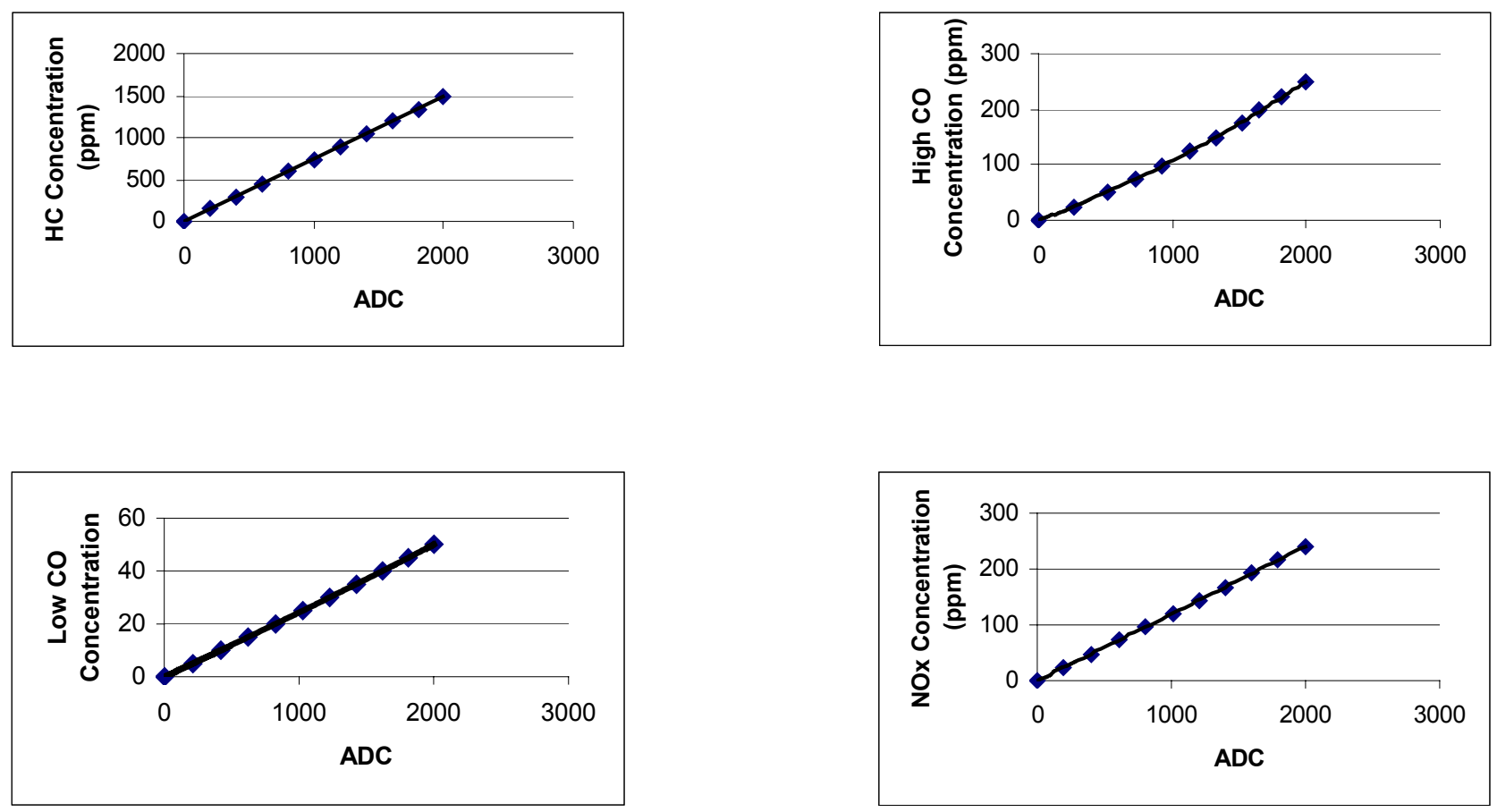

Figure 4.1 Calibration Curves for HC, High and Low CO, and $\mathrm{NO}_{\mathrm{x}}$ 


\subsection{Microbalance Calibration}

A Cahn 32 Microbalance was used to weigh filter media, and was equipped with a calibration mode. This mode allows the balance to be calibrated at specified weights programmed into the balance. NIST approved weights were used to calibrate the microbalance. The specified weight was placed on the balance stirrup and the balance was allowed to stabilize for several minutes. After stabilizing, the balance was calibrated and the user indicated the exact weight given by the analyzer. Calibration was complete when the balance weight indicated the same value as the measured weight. Some drift was unavoidable, but was maintained at a minimum. Any time power was lost to the balance, or the balance was transported from one test location to another, the balance was recalibrated.

\subsection{CFV-CVS Calibration}

CVS calibration was performed using an accurate flowmeter and restrictor valve (CFR 40, 2001). The calibration of a CFV was based upon the flow equation for a critical venturi. The following equation calculated the flow based on a calibration coefficient, absolute temperature, and absolute pressure.

$$
Q_{S}=\frac{K_{V} P}{\sqrt{T}}
$$

\section{Equation 4.1}

Where:

$\mathrm{Q}_{\mathrm{S}}=$ Flow.

$\mathrm{K}_{\mathrm{V}}=$ Calibration Coefficient.

$\mathrm{P}=$ Absolute Pressure.

$\mathrm{T}=$ Absolute Temperature.

Initially the flow restrictor was opened and the blower started. The system was allowed to stabilize and data from all instruments was recorded. After stabilization, the 
flow restrictor was varied and eight readings were made across the critical flow range of the venturi. The data obtained were used in the calibration coefficient calculation. That is,

$$
K_{V}=\frac{Q_{S} \sqrt{T_{V}}}{P_{V}} \quad \text { Equation } 4.2
$$

Where:

$\mathrm{Q}_{\mathrm{S}}=$ Flow rate in standard cubic feet per minute at standard conditions: $68^{\circ} \mathrm{F}$, $29.92^{\prime \prime} \mathrm{Hg}\left(20^{\circ} \mathrm{C}, 101.3 \mathrm{kPa}\right)$.

$\mathrm{T}_{\mathrm{V}}=$ Venturi inlet temperature, $\mathrm{R}(\mathrm{K})$.

$\mathrm{P}_{\mathrm{V}}=$ Venturi inlet Pressure, in. $\mathrm{Hg}(\mathrm{kPa})$.

The calculation for venturi inlet pressure was:

$$
\begin{aligned}
& P_{V}=P_{B}-P P I(\text { s.g./13.5955) } \\
& P_{V}=P_{B}-P P I
\end{aligned}
$$

\section{Equation 4.3}

Where:

$\mathrm{P}_{\mathrm{B}}=$ Barometric Pressure, in. $\mathrm{Hg}(\mathrm{kPa})$.

PPI $=$ Venturi inlet pressure depression, inches of fluid $(\mathrm{kPa})$.

s.g. $=$ Specific Gravity of monometer fluid.

The calibration coefficient value was plotted as a function of venturi inlet pressure.

During choked flow situations, the calibration coefficient had a relatively constant value, and as the flow became unchoked, the calibration constant value decreased. Using 8points in the critical flow (choked) region, the average calibration coefficient value and standard deviation were calculated. If the standard deviation exceeded 0.3 percent of the average $\mathrm{K}_{\mathrm{V}}$ value, action was taken to correct the calibration coefficient error. The calibration coefficient average value along with the absolute values of temperature and pressure were used to calculate gas flow. 


\subsubsection{CFV-CVS Calibration Verification}

Propane injections were performed to verify that the CVS and analytical equipment accurately measured a mass of gas that had been injected into the sampling system. To perform the test, a known quantity of propane was released into the dilution tunnel while the CFV-CVS was operating. CFR 40 describes a gravimetric method, which can be used when performing a propane injection and Horiba describes a method using a critical flow orifice.

In the gravimetric method, a small cylinder charged with pure propane was weighed initially. Weighing apparatus' must be accurate within 0.01 grams. After weighing the canister, a quantity of propane was injected into the CVS while operating in a normal manner. After the injection was performed, the cylinder was reweighed and the gravimetric mass of injected propane was determined. The gravimetric mass was then subtracted from the CVS mass that was measured by an HFID. This difference was then divided by the gravimetric mass to determine the percent accuracy of the system. The percent accuracy was defined by the following equation:

$$
\% A C C=\frac{G_{m}-M_{m C V S}}{G_{m}} * 100 \%
$$

\section{Equation 4.4}

Where:

$\mathrm{G}_{\mathrm{m}}=$ Gravimetric Mass.

$\mathrm{M}_{\mathrm{mCVS}}=$ Mass measured through CVS.

A percent accuracy of greater than $+/-2 \%$ indicated a leak or other problem.

Problems typically occurred due to a leak in the system or improper calibration of the HFID. After the problem was found and corrected and the percent accuracy was within limits; the system was ready for the testing procedure. 
The second method for propane injection used a critical flow orifice for verifying calibration of the venturi used by WVU (Ferguson, 1993). Propane was injected through a flow meter that used a critical flow device to accurately measure the flow. Temperature and pressure were used to determine the rate of gas flow through the orifice. The following equation was used to determine the flow rate through the orifice.

$$
q=\frac{A+(B * P)+\left(C * P^{2}\right)}{\sqrt{460+T}}
$$

Where:

$\mathrm{q}=$ Flow rate through orifice in SCFM at $29.92^{\prime \prime} \mathrm{Hg}$ and $528^{\circ} \mathrm{R}$.

$\mathrm{A}, \mathrm{B}, \& \mathrm{C}=$ Calibration coefficients that were furnished by orifice manufacturer. $\mathrm{P}=$ Absolute orifice inlet pressure, in psia (gauge + atmospheric pressure).

$\mathrm{T}=$ Orifice inlet temperature in Fahrenheit.

The volume flow rate through the CVS was given by,

$$
Q=\frac{V}{T} * 60 \quad \text { Equation } 4.6
$$

Where:

$\mathrm{V}=$ Volume in SCFM measured by CVS.

$\mathrm{t}=$ Time interval in seconds.

The calculated sample concentration was then determined using the following,

$$
C_{\text {calc }}=\left(\frac{q}{Q} * 10^{6}\right) * 3 \quad \text { Equation } 4.7
$$

The percent error of the system was defined by,

$$
\text { Error }=\left(\frac{C_{o b s}}{C_{c a l c}}-1\right) * 100 \% \quad \text { Equation } 4.8
$$

Where:

$\mathrm{C}_{\mathrm{obs}}=$ Measured concentration of the injected sample from the HFID. 
The same error criterion applied as for the gravimetric method. The WVU laboratory choose to use the critical flow orifice and not the gravimetric method due to size constraints.

\subsection{Test Procedures}

Starting a test required several preliminary steps to prepare the laboratory. Simulated loading conditions were set, and the test vehicle was prepared. Making adjustments to the flywheel assembly set simulated loading conditions. The outer rear wheels of the test vehicle were removed and hub adapters were fitted to the vehicle. The test vehicle was then backed onto the chassis dynamometer where the drive shafts were attached to the hub adapter via face plate adapters. As a safety precaution the vehicle was chained down to the bed of the chassis dynamometer. Care was taken to ensure that the tires of the test vehicle were not distorted, which would add to the loading of the vehicle. The vehicle was then leveled and the exhaust transfer tube was installed. Figure 4.2 shows the test vehicle installed on the chassis dynamometer. Figure 4.3 shows the exhaust transfer tube connected to the exhaust of the test vehicle. 


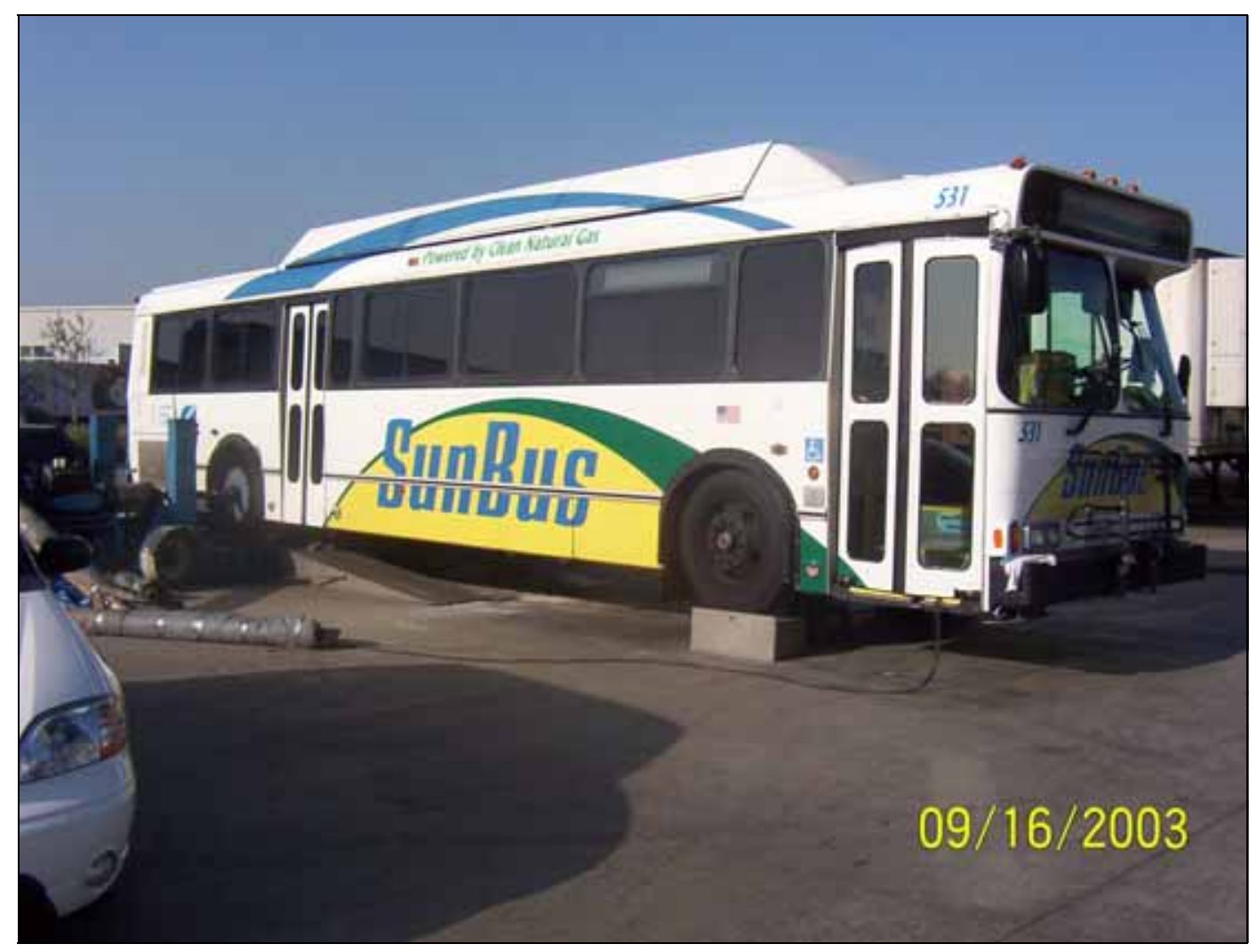

Figure 4.2 Test Vehicle Mounted on Chassis Dynamometer

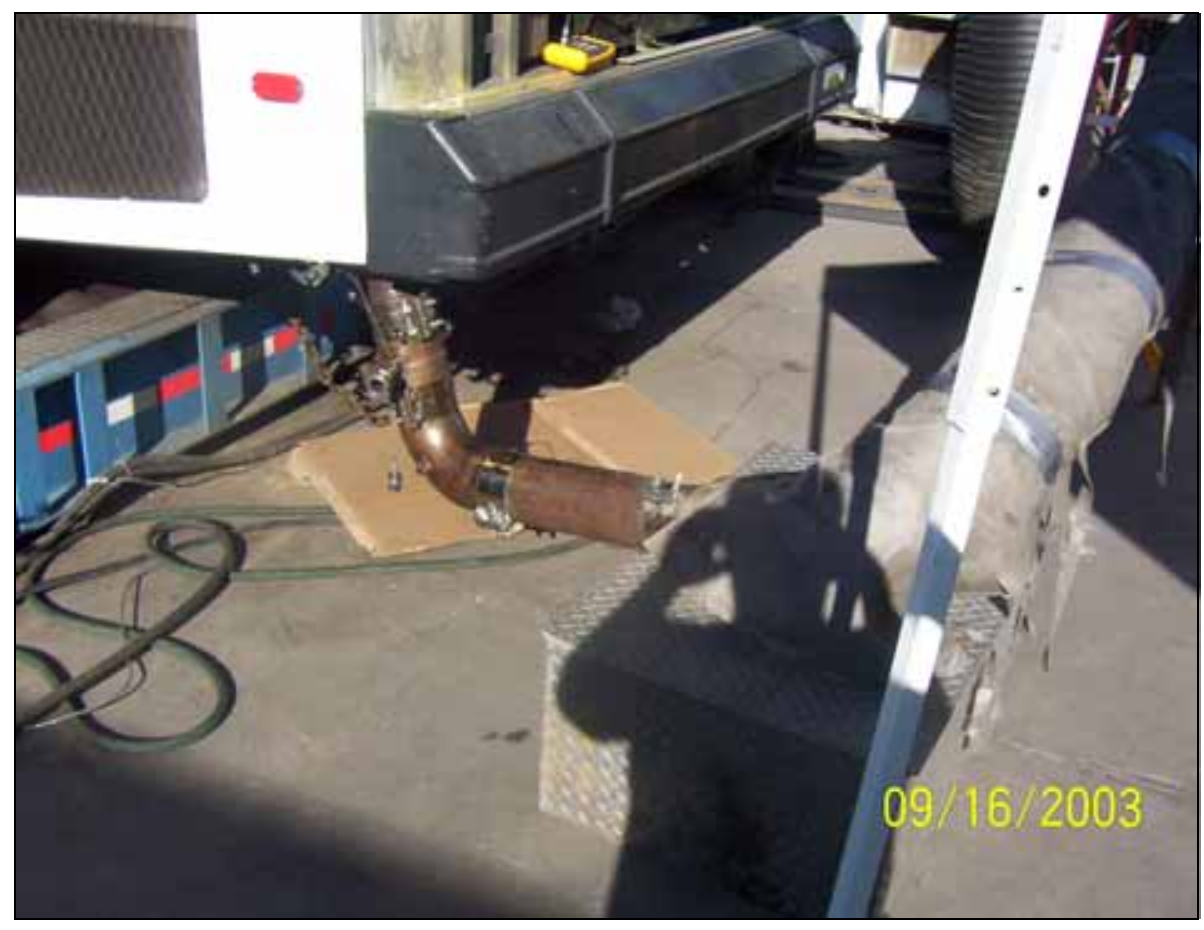

Figure 4.3 Exhaust Transfer Tube Connection 
After the test vehicle was properly positioned on the chassis dynamometer, the vehicle was run for a short time to warm the lubricating oils in the chassis dynamometer system. Heating these oils reduced the friction they add to the system during cold operation due to high viscosity. After the oils were heated the vehicle was shut off and allowed to soak for twenty minutes.

Prior to starting a test procedure, all media, analyzers, and collection devices were prepared for use. Filters used for chemical speciation and gravimetric analysis were loaded into filter holders and placed in their respective location on the primary dilution tunnel. Filter media was loaded inside of a clean media trailer to prevent contamination of the sample surface. Gravimetric filter media for this study were weighed, prior to testing, at the WVUEERC along with a set of control media that were sent to determine the effects of shipping on used and unused filter media mass. The average mass percent difference was $0.014 \%$. The PUF/XAD canister, $70 \mathrm{~mm}$ filter housing with filter, and tedlar bag were installed on the speciation cart, and the VOC canister was connected to the VOC sampling system. DNPH cartridges for aldehydes sampling were attached to a heated sampling train. Tedlar bags housed inside of the analytical trailer continuously collected dilute exhaust samples during the test procedure. The sample bags were used as continuous samples for evaluating regulated emission levels, and were evacuated after use via a rotary vane pump. A vacuum gauge was used to indicate when the bags were fully evacuated $(25$ 'Hg). If the gauge did not reach 25 ” $\mathrm{Hg}$, then the bags and lines were checked for leaks, and changed if necessary.

Prior to testing, all mass flow controllers and flow devices were checked to ensure that they were in proper working order. When a test was ready to begin, a horn sounded 
to indicate the start of a test. For this study, one ten-minute CBD cycle was run to properly warm-up the test vehicle. After the allotted warm-up, another horn sounded indicating the beginning of the actual test. At the sound of the horn, all sampling systems were started via a program on the host computer. As soon as the systems were started, the data-logging computer started logging temperature, pressure, humidity, and flow data from all specified points in the testing system. During the test procedure, the driver of the test vehicle carefully followed an outline of the driving schedule. The outline of the driving schedule was shown on a monitor installed in the test vehicle. The monitor indicated the engine speed $(\mathrm{rpm})$, temperature, remaining test time, and several other important values. For this study, data was collected over three CBD cycles to allow sufficient time for emissions to collect on filter media. The extended time was necessary due to the inherently low emissions of CNG fueled vehicles.

After a test procedure was completed, the engine was allowed another twenty-minute soak period until the next test procedure was ready to begin. The soak time allowed the engine to return to the rested state it was at before the test started. Allowing the engine to return to the rested state eliminated a possible source of variability. During this soak time, all used media were removed and placed in their respective storage locations and new media was installed for the next round of testing. During the soak period, a field engineer was responsible for checking flow characteristics obtained during the test procedure to detect any possible malfunctions that would make the test invalid. If any problems were noticed during a test, the problem was identified and the test procedure repeated. During a test the data-logging computer stored all of the information necessary for performing emissions calculations. 


\subsection{Emissions Calculations}

After a test procedure was completed, media was stored, and data was logged, emissions calculations were performed to determine the levels emitted from the test vehicle. Calculations were performed for regulated and unregulated emission levels based on the data logged during the test procedure and values obtained during chemical species extraction. CFR 40 sets the standard for performing calculations on vehicle emissions. The mass emissions collected during a test were dependant on the concentration of the gas in the dilution tunnel, the total volume of dilute gas pulled through the tunnel, and the ratio of raw exhaust to dilution air (Ferguson, 1993). Equations used for determining emission levels in heavy-duty vehicles will be discussed in this section.

\subsubsection{Standard Equations}

Mixture volume was defined as the total volume of diluted gas pulled through the primary dilution tunnel during a test procedure, and was defined by the following equation.

$$
V_{m i x}=\sum_{i=1}^{n}\left[V_{(m i x) i} * \Delta t\right]_{\text {Equation } 4.9}
$$

Where:

$\mathrm{V}_{(\text {mix }) \mathrm{i}}=$ Instantaneous dilute exhaust gas mixture flow rate $\left(\mathrm{ft}^{3} / \mathrm{sec}\right)$, and is calculated by the following equation

$$
V_{(m i x) i}=\frac{K_{v}^{*} P_{v i}}{\sqrt{T_{v i}}} \text { Equation } 4.10
$$


$\mathrm{K}_{\mathrm{v}}=$ Calibration constant for the critical flow venturi that has been corrected for standard conditions during the calibration.

$\mathrm{P}_{\mathrm{vi}}=$ Instantaneous absolute pressure at the venturi inlet (in. $\mathrm{Hg}$ ).

$\mathrm{T}_{\mathrm{vi}}=$ Instantaneous temperature at the venturi (R).

$\Delta \mathrm{t}=$ Time differential between the instantaneous measurement points (seconds).

$\mathrm{n}=$ Number of instantaneous measurements taken during the test.

The $\mathrm{V}_{\text {mix }}$ of a test was used during the calculation of regulated and unregulated emissions.

Dilution factor was the ratio of the theoretical amount of carbon dioxide in the undiluted exhaust due to stoichiometric combustion to the summation of the actual measured concentrations of carbon dioxide, carbon monoxide, and the individual components of the organic matter. The fuel composition was given as $\mathrm{C}_{\mathrm{x}} \mathrm{H}_{\mathrm{y}} \mathrm{O}_{z}$ for the fuel being burned during combustion in the test vehicle. Dilution factor was calculated using the following equation.

$$
D F=\frac{100 \% *\left(\frac{x}{x+\frac{y}{2}+3.76 *\left(x+\frac{y}{4}-\frac{z}{2}\right.}\right)}{\mathrm{CO}_{2 e}+\left(\mathrm{HC}_{e}+\mathrm{CO}_{e}+\mathrm{CH}_{3} \mathrm{OH}_{e}\right) * 10^{-4}} \text { Equation } 4.11
$$

Where:

$\mathrm{x}, \mathrm{y}, \mathrm{z}=$ The number of carbon, hydrogen, and oxygen atoms, respectively, in the initial fuel mixture.

$\mathrm{CO}_{2 \mathrm{e}}=$ The carbon dioxide concentration of the dilute exhaust sample corrected for background (ppm). 
$\mathrm{CO}_{\mathrm{e}}=$ The carbon monoxide concentration of the dilute exhaust sample corrected for background (ppm).

$\mathrm{HC}_{\mathrm{e}}=$ The hydrocarbon concentration of the dilute exhaust sample corrected for background (ppm).

$\mathrm{CH}_{3} \mathrm{OH}_{\mathrm{e}}=$ The methanol concentration of the dilute exhaust sample corrected for background (ppm).

Values for $\mathrm{x}, \mathrm{y}$, and $\mathrm{z}$ were determined by solving the stoichiometric combustion equation in which the products of combustion consist of carbon dioxide, water and excess nitrogen. The stoichiometric combustion equation was

$$
\mathrm{C}_{x} \mathrm{H}_{y} \mathrm{O}_{z}+a\left(\mathrm{O}_{2}+3.76 \mathrm{~N}_{2}\right) \rightarrow b \mathrm{CO}_{2}+c \mathrm{H}_{2} \mathrm{O}+3.76 d \mathrm{~N}_{2} \quad \text { Equation } 4.12
$$

Solving the equation for $\mathrm{x}, \mathrm{y}$, and $\mathrm{z}$ was achieved by performing the following calculations:

$$
\mathrm{C}: \mathrm{x}=\mathrm{b}
$$

H: $y=2 c$

O: $z+2 a=2 b+c$

$\mathrm{N}_{2}: \mathrm{a}=\mathrm{d}$

Solving for $\mathrm{a}, \mathrm{b}$, and $\mathrm{c}$ yielded the concentration of reactants and products.

\subsubsection{Equations for Calculating Regulated Emission Masses}

The equations for calculating the masses of regulated emissions from the test vehicle were standard equations set by the EPA in CFR 40. The equations were calculated using analyzer data stored during the test procedure and involve the mixture volume and the dilution factor. The following equations were used in determining the masses of regulated emissions.

$$
H C_{\text {mass }}=\sum_{i=1}^{n}\left[\frac{\left(H C_{e}\right)_{i}}{10^{6}} * V_{(\text {mix })} * \text { Density }_{H C} * \Delta t\right]-\frac{H C_{d}}{10^{6}}\left(1-\frac{1}{D F}\right) * V_{\text {mix }} * \text { Density }_{H C} \text { Equation 4.13 }
$$


Where:

$\mathrm{HC}_{\text {mass }}=$ Hydrocarbon emissions, in grams per test phase.

$\left(\mathrm{HC}_{\mathrm{e}}\right)_{\mathrm{i}}=$ Instantaneous hydrocarbon concentration.

$\mathrm{HC}_{\mathrm{d}}=$ Hydrocarbon concentration of the dilution air as measured, in ppm carbon equivalent.

Density $_{\mathrm{HC}}=$ Density of hydrocarbons, in $\mathrm{g} / \mathrm{ft}^{3}$.

For natural gas-fueled engine, $\mathrm{HC}_{\mathrm{e}}$ was the HFID measurement. The equation for calculating the mass of oxides of nitrogen was

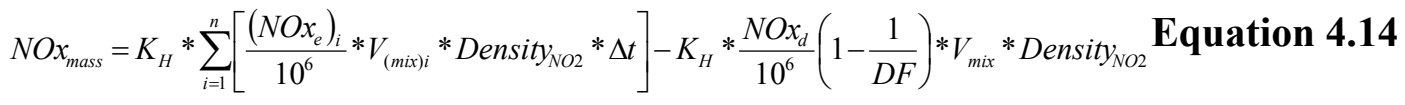

Where:

$\mathrm{NOx}_{\text {mass }}=$ Oxides of nitrogen emissions, in grams per test phase.

$\mathrm{K}_{\mathrm{H}}=$ Humidity correction factor.

Density $_{\mathrm{NO} 2}=$ Density of oxides of nitrogen assuming that they are in the form of nitrogen dioxide.

The humidity correction factor $\left(\mathrm{K}_{\mathrm{H}}\right)$ used in the calculation of oxides of nitrogen mass was used to correct for water vapor, and was calculated using the following equation.

$$
K_{H}=\frac{1}{[1-0.0026(H-75)]} \text { Equation 4.15 }
$$

Where:

$\mathrm{H}=$ Absolute humidity of the engine intake air in grains (grams) of water per pound (kilogram) of dry air.

The absolute humidity $(\mathrm{H})$ of the engine intake air was calculated using the following equation.

$$
H=\frac{\left[43.478 R_{i}^{*} P_{d}\right]}{\left[P_{B}-\left(P_{d} * \frac{R_{i}}{100}\right)\right]} \text { Equation 4.16 }
$$

Where: 
$\mathrm{R}_{\mathrm{i}}=$ Relative humidity of the engine intake air, percent.

$\mathrm{P}_{\mathrm{d}}=$ Saturated vapor pressure, in $\mathrm{mm} \mathrm{Hg}(\mathrm{kPa})$ at the engine intake air, dry bulb temperature.

$\mathrm{P}_{\mathrm{B}}=$ Barometric pressure, in $\mathrm{mm} \mathrm{Hg}(\mathrm{kPa})$.

To determine the mass of carbon monoxide during a test procedure, the following equation was used.

$$
C O_{\text {mass }}=\sum_{i=1}^{n}\left[\frac{\left(C O_{e}\right)_{i}}{10^{6}} * V_{(m i x) i} * \text { Density }_{C O} * \Delta t\right]-\frac{C O_{d}}{10^{6}}\left(1-\frac{1}{D F}\right) * V_{\text {mix }} * \text { Density }_{C O} \quad \text { Equation 4.17 }
$$

Where:

$\mathrm{CO}_{\text {mass }}=$ Mass of carbon monoxide, in grams per test phase.

Density $_{\mathrm{co}}=$ Density of carbon monoxide, $32.97 \mathrm{~g} / \mathrm{ft}^{3}\left(1.164 \mathrm{~kg} / \mathrm{m}^{3}\right)$.

The last equation used in the determination of the regulated emissions masses was for carbon dioxide.

$$
C O 2_{\text {mass }}=\sum_{i=1}^{n}\left[\frac{\left(C O 2_{e}\right)_{i}}{10^{6}} * V_{(m i x) i} * \text { Density }_{C O 2} * \Delta t\right]-\frac{C O 2_{d}}{10^{6}}\left(1-\frac{1}{D F}\right) * V_{\text {mix }} * \text { Density }_{C O 2} \text { Equation } 4.18
$$

Where:

$\mathrm{CO} 2_{\text {mass }}=$ Mass of carbon dioxide, in grams per test phase.

Density $_{\mathrm{CO} 2}=$ Density of carbon dioxide, $51.81 \mathrm{~g} / \mathrm{ft}^{3}\left(1.830 \mathrm{~kg} / \mathrm{m}^{3}\right)$.

The aforementioned equations were used in the WVU data reduction program to calculate the mass of regulated emissions in grams per test phase. After calculating the regulated emissions, unregulated emission levels were calculated. The equations for unregulated emissions are presented in the following section.

\subsubsection{Equations for Calculating Unregulated Emission Levels}

The equations for calculating the masses of unregulated emissions from the test vehicle were similar to the regulated emission equations set by the EPA in CFR 40. The equations used values obtained during chemical species extraction processes. 
Unregulated emissions were collected to determine the quantities of different chemical species emitted from vehicles. The equations for determining unregulated emissions will be discussed in the following sections.

To perform chemical speciation analysis, the total volumetric flow and the flow ratio were calculated. The total volumetric flow was the tunnel flow before exhaust samples are removed. The equation for the total volumetric flow was

$$
V_{\text {Tunnel }}=\left(\begin{array}{l}
V_{\text {fullflow }}+V_{\min i}+V_{P M 1}+V_{P M 2.5 G}+V_{P M 2.5 E} \\
+V_{P M 2.5 E C / O C}+V_{P M 10}+V_{T P M}+V_{P U F / X A D}
\end{array}\right) * t \text { Equation 4.19 }
$$

Where:

$$
\begin{aligned}
& \mathrm{V}_{\text {tunnel }}=\text { Total Tunnel Flow without samples removed } \\
& \mathrm{V}_{\text {full flow }}=\text { Full Flow Tunnel Flow (lpm) } \\
& \mathrm{V}_{\mathrm{mini}}=\text { Mini-dilution tunnel flow }(\mathrm{lpm}) \\
& \mathrm{V}_{\mathrm{pm} 1}=\text { PM1 gravimetric sample flow rate }(\mathrm{lpm}) \\
& \mathrm{V}_{\mathrm{pm} 2.5}=\mathrm{PM} 2.5 \text { gravimetric sample flow rate }(\mathrm{lpm}) \\
& \mathrm{V}_{\mathrm{pm} 2.5}=\mathrm{PM} 2.5 \text { Elemental sample flow rate }(\mathrm{lpm}) \\
& \mathrm{V}_{\mathrm{pm} 2.5}=\mathrm{PM} 2.5 \text { EC/OC sample flow rate }(\mathrm{lpm}) \\
& \mathrm{V}_{\mathrm{pm} 10}=\mathrm{PM} 10 \text { gravimetric sample flow rate }(\mathrm{lpm}) \\
& \mathrm{V}_{\mathrm{tpm}}=\mathrm{TPM} \text { sample flow rate }(\mathrm{lpm}) \\
& \mathrm{V}_{\mathrm{puf} / \mathrm{xad}}=\mathrm{PUF} / \mathrm{XAD} \text { sample flow rate }(\mathrm{lpm}) \\
& \mathrm{t}=\text { Test Time }
\end{aligned}
$$

The flow ratio was the total tunnel flow divided by the sample flow, where the sample flow was the flow of the respective sample being removed from the primary dilution tunnel. The equation for determining the flow ratio was

$$
V_{\text {ratio }}=\frac{V_{\text {Tunnel }}}{V_{\text {Sample }}} \text { Equation 4.20 }
$$

The aforementioned equations for total tunnel flow and the flow ratio were used in determining the chemical specie emission levels. All unregulated emissions, except gravimetric particulate matter, measurements were determined by scientists at Environment Canada. 


\subsubsection{Elemental Metals Equations}

Elemental metals were collected on Teflon filters using a PM2.5 cyclonic separator, and were analyzed using XRF spectrometry. XRF spectrometry was based on the measurement of fluorescent X-rays produced when an inner shell electron is ejected allowing a higher energy electron to drop into the lower energy orbital to fill the vacancy. The energy of the X-ray was characteristic of the emitting element and the area of the fluorescent peak was proportional to the number of atoms in the sample. The following equation used the concentration values obtained during spectrometry to calculate the level emitted on a grams per mile basis.

$$
X_{\text {emitted }}=V_{\text {ratio }} * \operatorname{Metal}_{\text {Conc. }} * A_{s} * \frac{1}{L} * 10^{-6} \text { Equation } 4.21
$$

Where:

$\mathrm{X}_{\mathrm{emitted}}=$ Level of a respective metal emitted during a test phase $(\mathrm{g} / \mathrm{mile})$.

Metal $_{\text {Conc. }}=$ Spectrometry Value for a respective metal $\left(\mu \mathrm{g} / \mathrm{cm}^{2}\right)$.

$\mathrm{A}_{\mathrm{S}}=$ Filter Stain Area $\left(\mathrm{cm}^{2}\right)$.

$\mathrm{L}=$ Distance traveled by the test vehicle during the test phase (miles).

This equation was used to determine the emission levels of metal species and quantified 47 elemental metals. Gravimetric calculations were also performed on the metals using the mass gained by the filter as the metal weight. The following equation was used to calculate a gravimetric mass for the metals.

$$
M_{\text {metals }}=V_{\text {ratio }} * \text { Filter }_{\text {mass }} * \frac{1}{L} * 10^{-6} \text { Equation } 4.22
$$

Where:

$\mathrm{M}_{\text {metals }}=$ Mass of metals accumulated during the test procedure $(\mathrm{g} / \mathrm{mile})$.

Filter $_{\text {mass }}=$ Mass difference of pre and post weight sample filter representative of the metal mass accumulated (grams).

The calculated values were not corrected for background emissions. 


\subsubsection{Elemental Carbon and Organic Carbon Equations}

Elemental and organic carbon (EC/OC) samples were collected on pre-fired quartz filters using a $\mathrm{PM}_{2.5}$ cyclonic separator, and were analyzed using a Thermal/Optical Transmittance (TOT) method. The TOT method took a $1.5 \mathrm{~cm}^{2}$ punch from a used filter media and heated the punch in two stages to release the carbon. In the first heating phase, the punch was heated in a pure helium atmosphere at set intervals up to $870^{\circ} \mathrm{C}$. This initial heating in pure helium evolves the volatile carbon. After the volatile carbon is evolved, the punch was cooled to $550^{\circ} \mathrm{C}$, and the atmosphere was changed to $10 \%$ oxygen in helium. The punch was then heated again to $910^{\circ} \mathrm{C}$, at which point carbon dioxide was converted to methane by catalytic reduction. The methane was then quantified using a flame ionization detector. Decreases in the transmittance of laser light during volatilization in a helium atmosphere occurred due to pyrolysis of organic material. Adding oxygen to the atmosphere increased the transmittance, as the light absorbing pyrolized carbon was combusted and removed. Organic carbon was defined as that which evolved prior to the re-attainment of the initial transmittance. Elemental carbon was that which evolved after the original transmittance has been attained. The following equation used the values obtained during the transmittance stages to calculate the mass emissions of elemental and organic carbon.

$$
E C / O C_{\text {mass }}=V_{\text {ratio }} * \text { Carbon }_{\text {conc }} * A_{s} * \frac{1}{L} * 10^{-6} \text { Equation 4.23 }
$$

Where:

$\mathrm{EC} / \mathrm{OC}_{\text {mass }}=\mathrm{EC}$ or $\mathrm{OC}$ Mass Emissions ( $\mathrm{g} / \mathrm{mile}$ ).

Carbon $_{\text {conc }}=\mathrm{EC}$ or OC Concentration from TOT Analysis $\left(\mu \mathrm{g} / \mathrm{cm}^{2}\right)$. 


\subsubsection{Semivolatile and Particle-bound Organic Speciation}

Semivolatile and particle-bound organic speciation included analyzing PUF/XAD and filter media for hopanes, steranes, polyaromatic hydrocarbons (PAH), and nitropolyaromatic hydrocarbons (n-PAH). The process for collecting these species, and the equations used to calculate the mass emissions will be discussed in this section.

During the test procedure, a PUF/XAD canister and 70mm filters were placed in series to collect semivolatile organic compounds and particle-bound organic compounds. After testing, the media cartridge was removed and taken into a dimly lit area and removed from their housing. The ends of the media cartridges were covered with foil and stored for analysis. Analysis of the species obtained during a test procedure was performed through extraction and column fractionation. Extraction involved placing the media in an extraction apparatus, spiking the media with $\mathrm{PAH}, \mathrm{n}-\mathrm{PAH}$, alkane, and biomarker surrogates, and allowing the media to sit for one hour while the solvent containing the surrogates evaporated. A 1-liter round-bottomed flask was charged with $750 \mathrm{~mL}$ of dichloromethane, connected to the extraction apparatus, and placed in a heating mantle. Extraction took 20 hours for completion, after which the solvent was allowed to cool, and was concentrated before column cleaning and fractionation.

A column of deactivated silica gel was prepared and transferred to a chromatography column packed with glass wool and topped with one gram of sodium sulfate. The sample was then loaded onto the column and fractionated. Vials were prepared for hopane, sterane, and PAH analysis. The vials were then concentrated and used to determine the levels of semivolatile and particle-bound species. The values obtained were used in the following equations to determine emission levels. 
To determine hopane and sterane levels, vials collected during column fractionation were analyzed using an HP $6890 \mathrm{GC}$. The levels obtained during the analysis were used to determine the hopanes and sterane levels emitted from the test vehicle via the following equation.

$$
X_{\text {emitted }}=V_{\text {ratio }} * X_{\text {mass }} * \frac{1}{L} * 10^{-6} \text { Equation 4.24 }
$$

Where:

$\mathrm{X}_{\text {emitted }}=$ Hopane or Sterane Level emitted from the test vehicle ( $\left.\mathrm{g} / \mathrm{mile}\right)$.

$\mathrm{X}_{\text {mass }}=$ Mass of Hopane or Sterane collected from column fractionation $(\mu \mathrm{g})$.

To determine polyaromatic and nitro-polyaromatic hydrocarbon emissions, a second fractionation vial was analyzed. This vial was split in half and one half was analyzed for $\mathrm{PAH}$, and the other for n-PAH. The PAH sample was analyzed using a low-resolution gas chromatograph and the n-PAH was analyzed using an HRGC/HRMS. The values obtained during the vial analysis were used in the following equation to determine the polyaromatic hydrocarbon and nitro-polyaromatic hydrocarbon emission levels.

$$
X_{\text {emitted }}=V_{\text {ratio }} * X_{\text {mass }} * \frac{1}{L} * 10^{-6} \quad \text { Equation } 4.25
$$

Where:

$\mathrm{X}_{\text {emitted }}=\mathrm{PAH}$ or n-PAH compound level emitted from test vehicle (g/mile).

$\mathrm{X}_{\text {mass }}=\mathrm{PAH}$ or $\mathrm{n}-\mathrm{PAH}$ compound mass collected from column fractionation $(\mu \mathrm{g})$.

\subsubsection{Methane and Non-Methane Hydrocarbon Analysis}

Methane and non-methane hydrocarbons were collected during the test procedure using a VOC sampling system and stainless steel VOC canisters. A sample canister under vacuum was filled to approximately 10 psig during the test procedure. After testing, the canisters were shipped back to Environment Canada's Environmental 
Research and Measurements Division. Approximately 165 non-methane hydrocarbons were determined using high-resolution gas chromatography with a flame ionization detector following cryogenic pre-concentration. Data was collected from the GC system, and sample concentrations were calculated. This method was known as the NMHC method.

Methane and $\mathrm{C}_{2}$ and $\mathrm{C}_{3}$ hydrocarbon concentrations were determined using an alternate method to the NMHC method known as LHC or light hydrocarbons. In this method, the sample loop was flushed with sample and the contents of the loop were injected directly into a capillary column. The sample was then analyzed by a gas chromatograph with a flame ionization detector. Data collected from the GC system was reduced and concentrations obtained.

Emission levels for methane and non-methane hydrocarbons were calculated using the concentrations determined during sample analysis. The following equation was used to determine the vehicle emissions for methane and non-methane hydrocarbons.

$$
X_{\text {emitted }}=V_{\text {ratio }} * X_{\text {conc }} * V_{\text {sample }} * \frac{1}{L} * 10^{-9} \quad \text { Equation } 4.26
$$

Where:

$\mathrm{X}_{\text {emitted }}=$ Methane or non-methane hydrocarbon level emitted from the test vehicle $(\mathrm{g} / \mathrm{mile})$.

$\mathrm{X}_{\text {conc }}=$ Methane or non-methane hydrocarbon concentration obtained during GC analysis $(\mathrm{ng} / \mathrm{L})$.

$\mathrm{V}_{\text {sample }}=$ Volume Sampled during analysis $(\mathrm{L})$.

The calculated values were the reported values of methane and non-methane hydrocarbons in grams per mile. For this testing procedure, only 1,3-butadiene, benzene, toluene, ethyl benzene, and xylene isomer values were calculated and compared to the on-site bag sample analysis. 


\subsubsection{1,3-butadiene and BTEX On-Site Analysis}

1,3-butadiene and BTEX samples were collected during the test procedure using a vacuum sampling system. Gas sample bags were used to collect the samples during the test procedure and were analyzed on-site for 1,3-butadiene and BTEX using a highresolution $\mathrm{GC}$ with a flame ionization detector following cryogenic pre-concentration. Data collected during the GC analysis was reduced and concentrations were obtained for the aforementioned compounds. The following equation was used to determine the 1,3butadiene and BTEX emission levels from the test vehicle.

$$
X_{\text {emitted }}=V_{\text {ratio }} * X_{\text {conc }} * V_{\text {sample }} * \frac{1}{L} * 10^{-9} \quad \text { Equation } 4.27
$$

Where:

$\mathrm{X}_{\text {emitted }}=1,3$-but. or BTEX level emitted from the test vehicle $(\mathrm{g} / \mathrm{mile})$.

$\mathrm{X}_{\text {conc }}=1,3$-but. or BTEX concentration obtained during $\mathrm{GC}$ analysis (ng/L).

$\mathrm{V}_{\text {sample }}=$ Volume Sampled during analysis (L).

The calculated values obtained for 1,3-butadiene and BTEX were the reported emission values in grams per mile.

\subsubsection{Gravimetric Analysis of Particulate Matter}

Particulate matter samples were obtained using size selective cyclonic separators and filter media. The media used during a test procedure was conditioned in accordance with the requirements set forth by CFR 40 and methods described in Chapter 3 of this report. Mass emission levels for $\mathrm{PM}_{1}, \mathrm{PM}_{2.5}$, and $\mathrm{PM}_{10}$ were calculated using the following equation.

$$
P_{\text {mass }}=\left(V_{\text {mix }}+V_{s f}\right) *\left[\frac{P_{f}}{V_{s f}}-\left(\frac{P_{b f}}{V_{b f}} *\left[1-\left(\frac{1}{D F}\right)\right]\right)\right] \text { Equation 4.28 }
$$

Where: 
$\mathrm{P}_{\text {mass }}=\mathrm{PM}$ mass emitted from the test vehicle (grams).

$\mathrm{V}_{\mathrm{sf}}=$ Total volume of sample remove from the primary dilution tunnel (scf).

$\mathrm{P}_{\mathrm{f}}=$ Mass of particulate on the sample filter (grams per test phase).

$\mathrm{P}_{\mathrm{bf}}=$ Net mass of particulate on the background filter (grams).

$\mathrm{V}_{\mathrm{bf}}=$ Total volume of sample removed from the primary dilution tunnel during the background test (scf).

$\mathrm{DF}=$ Dilution Factor.

The mass values obtained from the aforementioned equation for PM were used in the following equation to determine the reportable emission levels.

$$
P M_{\text {emitted }}=\frac{P_{\text {mass }}}{L} \text { Equation } 4.29
$$

Where $\mathrm{L}$ was the distance traveled during the test procedure. The values obtained were reported in grams per mile.

Values obtained during the data reduction and emission calculations process were analyzed and evaluated for validity. Close attention to detail and characteristics demonstrated by the emission levels were analyzed carefully. Chapter 5 discusses emission results obtained during this study and examines the effects of the aftertreatment devices implemented. 


\section{Results and Discussion}

Again, the global objective of this study was to develop an exhaust aftertreatment system to reduce gaseous and particulate matter emissions from natural gas fueled vehicles. Specific objectives of this study were to evaluate and characterize emissions from a natural gas fueled vehicle powered by a Cummins C8.3G+ engine with and without the particulate matter (PM) filter and oxidation catalyst (OC) combination, which was designed and developed by West Virginia University in collaboration with LubrizolECS. Central Business District (CBD) Cycle tests were performed on West Virginia University's transportable emissions testing laboratory. The results obtained in this study include baseline emissions from a Cummins $\mathrm{C} 8.3 \mathrm{G}+$ engine without the OEM catalyst, emissions with the OEM oxidation catalyst installed, and an exhaust aftertreatment system developed by WVU and Lubrizol-ECS, which was comprised of a particulate filter and an oxidation catalyst. Effects of background emission levels will be discussed to demonstrate a cause of variability that is inherent to the nature of the work.

Vehicle emission levels obtained during this study are reported in this chapter. Results for regulated and unregulated emissions are presented and discussed. Again, regulated emissions include carbon monoxide, total hydrocarbons, oxides of nitrogen, and total particulate matter. Hydrocarbon results will be discussed in reference to methane and non-methane hydrocarbons. Unregulated emissions include carbonyls, polyaromatic hydrocarbons, nitro-polyaromatic hydrocarbons, and volatile organic compounds. In addition to the aforementioned chemical species analyzed, the particulate matter levels for $\mathrm{PM}_{1}, \mathrm{PM}_{2.5}$, and $\mathrm{PM}_{10}$ are also analyzed. Note that plotted results are 
the average of multiple equivalent runs over the same test cycle and vehicle configuration.

\subsection{Background Emission Levels}

As mentioned earlier, dilution systems with extensive tunnel history can adsorb and release chemical constituents into the dilute exhaust sample stream during the test procedure. Lev-On et al. (2002) determined that high background levels could compromise speciation results from ULEV exhaust samples. Tunnel background samples were taken during both rounds of testing. To demonstrate the potential effects of background levels on emission calculations, several emission plots are shown that include background levels. Again, tunnel background values were taken for regulated and unregulated emission levels, but due to the complexity of the study ambient air background samples were taken for regulated emissions only.

Figure 5.1 demonstrates background levels for XRF metals sampled during Round 1. As can be seen from Figure 5.1, background levels were not present for all elements analyzed, but sulfur, for example, was prevalent in the background levels obtained, thus indicating a possible problem when computing background corrected emission levels. 


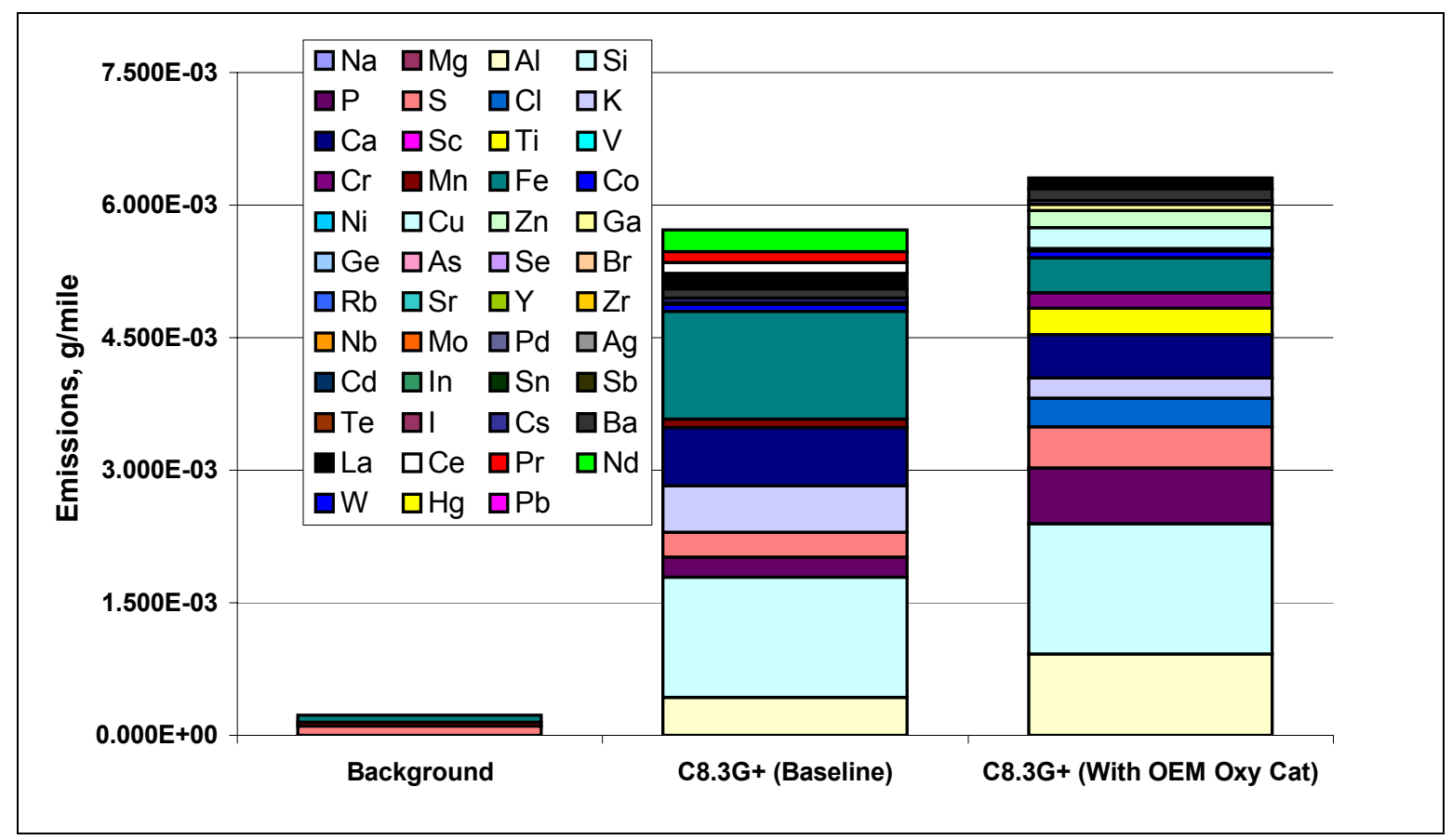

Figure 5.1 XRF Metal Background Levels from Round 1

Figure 5.2 demonstrates background values for 1,3-butadiene and BTEX emissions compared to dilute emissions taken during the test procedure. Note that the baseline and OEM catalyst test values presented in Figure 5.2 were not background corrected. It is apparent that many of the background values obtained are higher than the baseline and OEM exhaust configurations. Typically one could say this is a result of tunnel history, but the tunnel implemented was a dedicated "clean" primary dilution tunnel, which theoretically should eliminate tunnel background levels. It is a possibility that the high background levels could be from the ambient air being used for dilution purposes, but ambient samples were not analyzed for the unregulated compounds being analyzed. 


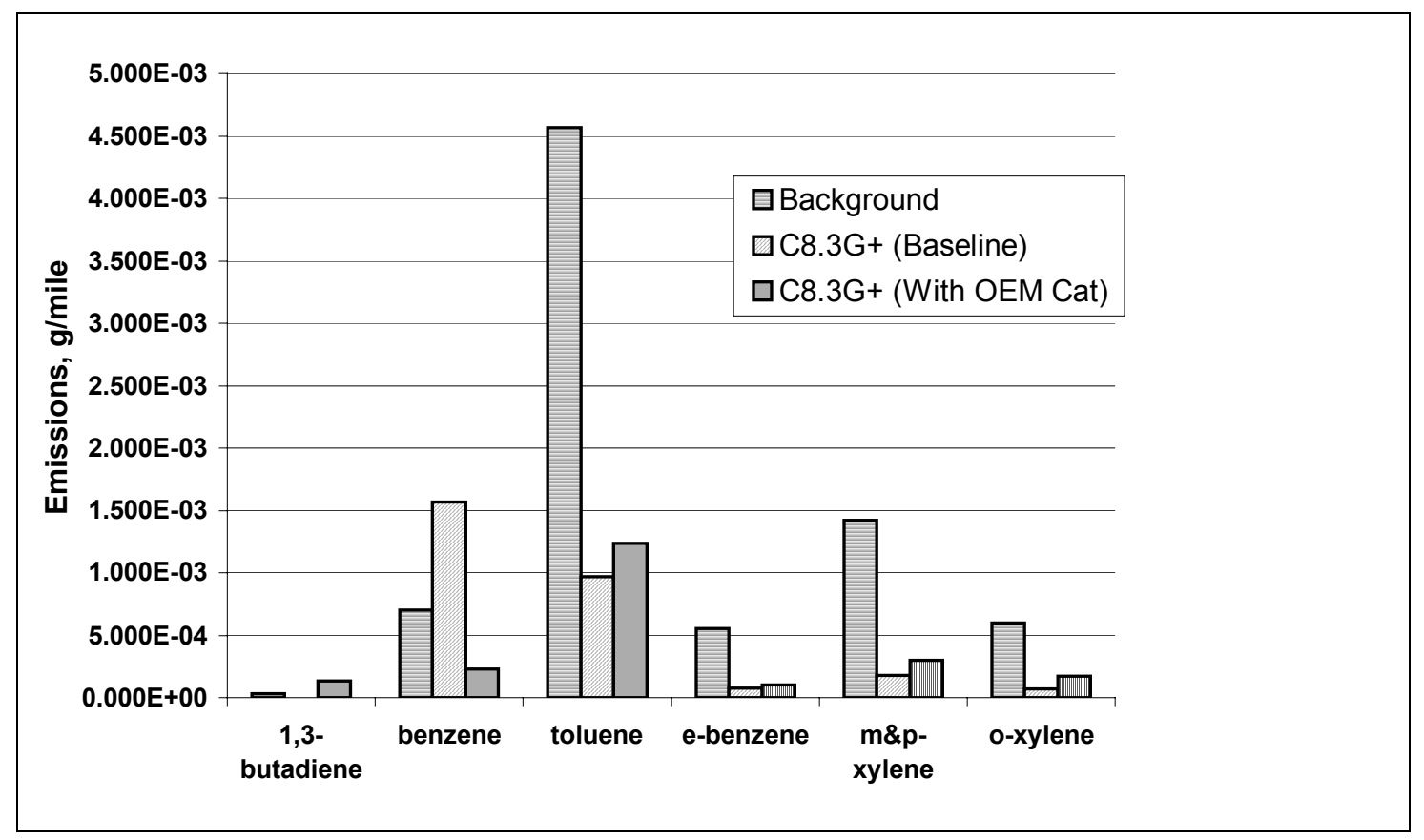

Figure 5.2 1,3-butadiene and BTEX Background Levels from Round 1

Background levels for particulate matter during Round 1 were below the values obtained during the actual test procedure, thus generating no problems when calculating background corrected emission levels for PM. But, when the WVU-Lubrizol aftertreatment system was installed during Round 2, PM levels obtained due to the exceptional performance of the aftertreatment system indicated that some of the background levels were higher than sample values. Figure 5.3 presents the filter mass background and test uncorrected filter mass values for Round 2. Filter masses indicate that background levels were typically higher than the actual emitted values. 


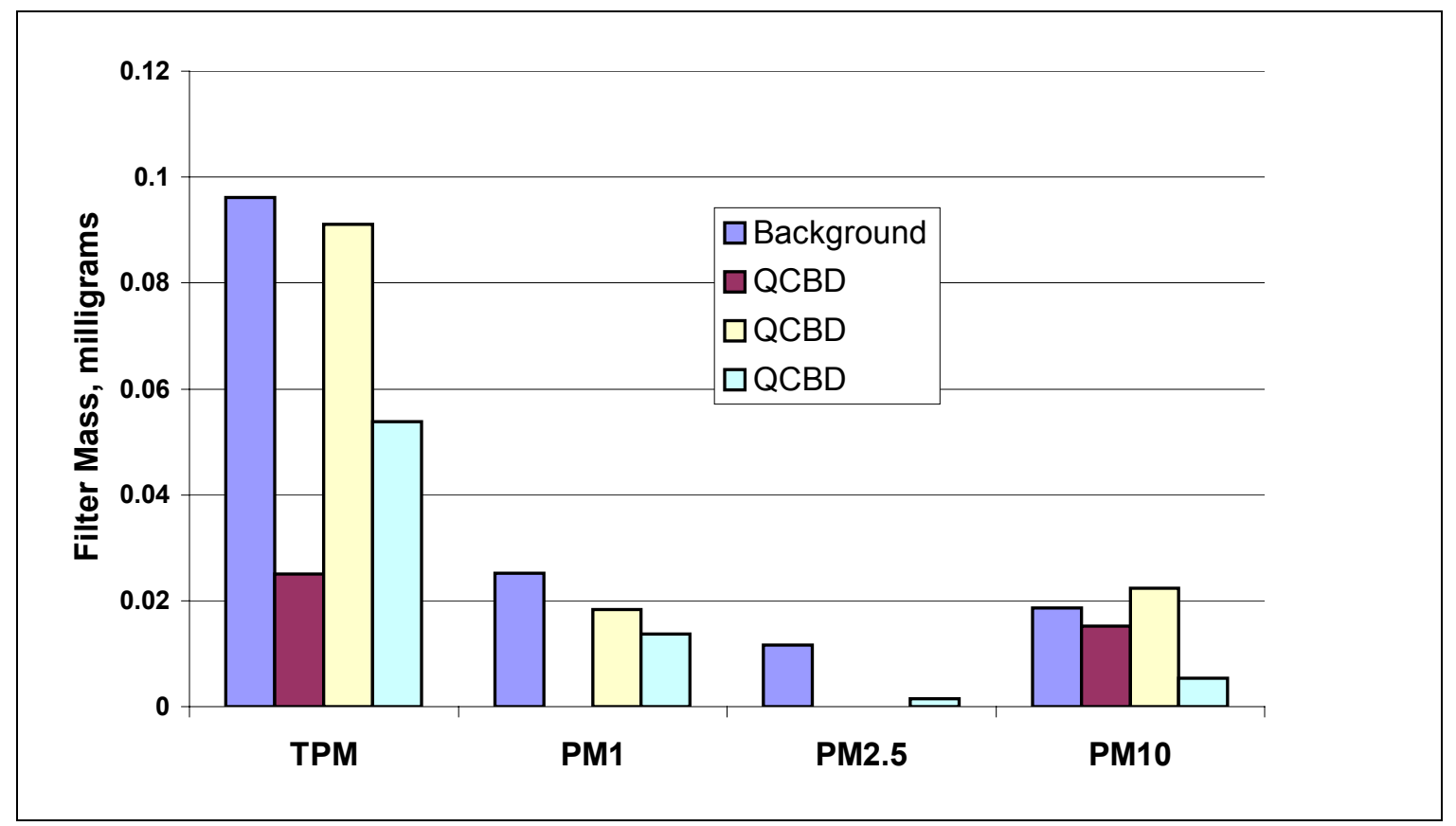

Figure 5.3 Background and Test Uncorrected Gravimetric Filter Mass Values

It is apparent that background levels are still a problem for PM and some of the chemical species analyzed, and that there may be no immediate method for alleviating these background constituents when testing ULEV's. Background values for other chemical species are presented in Appendix E, and interpretation of these values is left to the reader. Unregulated emissions presented, excluding gravimetric PM, have not been corrected for background tunnel emissions.

\subsection{Round 1: Vehicle Emission Levels}

The vehicle tested during this study was an Orion 40-foot high-floor transit bus equipped with a Cummins-Westport C-Series, 8.3 Liter Gas Plus (C8.3G+) engine. Regulated and unregulated emissions calculations were performed using the equations discussed in Chapter 4. Baseline emission levels were taken to quantify the true emission levels of the vehicle without any type of aftertreatment device. The baseline levels obtained were used as the actual emission levels when performing statistical calculations 
to determine the reduction of emissions due to aftertreatment devices. Emission levels of the vehicle with an OEM catalyst installed were also analyzed and are presented here.

\subsubsection{Round 1: Regulated Emissions}

All regulated emission levels were background corrected. Figure 5.1 shows the levels obtained for carbon monoxide, oxides of nitrogen, hydrocarbons, and total particulate matter. The baseline values were used as the actual emission levels of the vehicle without aftertreatment, and were used to evaluate the reduction of emissions due to the OEM Catalyst. Looking at the plot of regulated emission levels for Round 1, it can be seen that the OEM catalyst effectively reduced the regulated emission levels of the vehicle. A 97\% reduction in carbon monoxide can be noticed due to the OEM catalyst. This demonstrates the OEM catalysts effectiveness in converting the $\mathrm{CO}$ to $\mathrm{CO}_{2}$. Hydrocarbon levels were reduced by approximately $28 \%$ due to the OEM catalyst, while PM was reduced by nearly $62 \%$. $\mathrm{NO}_{\mathrm{x}}$ was reduced by $13 \%$, which raises some concern with the catalyst formulation for the reduction of oxides of nitrogen. After evaluating the results for the OEM catalyst, the author and other investigators determined that regulated emission levels for this vehicle could be reduced even further, with an emphasis on reducing hydrocarbons and oxides of nitrogen. It was determined that PM reduction would take place via a novel aftertreatment system that consisted of a catalyzed particulate filter installed before an oxidation catalyst. As a note to the reader, PM values in Figure 5.1 were multiplied by one hundred for visualization purposes. 


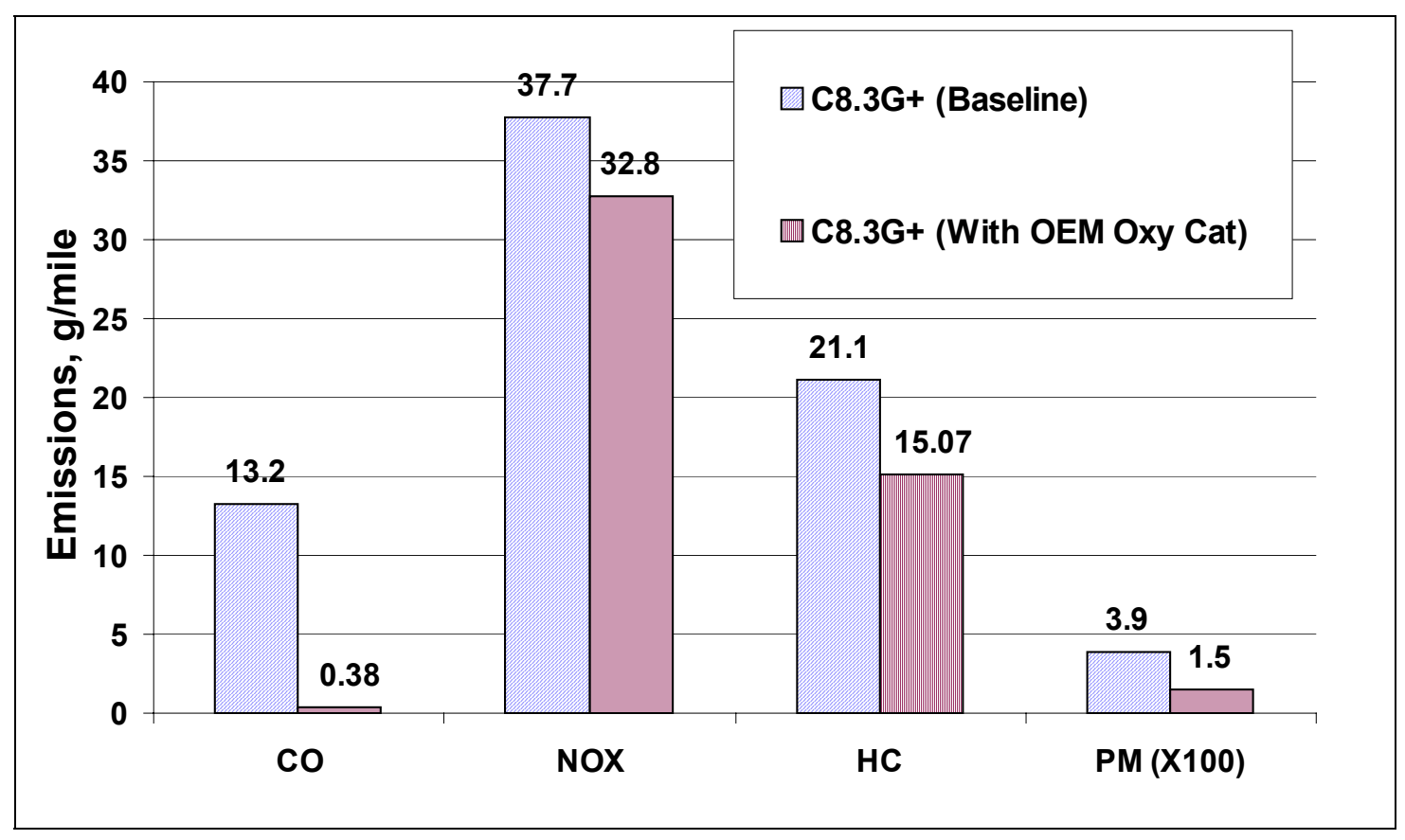

Figure 5.4 OEM Oxidation Catalyst Regulated Emission Reductions

Hydrocarbon values shown in Figure 5.4 include methane and nonmethane hydrocarbons. Due to the higher response factor of the FID to methane, methane and nonmethane values were obtained using gas chromatography (GC) analysis. The GC results were evaluated and it was determined that approximately $97 \%$ of the GC value was due to methane in the sample, leaving 3\% as NMHC. Figure 5.5 shows results for methane and $\mathrm{NMHC}$ using $\mathrm{GC}$ analysis. 




Figure 5.5 OEM Oxidation Catalyst HC Emission Reductions

Results from Round 1 show that the OEM catalyst did help reduce the regulated emissions, but reductions were statistically low compared to reductions seen in vehicles equipped with up-to-date aftertreatment systems. Now, unregulated results for Round 1 are presented and discussed.

\subsubsection{Round 1: Unregulated Emissions}

Unregulated emission samples were taken during this study and analyzed by Environment Canada. Exhaust products analyzed include: engine wear metals, lubrication oil contribution elements, hopanes, steranes, polycyclic aromatic hydrocarbons, nitro-polycyclic aromatic hydrocarbons, BTEX, 1,3-butadiene, carbonyls, and particulate matter. Baseline and OEM vehicle configurations will be presented in this section. The results presented for unregulated emissions are not background corrected for reasons mentioned earlier in this work. 
Lead, copper, and iron were engine wear metals analyzed during this study. Engine wear metals were analyzed as a means of determining how engine components are performing and their contribution to emission levels. High levels of wear metals present in the elemental analysis of particulate matter indicate an engine component malfunction. Wear metals can come from a variety of malfunctioning components including: valve stem seals, pistons, rings, cylinder walls, etc. Negative results of high levels of engine wear metals include poor gas mileage, high oil consumption, and decreased engine performance to name a few. Figure 5.6 shows engine wear metal emission levels for baseline and OEM vehicle configurations.



Figure 5.6 OEM Oxidation Catalyst Engine Wear Metal Emission Reductions

The results indicate that the OEM catalyst reduced iron levels by $68 \%$. The reason for the appearance of copper in the sample when the OEM catalyst is installed is still unknown. The most plausible sources of copper were bearings and the oxidation catalyst 
housing. Uncertainty values are not shown in this section, but can be seen in the charts in Appendix F. Lead concentrations were not noticed during media analysis.

Lube oil contribution to emission levels was primarily due to crankcase blow-by in the engine cylinders during the combustion process, and at leakage points around the valve stem seals. This is primarily to avoid carbon deposits on the valves. Crankcase blow-by occurs when in cylinder pressures become too high for the piston rings to stop oil transfer into the combustion chamber. Reasons for blow-by are primarily due to engine component aging, failure, or improper design. The most common causes of blowby occur due to improper piston ring tolerances and cylinder wall wear. In older engines, crankcase blow-by was vented to the atmosphere, but EPA regulations have curtailed this procedure. A procedure commonly used today involves the re-circulating the blow-by back into the intake or exhaust manifold. Lubrication oil elements seen in the exhaust stream could potentially be attributed to the re-circulation strategies implemented. Also, when blow-by factors become excessive, oil is allowed to enter into the cylinder during the combustion process and burn with the fuel/air mixture. The burning of lube oil during the combustion process increases particulate and hydrocarbon emissions. Lube oil elements analyzed include zinc, phosphorus, sulfur, magnesium, calcium, and molybdenum. Oil Science Laboratory performed a lubrication oil analysis of the oil used in the test vehicle. A clean, baseline, oil sample and a used oil sample from the bus were analyzed. Results indicated very low wear metals constituents in the baseline sample, and only a slight increase in iron, tin, copper and lead was seen in the used sample. Additive groups were identified as zinc, phosphorus, calcium and minor boron, which 
were consistent with natural gas engine oil formulations. Figure 5.7 shows the lube oil contribution to baseline emissions, and the reduction due to the OEM catalyst.

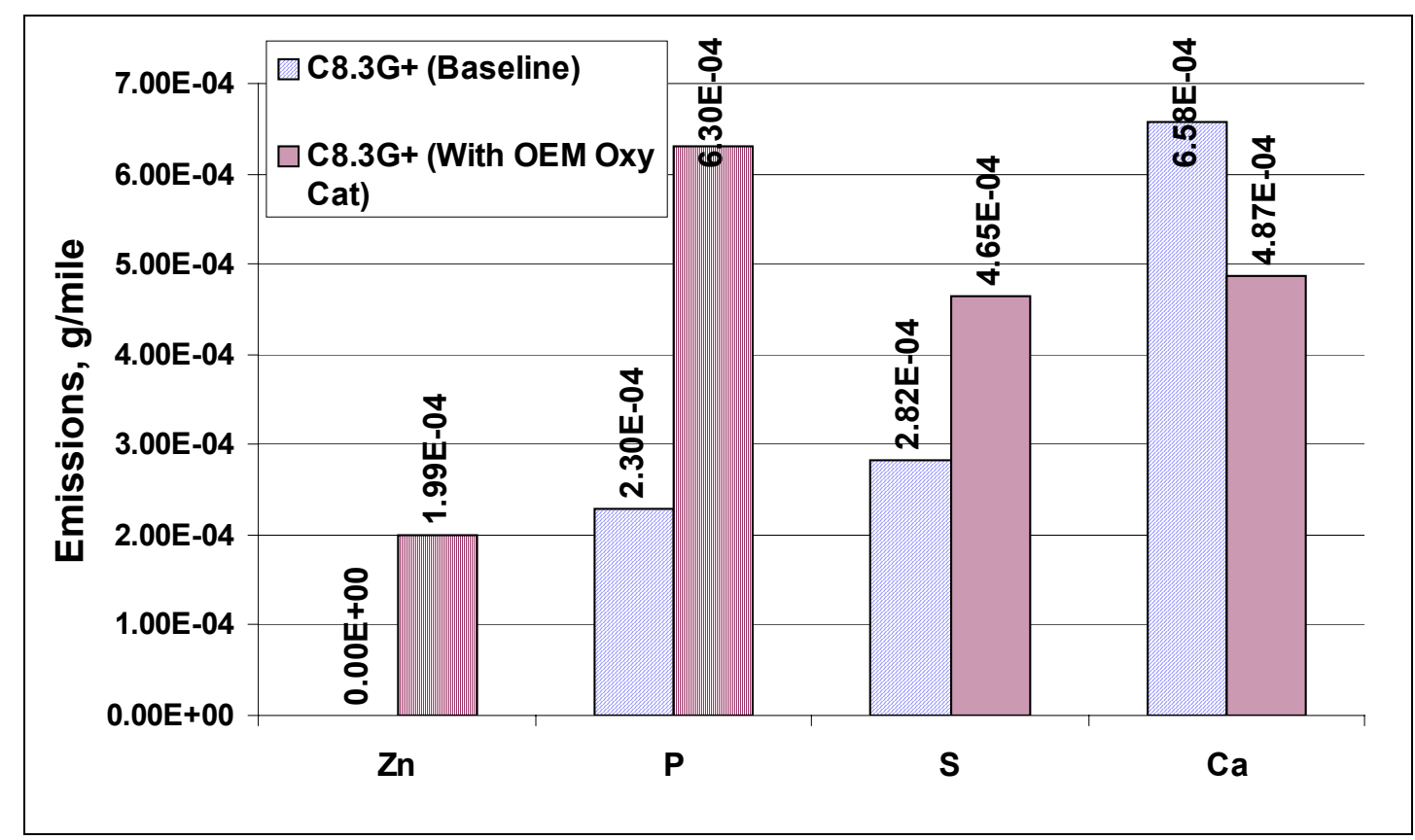

Figure 5.7 Lubrication Oil Emission Reductions Due to the OEM Catalyst

Analysis of oil consumption contribution to emission levels indicated that the OEM oxidation catalyst resulted in increased emission levels of zinc, phosphorus, and sulfur, which were identified as components of the lubrication oil additive package. The OEM catalyst installed on the vehicle during Round 1 of testing, was dismantled and analyzed after testing. Reports from Sunline Transit on Bus \#531 used during this study indicate that the OEM catalyst was the original diesel oxidation catalyst installed on the bus. Thus making the catalyst approximately 10 years old. Reports on the condition of the OEM catalyst indicate that the catalyst was crumbling inside of the catalyst housing. It is quite possible that the crumbling of the catalyst created clogging, which added to the engine backpressure, which would increase lubrication oil blow-by during the 
combustion process, and consequently increase lube oil elements in the engine exhaust. Causes of catalytic failure may include sintering due to high temperatures, sulfur and phosphorus poisoning, or old age.

Polycyclic and nitro-Polycyclic aromatic hydrocarbons are heavy hydrocarbons that at high levels are considered toxic. Determination of PAH and n-PAH levels in vehicle emissions is useful in determining their contribution to these levels in the atmosphere.

PAH levels are presented in Figure 5.8, and nitro-PAH levels are presented in Figure 5.9.



Figure 5.8 PAH Reduction Due to OEM Catalyst 


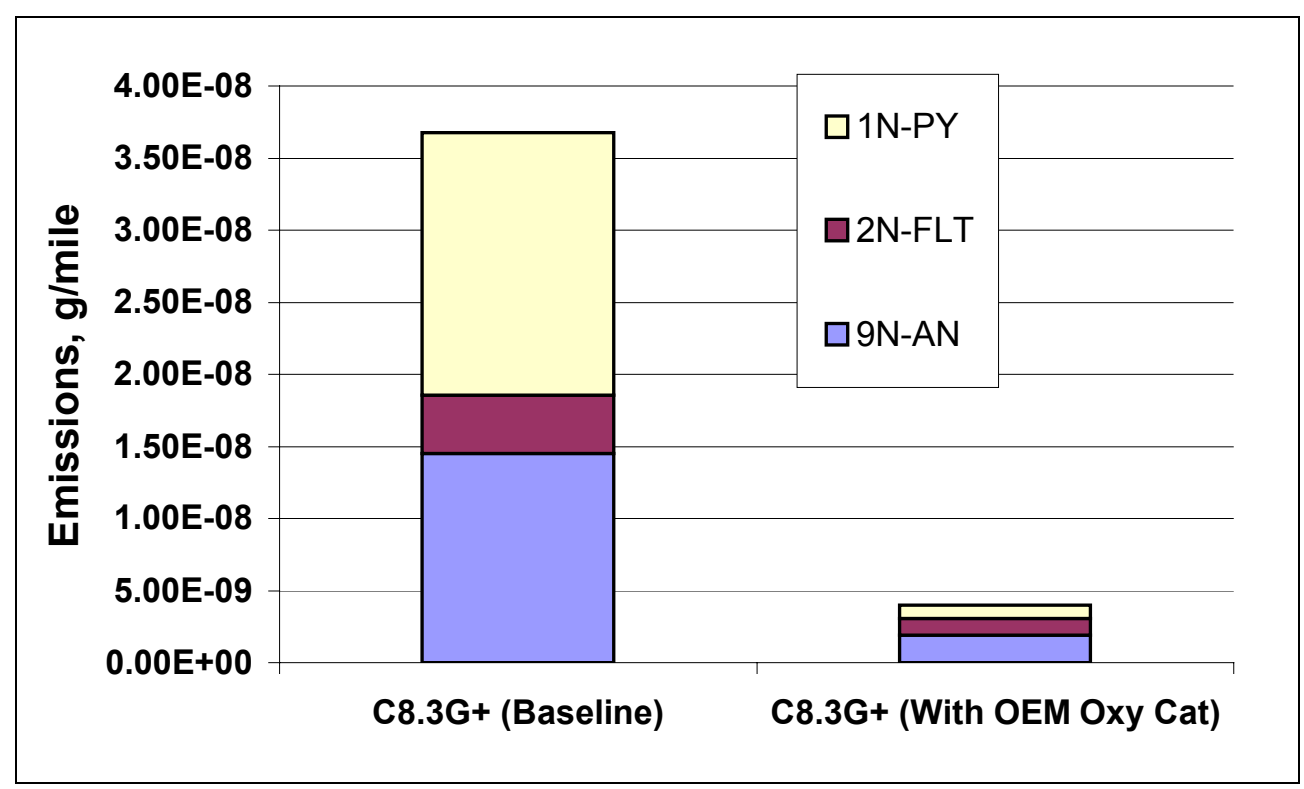

Figure 5.9 Nitro-PAH Reductions Due to OEM Catalyst

Thirty-two different organic species of PAHs were found during analysis. Of the 32 species, 15 were identified as contributors. Contributors were defined as those constituents whose levels were detectable during the analysis. The most abundant constituent was naphthalene, which constituted approximately $75 \%$ of the total $\mathrm{PAH}$, and was reduced by approximately $87 \%$ when the OEM catalyst was installed in the exhaust system. Table 5.1 lists the fifteen PAH contributors.

Table 5.1 15 PAH Contributors Collected During Round 1

\begin{tabular}{|c|c|}
\hline PAH & Symbol \\
\hline Naphthalene & NAP \\
\hline Acenaphthylene & $\mathrm{AL}$ \\
\hline Acenaphthene & $\mathrm{AE}$ \\
\hline Fluorene & $\mathrm{FL}$ \\
\hline 2-Me-Fluorene & $\mathrm{MFL}$ \\
\hline Phenanthrene & $\mathrm{PHE}$ \\
\hline Anthracene & $\mathrm{AN}$ \\
\hline Fluoranthene & $\mathrm{FLT}$ \\
\hline Pyrene & $\mathrm{PY}$ \\
\hline Retene & $\mathrm{RET}$ \\
\hline 1-Me-Pyrene & $\mathrm{MPY}$ \\
\hline Benzo(g,h,i)Fluoranthene & $\mathrm{B}(\mathrm{ghi}) \mathrm{F}$ \\
\hline Benzo(a)Anthracene & $\mathrm{B}(\mathrm{a}) \mathrm{A}$ \\
\hline Triphenylene & Tri \\
\hline Chrysene & Chrysene \\
\hline
\end{tabular}


Twenty-four different organic species of nitro-PAH were found during analysis. Of the twenty-four species, only 9-nitroanthracene (9N-AN), 2-nitrofluoranthene(2N-FLT), and 1-nitropyrene (1N-PY) were sampled at levels above identification limits. 1nitropyrene makes up approximately $50 \%$ of the total n-PAH, with 9-nitroanthracene contributing $40 \%$ and 2-nitrofluoranthene making up $10 \%$ of the total. With the OEM catalyst installed, $9 \mathrm{~N}-\mathrm{AN}$ and $1 \mathrm{~N}-\mathrm{PY}$ were reduced by $87 \%$ and $97 \%$ respectively. Again, determining aromatic hydrocarbon emissions helps in evaluating a vehicles contribution to atmospheric levels.

On-site gas chromatograph analysis of gaseous sample bags was performed to identify 1,3-butadiene and BTEX emission levels. BTEX includes: benzene, toluene, ethyl benzene, m\&p-xylene, and o-xylene. These organic species were all forms of volatile organic compounds which are toxic in high doses, and were typically found in all combustion fuels. Figure 5.10 shows BTEX reductions due to the OEM catalyst.

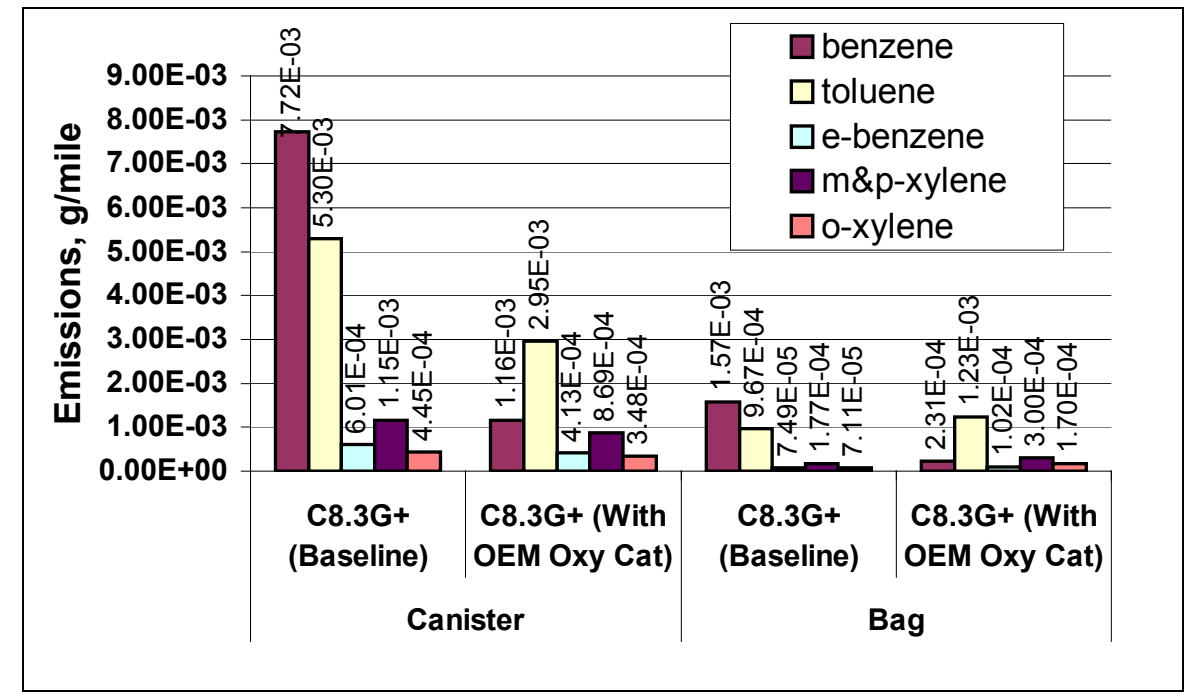

Figure 5.10 BTEX Reductions due to OEM Catalyst

Results for 1,3-butadiene and BTEX emissions were relatively inconclusive due to issues concerning the bags used during the collection process. Canister results indicated 
that all species were reduced when the OEM catalyst was installed, but bag results indicated that toluene, ethyl benzene, m\&p-xylene, and o-xylene increase after installation of the OEM catalyst. In nature these species are susceptible to degradation in sunlight, and they do not have a very long sample life, thus indicating the need for on-site analysis. Also, these species should have degraded in the canister by the time the canister was analyzed, thus making the values lower than the bag values, but that is not the case. To analyze problems with the bags used during this analysis, a sample bag (BAG 1) was filled with a known concentration of gas and analyzed using a gas chromatograph similar to the one used in the field. The reader should note that BAG 1 was of the same material and was made by the same manufacturer as the bags used during testing. Results indicated a $20 \%$ to $30 \%$ loss of chemical species in BAG 1 . To check these findings, a sample bag manufactured by a different company, but the same material, (BAG 2) was filled with the same known concentration of gas. The results for the second bag indicated that less than $0.5 \%$ of the chemical species were lost. Several test runs were performed using BAG 1 and BAG 2 with results indicating that with time, the percentage of chemical species lost to BAG 1 was reduced. This indicated that some type of chemical absorption into the bag material was taking place in BAG 1, and not in BAG 2. Over time BAG 1 came to an equilibrium state and adsorbed smaller percentages of chemical species, verifying that adsorption was taking place in BAG 1. For Round 2 testing, bags similar to BAG 2 were used for sample collection.

2,4-dinitrophenylhydrazone (DNPH) cartridges were used during Round 1 to collect aldehyde samples. The cartridges were analyzed for formaldehyde, acetaldehyde, acrolein, acetone, and propionaldehyde. Aldehydes were of concern due to their adverse 
effects on human health. Again, in this study aldehydes were sampled to quantify levels emitted from a specific type of vehicle. Figure 5.11 shows the results obtained for aldehydes during Round 1 and the reduction due to the OEM catalyst.

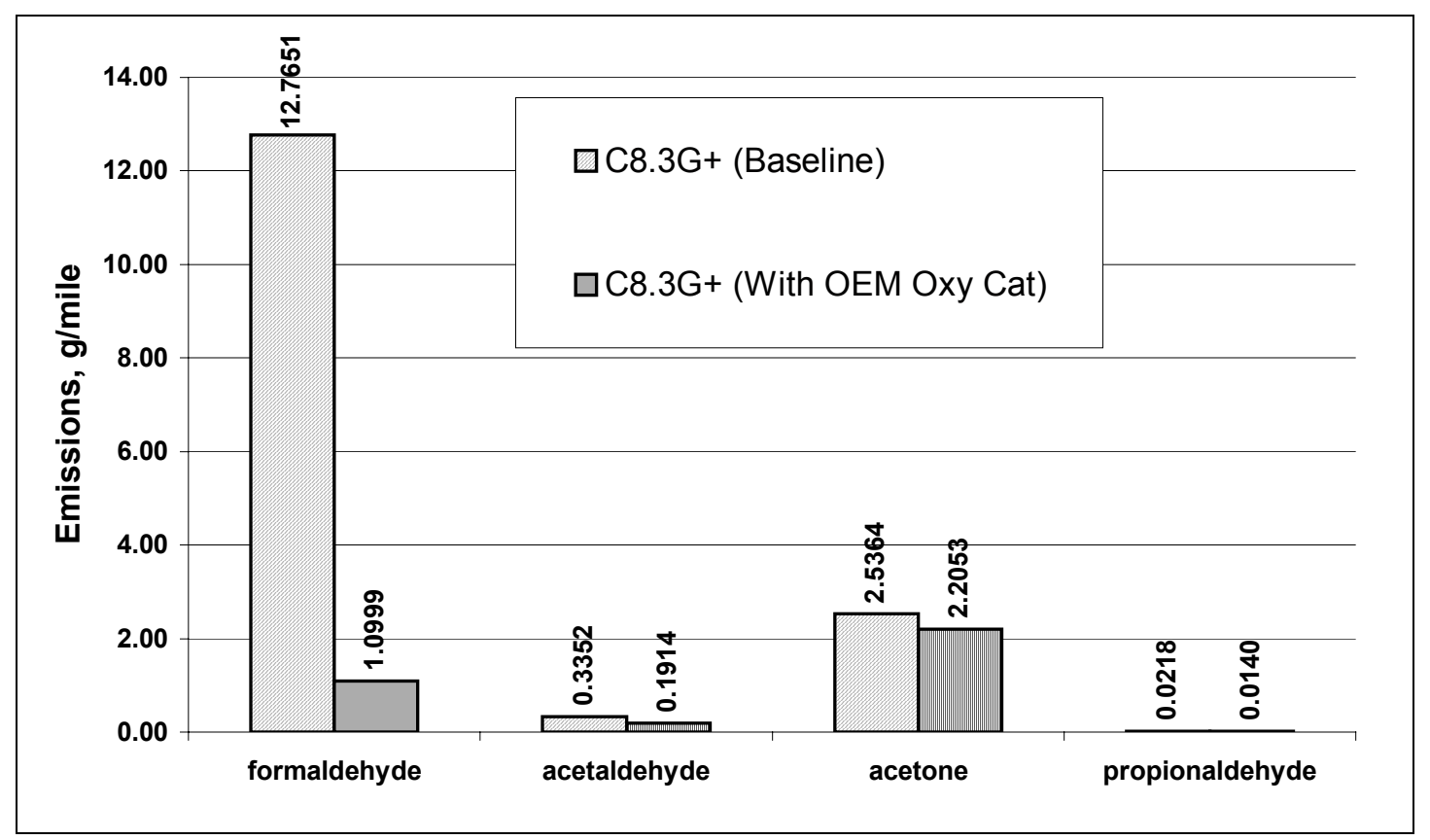

Figure 5.11 Aldehyde Reductions Due to the OEM Catalyst

As can be seen from Figure 5.11, when the OEM catalyst was installed aldehyde levels were lowered significantly. Reductions from baseline emission levels for formaldehyde, acetaldehyde, acetone, and propionaldehyde were $91 \%, 43 \%, 13 \%$, and $36 \%$ respectively. During the analysis, acrolein was not detected in the sample.

Reductions indicated that the OEM catalyst has some positive effect on reducing aldehyde levels.

Particulate matter samples were taken for gravimetric analysis of size specific particulate matter. $\mathrm{PM}_{1}, \mathrm{PM}_{2.5}, \mathrm{PM}_{10}$, and TPM samples were weighed and evaluated during Round 1 analysis using a microbalance. Figure 5.12 shows particulate matter levels obtained and reductions due to the OEM catalyst. 


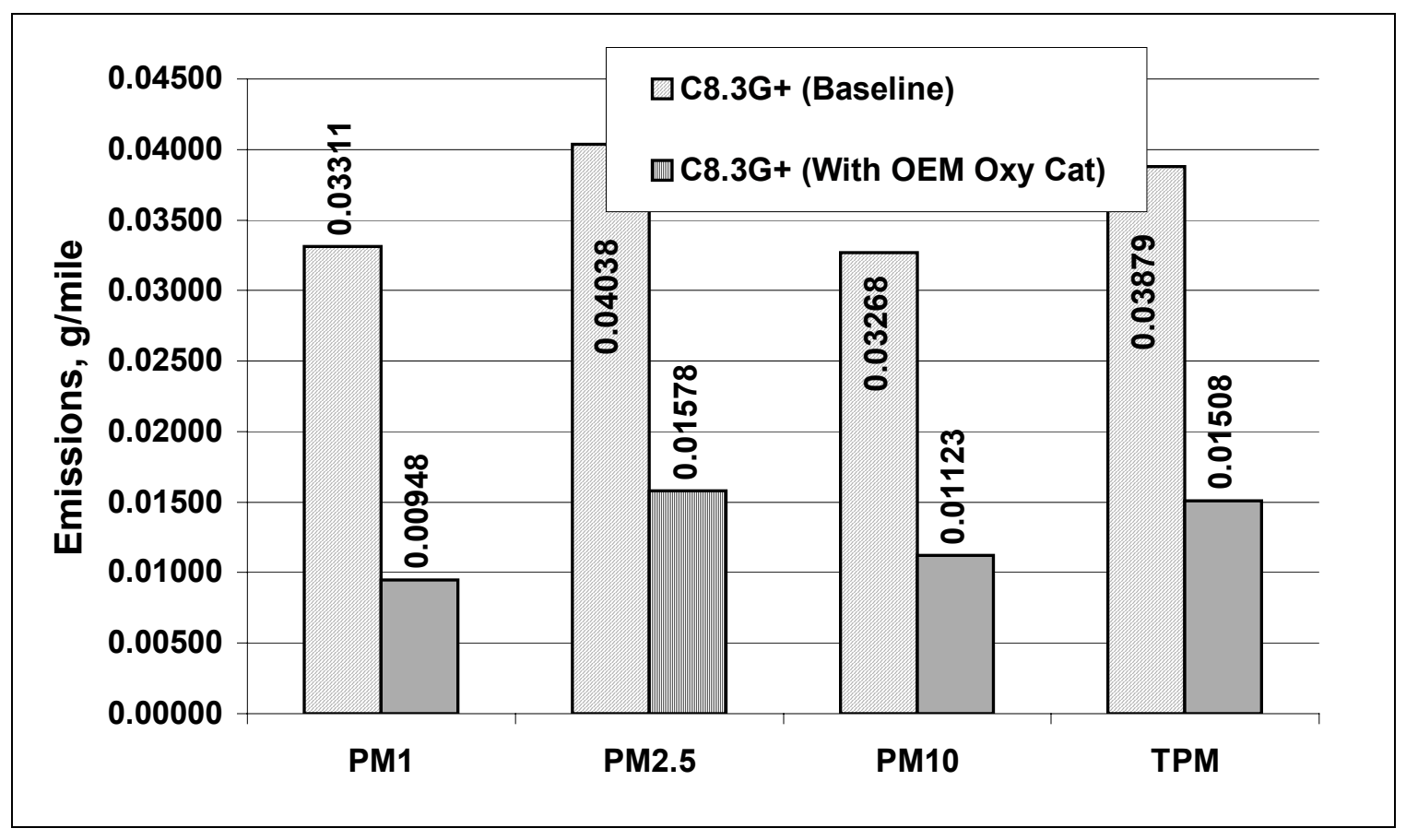

Figure 5.12 PM Reductions Due to the OEM Catalyst

Particulate matter levels obtained during Round 1 were reduced when the OEM catalyst was installed. The reductions were approximately $60 \%$ to $70 \%$, with an average reduction of around $65 \%$. Particulate matter emitted from natural gas vehicles is of great concern due to the much smaller size distribution of $\mathrm{CNG}$ fueled vehicles. Although CNG fueled buses emit much lower mass levels of particulate matter, they also emit much smaller particulate sizes such as nanoparticles. Nanoparticles are of particular concern due to their ability to enter the lower branches of the lungs and cause respiratory problems. Particulate matter sizing using an SMPS was performed during this study, but was not detailed as a primary objective for this study. Therefore, the details of particulate sizing are not discussed.

Looking at the regulated and unregulated results from Round 1, it can be said that the OEM catalyst is only minutely sufficient in reducing baseline emissions from the test 
vehicle. In order to further reduce the emission levels, an advanced aftertreatment system was developed via WVU and Lubrizol-ECS. The aftertreatment system consisted of a particulate trap and an oxidation catalyst. After installing this system, the vehicle was tested again and emission levels were analyzed. The results from Round 2 are discussed in the next section.

\subsection{Round 2: WVU-Lubrizol Aftertreatment System Emission Levels}

Results from Round 1 indicated a need for an advanced aftertreatment system to reduce toxic pollutants. West Virginia University and Lubrizol-ECS teamed up to develop an aftertreatment strategy consisting of a particulate trap and an oxidation catalyst based on emission levels obtained during Round 1. Lubrizol formulated the catalyst based upon speciation results from Round 1. The aftertreatment system is a novel aftertreatment system, in that, typically the oxidation catalyst has been installed before the particulate trap. But, WVU and Lubrizol-ECS have installed the trap before the catalyst. The primary reason for installing the trap before the catalyst was to reduce the amount of PM that was collected on the catalyst, which typically decreases the performance of the oxidation catalyst. The WVU-Lubrizol-ECS aftertreatment system and its effect on the emission levels of the test vehicle are discussed in this section.

\subsubsection{WVU-Lubrizol Aftertreatment System: Formulation and Protection}

Oxidation catalytic converters (OCC) and to some extent particulate traps, are commonly used to reduce the emission levels from gasoline and diesel fueled vehicles, and OCC's are becoming more common in CNG fueled vehicle exhaust systems. Using oxidation catalysts and traps in series enables greater reduction characteristics and a greater reduction efficiency of regulated and unregulated emissions. This section will 
discuss the formulation and protection of the WVU-Lubrizol-ECS designed exhaust aftertreatment system.

After collecting vehicle emission levels during Round 1, a catalyzed particulate trap and oxidation catalyst system was developed by WVU and Lubrizol-ECS. The aftertreatment configuration was designed so that the particulate trap would remove particulate matter in the exhaust stream before entering the oxidation catalyst. The removal of PM from the exhaust stream helps to prevent clogging of the oxidation catalyst and also aids in the temperature requirements of the oxidation catalyst. Higher temperatures are needed to effectively oxidize the $\mathrm{CO}$ and $\mathrm{HC}$ adsorbed onto the oxidation catalyst. The catalyzed particulate trap oxidizes the $\mathrm{CO}, \mathrm{HC}$, and heavy organics once the light-off temperatures are reached. Light off temperature is defined as the temperature at which the catalyst becomes more than 50\% effective (Heywood, 1988). The increase in catalytic activity with increasing temperatures makes the conversion efficiency of the oxidation catalyst increase.

The WVU-Lubrizol-ECS aftertreatment system was arranged so that the particulate trap was as close to the exhaust manifold of the engine as possible, so that temperatures of the exhaust stream were able to aid in the heating of the catalyst material on the trap and oxidation catalyst. The catalyzed particulate trap was a Diesel Particulate Filter (DPF) made of Silicon Carbide. The DPF was a segmented honeycomb structure with a 200 square CPI cell density with platinum (Pt) coated on a proprietary wash-coat for passive regeneration. Passive regeneration occurred over duty cycles that produce temperatures from 280 to $320^{\circ} \mathrm{C}\left(536\right.$ to $\left.608^{\circ} \mathrm{F}\right)$ for greater than $25 \%$ of the time. The oxidation catalyst was a Cordierite monolith with a cell density of 400-square CPI. The 
oxidation catalyst was primarily palladium $(\mathrm{Pd})$ coated on a proprietary wash-coat, but some platinum was also present. The dimensions in inches of the DPF and the oxidation catalyst were $11.25 \times 12$ and 10.5 x 6 (D x L) respectively.

In order to maintain a safe operating environment for the vehicle operator and passengers, engine and exhaust systems must have some sort of protection. Protective devices include: pressure sensors, oxygen sensors, and temperature sensors. These devices function in control loops to communicate with the engine control module (ECM) what is happening during operation. Changes in the exhaust backpressure affect the oxygen sensor output. The backpressure is measured and used via the ECM to compensate sensor output. Diagnostic systems within the ECM evaluate the exhaust backpressure. If a pressure threshold is reached for more than 1 second, a fault lamp will illuminate in the driver compartment warning the driver of a possible malfunction. During high backpressure situations, the ECM commands the engine to de-rate in order to decrease the backpressure. Engine operating temperature is typically evaluated through a closed-loop control strategy that evaluates the coolant temperature. When the coolant reaches a specified temperature, the engine de-rates to allow the engine to cool. If excess temperatures are reached, the engine de-rates severely. These performance enhancements are ideal for proper engine function, but a protective system for the exhaust aftertreatment system needs to be developed. The control system should be a temperature-based control system that monitors the catalytic device temperatures, with control being implemented at excessive temperatures. Extreme temperatures would occur in the event of combustion in one of the catalytic devices. The protection system should consist of a thermocouple and controller that is coupled to the ECM. In the event that a set-point temperature was 
exceeded, the engine would de-rate and the driver be alerted that there was a problem. WVU and Lubrizol-ECS, in conjunction with Cummins Westport Innovations (CWI), are taking steps to implement a temperature control system in the aftertreatment devices. The proposed system may incorporate a thermocouple located at the inlet of the exhaust aftertreatment device and a controller that provides a signal to the existing ECM. A setpoint value of $700^{\circ} \mathrm{C}\left(1292^{\circ} \mathrm{F}\right)$ is proposed as the temperature limit. Emission results obtained during Round 2 will now be presented.

\subsubsection{WVU-Lubrizol Aftertreatment System: Emission Reductions}

Round 2 of this study was performed with the WVU-Lubrizol-ECS aftertreatment system described above installed on the test vehicle. The same test vehicle used in Round 1 was used during Round 2. Regulated and unregulated emissions were sampled during this round, but due to problems with the subcontractor's GC only partial results were available for speciation analysis at the time of the creation of this work.

\subsubsection{Round 2: Regulated Emissions}

Regulated emission levels obtained during Round 2 are presented along with baseline emissions and OEM catalyst emissions in this section to demonstrate the reduction characteristics of the WVU-Lubrizol-ECS Aftertreatment System. The primary objective though is to look at the reduction to the baseline emission levels. Figure 5.13 on the following page shows the emission levels for $\mathrm{CO}, \mathrm{NO}_{\mathrm{x}}$, hydrocarbons, and $\mathrm{PM}$. The reader should again note that PM is multiplied by one hundred for visualization purposes. 


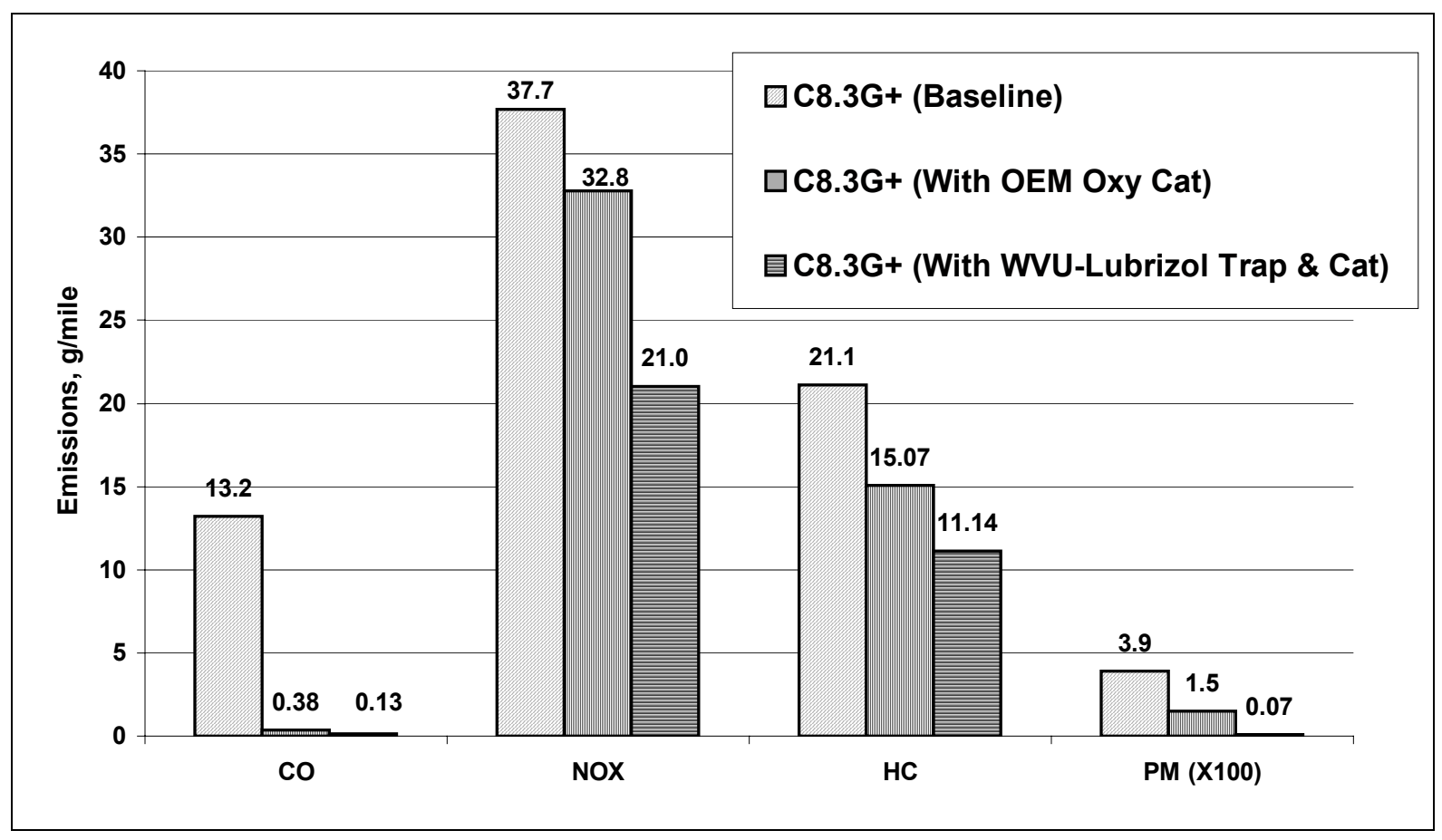

Figure 5.13 WVU-Lubrizol Aftertreatment Regulated Emission Reductions

Carbon monoxide samples analyzed from Round 2 have shown a 99\% reduction from baseline levels, and a $66 \%$ reduction from OEM catalyst levels when using the WVU-Lubrizol-ECS aftertreatment system. $\mathrm{NO}_{\mathrm{x}}$ reductions from baseline and OEM emission levels due to the WVU-Lubrizol system were $44 \%$ and $36 \%$ respectively. Hydrocarbon reductions due to the WVU-Lubrizol-ECS configuration were $46 \%$ from baseline and 25\% from OEM emission levels. Particulate matter levels were drastically reduced when the WVU-Lubrizol-ECS aftertreatment system is installed. PM reduction from baseline levels was $99.2 \%$, and from OEM levels was $95.3 \%$, indicating a dramatic decrease in the amount of Total PM emitted to the environment. 




Figure 5.14 WVU-Lubrizol Aftertreatment System HC Reductions

Methane and non-methane hydrocarbon levels seen in Figure 5.14 were determined using gas chromatography techniques. FIDHC values were the values obtained from the in-field analytical hydrocarbon analyzer. The FIDHC value was corrected for methane in the field using a methane correction factor obtained from the FID. Baseline emission reductions were $51 \%$ with the WVU-Lubrizol aftertreatment system installed. Nonmethane hydrocarbon levels increased by $111 \%$ when the WVU-Lubrizo-ECS system was installed. Causes for the increase in NMHC levels are still being investigated.

Particulate matter results obtained during Round 2 were evaluated and it has been determined that the WVU-Lubrizol aftertreatment system effective reduces the PM levels in the exhaust stream. Results indicate that $\mathrm{PM}_{1}$ and $\mathrm{PM}_{2.5}$ were below background levels, thus generating a null value, and a $92 \%$ reduction of $\mathrm{PM}_{10}$. Again, baseline TPM 
levels were reduced by $99.2 \%$. Figure 5.15 shows the reduction characteristic of all three vehicle-configurations.

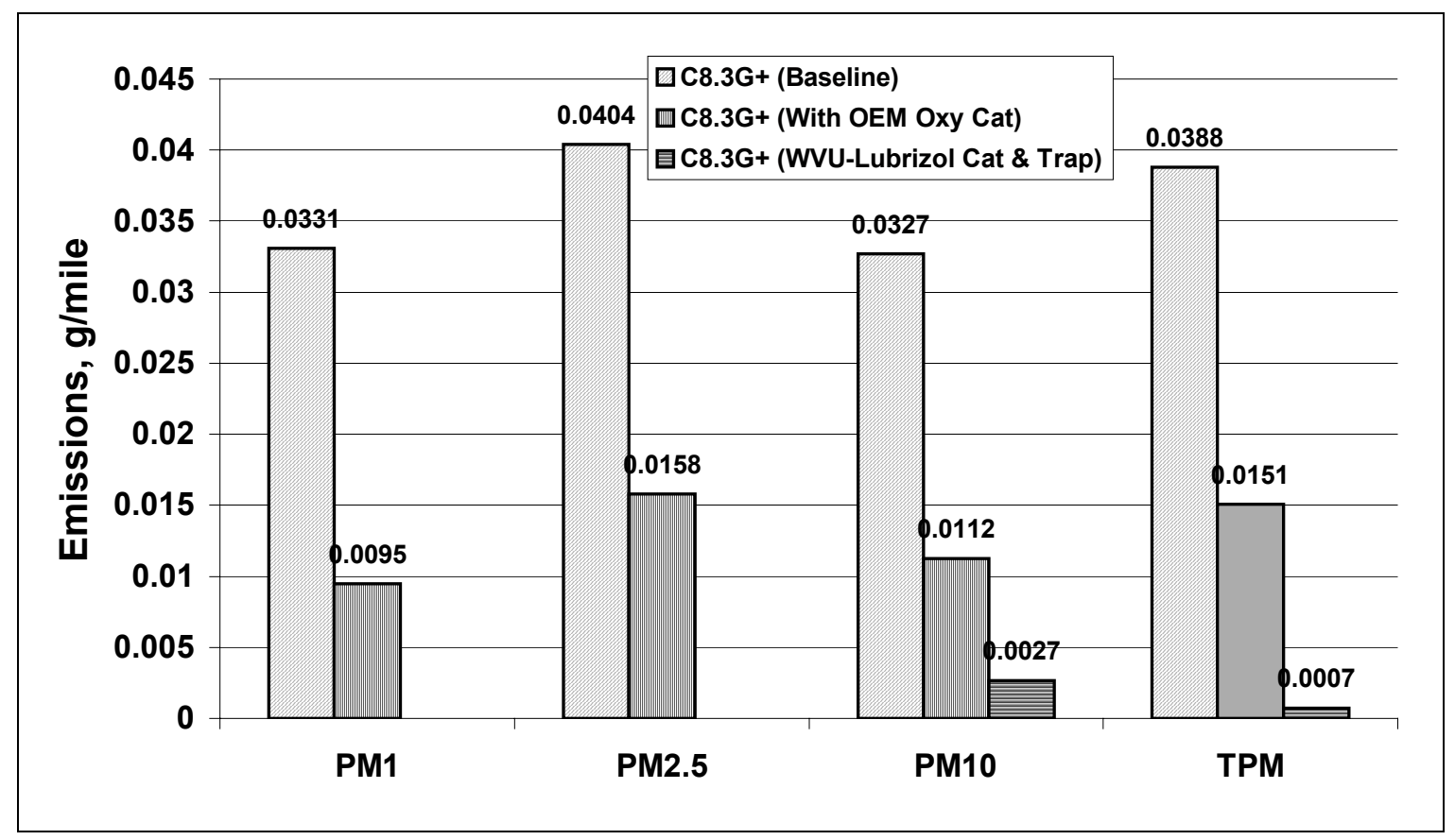

Figure 5.15 WVU-Lubrizol Aftertreatment System PM Reductions

Unregulated emission sample results for Round 2 of the study have not yet been analyzed. Therefore, it is with regret that these results will not be displayed in this text. The author feels that analysis of these results will demonstrate similar reduction characteristics to the OEM catalyst, but with a greater yield in reduction. 


\section{Conclusions and Recommendations}

\subsection{Conclusions}

A study was successfully performed to assist in the development of an exhaust aftertreatment system to reduce gaseous and particulate matter emissions from natural gas fueled vehicles. A dedicated "clean" primary dilution tunnel was designed and commissioned for testing ULEV's. A detailed speciation was performed on exhaust samples that were collected from a CNG fueled transit bus supplied by Sunline Transit Authority of California. The transit bus was tested using West Virginia University's transportable chassis dynamometer testing facility in Riverside, CA. Results of the exhaust analyses served as a basis for the design of a catalyzed exhaust aftertreatment system for the CNG fueled transit bus. The transient test cycle used was a Central Business District (CBD) Cycle modified to run four times back-to-back for sufficient sample collection over the test period. The modified CBD cycle was referred to as a Quad-CBD.

Regulated and unregulated emissions were sampled during this study and analyzed under three different vehicle configurations. The three configurations included: baseline (no aftertreatment), with an OEM catalyst installed, and with a novel aftertreatment system, developed by WVU and Lubrizol-ECS, installed. The emission levels collected during Round 1 and Round 2 of the study were analyzed and were reported in this work.

Comparison of the emission levels obtained using the three vehicle configurations demonstrated that the baseline emission levels were reduced via aftertreatment devices. OEM aftertreatment devices do assist in the reduction of emissions from the vehicle, but more advanced systems need to be implemented to further reduce toxic emissions from 
these vehicles. The novel use of a catalyzed particulate trap and an oxidation catalyst in series has proven to be an effective method for reducing particulate matter and gaseous emissions, without creating excessive strain on the engine. The use of the WVULubrizol-ECS aftertreatment system does not hinder nor alter the performance characteristics of the engine, making it a safe system according to vehicle performance.

The experimental data collected during this study proved that regulated emission levels were reduced using a catalyzed particulate filter and an oxidation catalyst. Total PM emissions were reduced from $.0388 \mathrm{~g} / \mathrm{mile}$ to $.0007 \mathrm{~g} /$ mile indicating a reduction of over $98 \%$ when the WVU-Lubrizol-ECS aftertreatment system was implemented. $\mathrm{NO}_{\mathrm{x}}$, on a mass basis, was lowered from $37.7 \mathrm{~g} / \mathrm{mile}$ to $21 \mathrm{~g} /$ mile using the WVU-Lubrizol system. CO was lowered from $13.2 \mathrm{~g} / \mathrm{mile}$ to $0.13 \mathrm{~g} /$ mile indicating a $99 \%$ reduction from baseline levels via the WVU-Lubrizol-ECS system, and THC was lowered from $21.9 \mathrm{~g} / \mathrm{mile}$ to $11.8 \mathrm{~g} / \mathrm{mile}$ indicating a $46 \%$ reduction from baseline levels.

Preliminary data from Round 2 shows promise that the novel aftertreatment system can reduce unregulated chemical species. A complete set of data from Round 2 of this study will be presented along with results from Round 3 in a future paper. This study has effectively demonstrated the ability to use a particulate trap and an oxidation catalyst in series to reduce emission levels from in-use $\mathrm{CNG}$ fueled vehicles.

\subsection{Recommendations}

Extensive research has been, is being, and will be performed on the emission characteristics of in-use vehicles. Additional research of the effects of aftertreatment device configurations on the emission levels natural gas engines needs to be performed to further evaluate lube oil contribution, wear metal elements, and other unregulated toxic 
emission levels and their reduction via aftertreatment devices. The reduction of many toxics can be performed through engine design modifications on items such as valve stem seals, piston ring configurations, cylinder linings, and many other components. It is possible to over evaluate and potentially implement negative effects on emission levels through improper design of engine components; thus, proper care should be taken to thoroughly evaluate new designs. Emphasis should be put on evaluating the effect of lubrication oils on particulate number counts in CNG fueled vehicles. Further studies need to be performed, that will evaluate the adsorption characteristics of chemical speciation bags. The chemical absorption characteristics seen during this study indicate a problem with some bag types. The absorption of these chemical species has the ability to induce great error when performing GC analysis. 


\section{Literature Cited}

Brookhaven National Laboratory: Environmental Restoration Division. Cleanupdate Newsletter. $<$ http://mfnl.xjtu.edu.cn/gov-doe-bnl/erd/cleanupd.html > Accessed: 09 Sept. 2003. Revised: 25 June 2001.

Byers, R.J. (1999). Measurement of Particulate Matter Size, Concentration and Mass Emissions from In-Use Heavy Duty Vehicles. M.S. Thesis, Department of Mechanical and Aerospace Engineering, West Virginia University, Morgantown, WV.

Carder, D.K. (1999). Performance Evaluations of Exhaust Aftertreatment Devices Used for Emissions Control on Diesel Engines Employed in Underground Coal Mines. M.S. Thesis, Department of Mechanical and Aerospace Engineering, West Virginia University, Morgantown, WV.

CASA Data Warehouse. Pollutants monitored.

<http://www.casadata.org/pollutants/index.asp> Accessed: 29 July 2003. Updated: October 8, 2002.

Cirillo, E.D. (2001). Development of a Micro-Dilution Tunnel System for In-Use, OnBoard Heavy Duty Vehicle Particulate Matter Emissions Measurement. M.S. Thesis, Department of Mechanical and Aerospace Engineering, West Virginia University, Morgantown, WV.

Clark, C.A., May, M.P., and Challen, B.J. (1984). Transient Testing of Diesel Engines. SAE 840348.

Clark, N., Boyce, J.E., Xie, W., Gautam, M. Lyons, D.W., Vertin, K., LeTavec, C.A., and Coburn, T.C. (2000). Class 8 Trucks Operating On Ultra-Low Sulfur Diesel with Particulate Filter Systems: Regulated Emissions. SAE 2000-01-2815.

Clark, N., Tehranian, A., Jarret, R., and Nine, R. (2002). Translation of DistanceSpecific Emissions Rates between Different Heavy Duty Vehicle Chassis Test Schedules. SAE 2002-01-1754.

Code of Federal Regulations. CFR 40 Parts 86 to 99, Washington, D.C., 2001.

Coordinating Research Council (2003). Heavy-Duty Vehicle Chassis Dynamometer Testing For Emissions Inventory, Air Quality Modeling, Source Appointment, and Air Toxics Emissions Inventory. Phase 1 Report: CRC Project No. E-55/E-59. April 1, 2003.

Croom, M.L. (1995) Filter Dust Collectors: Design and Application. McGraw-Hill, Inc. New York. 
Dietzmann, H.E. and Warner-Selph, M.A. (1985). Comparison of Emissions from Heavy-Duty Engines and Vehicles During Transient Operation. ASME Paper.

Eastwood, P. (2000). Critical Topics in Exhaust Gas Aftertreatment. Baldock: Research Studies Press LTD.

Emissions Standards: USA: Heavy-Duty Truck and Bus Engines.

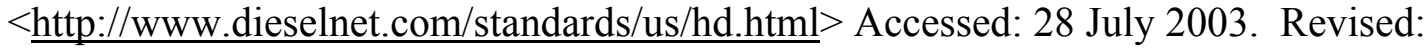
2001.

Emissions Test Cycles: Central Business District.

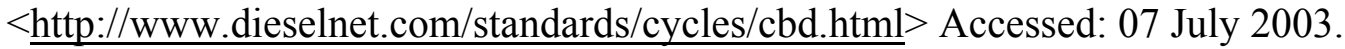

Environment Canada. Particulate Matter $\left(P M_{\leq 10}\right)$.

$<$ http://www.ec.gc.ca/air/p-matter_e.html $>$ Accessed: 30 July 30, 2003. Revised: 25

Nov. 2002

Ferguson, D. (1993). Design, Fabrication, and Testing of an Emissions Measurement System for a Transportable Heavy Duty Vehicle Emissions Testing Laboratory. M.S. Thesis, Department of Mechanical and Aerospace Engineering, West Virginia University, Morgantown, WV.

Gautam, M. (2002). Development and Demonstration of Aftertreatment Technologies for PM Emissions Control of CNG-Fueled Heavy-Duty Engines. Volume 1: Technical Proposal.

Gautam, M., Clark, N., Lyons, D., Long, Jr., T., Howell, A., Loth, J., Palmer, G., and Bata, R. (1991). Design Overview of a Heavy-Duty Mobile Vehicle Emissions Testing Laboratory. ASME DE-Vol.40, Advanced Automotive Technologies, 1991.

Gulati, S.T. (1992). Design Considerations for Diesel Flow-Through Converters. SAE 920145.

Gupta, D. (1996). Speciation of Heavy Duty Diesel Exhaust Emissions Under Transient and Steady State Operating Conditions. M.S. Thesis, Department of Mechanical and Aerospace Engineering, West Virginia University, Morgantown, WV.

Heck, R.M. and Furrauto, R.J. (1995). Catalytic Air Pollution Control: Commercial Technology. New York: International Thompson Publishing Inc.

Heywood, J.B. (1988). Internal Combustion Engine Fundamentals. McGraw-Hill, Inc. New York, 1988.

Harayama, N., Niimura, K., and Watanabe, Y. (1992). Effects of Sulfate Adsorption on Performance of Diesel Oxidation Catalysts. SAE 920852 
Horiuchi, M., Saito, K., and Ichihara, S. (1990). The Effects of Flow-through Type Oxidation Catalysts on the Particulate Reduction of 1990's Diesel Engines. SAE 900600.

Kittelson, D.B. and Johnson, J.H. (1991). Variability in Particle Emission Measurements in the Heavy Duty Transient Test. SAE 910738.

LeTavec, C., Uihlein, J., Vertin, K., Chatterjee, S., Hallstrom, K., Wayne, S., Clark, N., Gautam, M., Thompson, G., Lyons, D., Chandler, K., and Coburn, T. (2002). Year-Long Evaluation of Trucks and Buses Equipped with Passive Diesel Particulate Filters. SAE 2002-01-0433.

Lev-on, M., LeTavec, C., Uihlein, J., Alleman, T., Lawson, D., Vertin, K., Thompson, G., Gautam, M., Wayne, S., Zielinska, B., Sagebiel, J., Chatterjee, S., and Hallstrom, K. (2002). Chemical Speciation of Exhaust Emissions from Trucks and Buses Fueled on Ultra-Low Sulfur Diesel and CNG. SAE 2002-01-0432

Lev-on, M., LeTavec, C., Uihlein, J., Kimura, K., Alleman, T., Lawson, D., Vertin, K., Gautam, M., Thompson, G., Wayne, S., Clark, N., Okamoto, R., Rieger, P., Yee, G., Zielinska, B., Sagebiel, J., Chatterjee, S., and Hallstrom, K. (2002). Speciation of Organic Compounds from the Exhaust of Trucks and Buses: Effect of Fuel and Aftertreatment on Vehicle Emission Profiles. SAE 2002-01-2873

MacDonald, J.S., and Simon, G. M. (1988). Development of a Particulate Trap System for a Heavy-Duty Diesel Engine. SAE 880006.

Mayer, A., Evequoz, R., Wyser-Huesi, M., Czerwinski, J., Matter, U., and Graf, P. (2000). Particulate Traps Used in City-Buses in Switzerland. SAE 2000-01-1927.

Nagendran, V. (2003). Characterization of Exhaust Emissions from Catalyzed TrapEquipped Non-Road Heavy-Duty Diesel Engines. M.S. Thesis, Department of Mechanical and Aerospace Engineering, West Virginia University, Morgantown, WV.

Parker, D., O’Conner, S., Lemieux, S., and Nolan, K. (1999). CARB Evaporative Emissions Test Program. SAE 1999-01-3528.

Perez, J.M. and Williams, R.L. (1989). A Study of Particulate Extracts from 1980's Heavy Duty Diesel Engines Run on Steady-State and Transient Cycles. SAE 892491.

Rideout, G. (1991). Exhaust Emissions from Natural Gas and Diesel Powered Urban Transient Buses During Transient Operation. Final Report. Mobile Sources Emissions Division, Environment Canada, Ottawa, Canada.

Shade, B.C. (2000). A Performance Evaluation of the MEMS-An On-Road Emissions Measurement System Study. M.S. Thesis, Department of Mechanical and Aerospace Engineering, West Virginia University, Morgantown, WV. 
Smith II, R.C. (1993). Comparison of Heavy Duty Diesel Engine Transient Emissions Measurements Using a Mini- and a Full-Flow Dilution Tunnel. M.S. Thesis, Department of Mechanical and Aerospace Engineering, West Virginia University, Morgantown, WV.

Stump, F., Tejada, S., Black, F., Ray, W., Crews, W., and Davis, R. (1996). Compound Injection to Assure the Performance of Motor Vehicle Emissions Sampling Systems. SAE 961118.

URG. 2003 Parts Catalog:Inlets. $\quad<$ http://www.urgcorp.com/catalogs/urgcatalog.pdf $>$ Accessed:03 December 2003.

U.S.E.P.A. Benefits and Costs of the Clean Air Act, 1970 to 1990: Appendix D.

$<$ http://www.epa.gov:80/airprogm/oar/sect812/appen_d.pdf $>$ Accessed: 29 July 2003. Updated: 10 July 2003.

U.S.E.P.A. Clean Air Act. < http://www.epa.gov/air/oaq caa.html > Accessed: 28 July 2003. Revised: Nov. 2002.

U.S.E.P.A. Sources of Indoor Air Pollution-Organic Gases (Volatile Organic Compounds - VOCs). <http://www.epa.gov/iaq/voc.html > Accessed: 31 July 2003. Revised: 30 July 2003.

U.S.E.P.A. Particulate Matter (PM 10$)$.

$<$ http://www.epa.gov/oar/aqtrnd97/brochure/pm10.html $>$ Accessed: July 30, 2003.

Updated: April 9, 2002.

California Air Resources Board. <www.arb.ca.gov>

Zielinska, B., Sagebiel, J., Lev-On, M., LeTavec, C., Alleman, T., Lawson, D., Vertin, K., Thompson, G.J., Gautam, M., Wayne, S., and Okamoto, R. (2001). Chemical Characterization of Exhaust Emissions from Heavy Duty Diesel Vehicles Using Low Sulfur Fuel and Equipped with Particulate Filters. SAE 42565. 


\section{Appendix A: Vehicle and Engine Specifications}

\section{Vehicle Data}

Make: Orion

Model: 1994

Style: 40 foot, High-Floor

\section{Engine Data}

Make: Cummins Westport Innovations (CWI)

Model Year: 2000

Model: C-Series, Gas Plus

Cylinders: 6

Bore and Stroke: 4.49 x 5.32 in. $(114 \times 135 \mathrm{~mm})$

Displacement: $505 \mathrm{cu}$. in. (8.3L)

Compression Ratio: 10:1

Operating Cycles: 4

Oil Capacity: 6.3 US Gallons (23.8 Liters)

Coolant Capacity: 10.7 US Quarts. (10.1 Liters)

Net Weight: 1330 lbs. (604 kg)

\section{Operating Data}

Engine Power: $280 \mathrm{hp}(205 \mathrm{~kW})$

Peak Torque: 850 lb-ft (1152 N-m) 


\section{Appendix B: Vehicle Configurations and Test Matrix}

Table B.1 Test Matrix

\begin{tabular}{|c|c|c|c|}
\hline $\begin{array}{c}\text { Test } \\
\text { Configuration }\end{array}$ & $\begin{array}{c}\text { Test } \\
\text { Sequence } \\
\text { Number }\end{array}$ & Date & $\begin{array}{c}\text { Test } \\
\text { Validity }\end{array}$ \\
\hline Background & $2733-01$ & $9 / 18 / 2003$ & Invalid \\
\hline Background & $2736-01$ & $9 / 18 / 2003$ & Invalid \\
\hline Background & $2740-01$ & $9 / 19 / 2003$ & Valid \\
\hline Background & $2743-01$ & $9 / 19 / 2003$ & Valid \\
\hline Background & $2992-01$ & $3 / 17 / 2004$ & Valid \\
\hline Background & $2995-01$ & $3 / 17 / 2004$ & Valid \\
\hline Baseline & $2735-01$ & $9 / 18 / 2003$ & Invalid \\
\hline Baseline & $2735-02$ & $9 / 18 / 2003$ & Invalid \\
\hline Baseline & $2735-03$ & $9 / 18 / 2003$ & Invalid \\
\hline Baseline & $2742-01$ & $9 / 19 / 2003$ & Valid \\
\hline Baseline & $2742-02$ & $9 / 19 / 2003$ & Valid \\
\hline OEM & $2734-01$ & $9 / 18 / 2003$ & Invalid \\
\hline OEM & $2734-02$ & $9 / 18 / 2003$ & Invalid \\
\hline OEM & $2734-03$ & $9 / 18 / 2003$ & Invalid \\
\hline OEM & $2741-01$ & $9 / 19 / 2003$ & Valid \\
\hline OEM & $2741-02$ & $9 / 19 / 2003$ & Invalid \\
\hline OEM & $2741-03$ & $9 / 19 / 2003$ & Valid \\
\hline OEM & $2741-04$ & $9 / 19 / 2003$ & Valid \\
\hline WVU-Lubrizol & $2994-01$ & $3 / 17 / 2004$ & Valid \\
\hline WVU-Lubrizol & $2994-02$ & $3 / 17 / 2004$ & Valid \\
\hline WVU-Lubrizol & $294-03$ & $3 / 17 / 2004$ & Valid \\
\hline & & &
\end{tabular}




\section{Appendix C: WVU-Lubrizol Aftertreatment Specifications}

\section{Diesel Particulate Filter}

Silicon Carbide segmented honeycom11.25 x 12 (D x L) inches

200 square CPI Cell density

Pt coated on proprietary wash-coat for passive regeneration over duty cycles producing exhaust temperature $280-320 \mathrm{C}$ for $>25 \%$ of time

\section{Oxidation Catalyst}

Cordierite monolith 10.5 x $6(\mathrm{D} \times \mathrm{L})$ inches

400 square CPI Cell Density

Pd coated on proprietary wash-coat 


\section{Appendix D: VOC Sampling System Operation}

The VOC sampling system mass flow controller and power supply/readout are

integrated into the sampling system. A warm-up period of 30 minutes is required for the electronic equipment stabilization before sampling. The sample canisters hold $6.0 \mathrm{~L}$ at ambient pressure and temperature, and are to be pressurized to 10 psig during the sampling procedure. In order to achieve the desired canister pressure, a total volume of 10.1 L must be sampled according to the following equation.

$$
\left(\frac{10+14.7}{14.7}\right) * 6.0 L=10.1 L \text { Equation D.1 }
$$

The flow rate required to achieve the desired volume is calculated using the following equation.

$$
\frac{10.1 L}{30 \min } *\left(\frac{1000 m l}{L}\right)=337 \frac{\mathrm{ml}}{\min } \text { Equation D.2 }
$$

1. With the 3-way valve selecting SAMPLE BYPASS and the pump off, BYPASS pressure should read 0 psig and the SAMPLE pressure should read 0 psig (atmospheric). 2. Turn the pump on.

3. BYPASS pressure should now read $15 \mathrm{psig}$. Use the needle valve to adjust this pressure accordingly.

4. The mass flow controller should be set to deliver the aforementioned flow rate. A rotameter can be used to verify the flow rate.

5. A leak check must be performed on the system. To perform a leak check, attach a short Teflon hose to the SAMPLE port and cap it off. Next, turn the 3-way valve to SAMPLE and watch the pressure increase. When the pressure increase halts, turn the 3- 
way valve to SAMPLE BYPASS and record the pressure on the sample line. If the line is leak free, the pressure on the SAMPLE gauge should stay constant. Locate and correct any leaks. The leak check must be repeated after any leak is corrected.

6. To start sampling, uncap the sample canister and attach the SAMPLE line to the canister. DO NOT OPEN the canister valve.

7. Verify that the 3-way valve is set to SAMPLE BYPASS.

8. After step 7 is verified, open the canister valve and record the vacuum pressure indicated via the SAMPLE pressure gauge. The gauge should read approximately 28 inches of vacuum.

9. To start sampling, turn the 3-way valve to SAMPLE. To stop sampling, turn the 3-way valve to BYPASS. Record the final pressure on the canister. This value should be close to 10 psig.

10. Close the canister valve before removing the sample line from the canister. Cap the canister valve.

11. Be very careful when replacing canister valve caps, not to over tighten the cap. Turn the cap until finger tight, and then turn an additional 1/8 turn with the correct wrench. DO NOT FORCE. 


\section{Appendix E: Lubrication Oil Analysis}

Oil Science Laboratory of Lawndale, CA performed lubrication oil analysis on clean lubricating oil and used oil samples.

Table E.1 Lubrication Oil Analysis

\begin{tabular}{|c|c|c|}
\hline \multicolumn{3}{|c|}{ Oil: 76 Triton VGEO+ 15w40 } \\
\hline & Baseline & Used \\
\hline Metal & $\mathbf{p p m}$ & $\mathbf{p p m}$ \\
\hline Iron & $<1$ & 9 \\
\hline Chromium & $<1$ & $<1$ \\
\hline Zinc & 780 & 904 \\
\hline Aluminum & $<1$ & 1 \\
\hline Manganese & $<1$ & $<1$ \\
\hline Tin & $<1$ & 1 \\
\hline Phosphorus & 565 & 670 \\
\hline Calcium & 943 & 1110 \\
\hline Nickel & $<1$ & $<1$ \\
\hline Copper & $<1$ & 4 \\
\hline Lead & $<1$ & 3 \\
\hline Boron & 21 & 2 \\
\hline Silicon & 1 & 4 \\
\hline Sodium & $<1$ & 2 \\
\hline Barium & $<1$ & 1 \\
\hline Magnesium & $<1$ & 48 \\
\hline Titanium & $<1$ & $<1$ \\
\hline
\end{tabular}




\section{Appendix F: Round 1 Speciation Results}

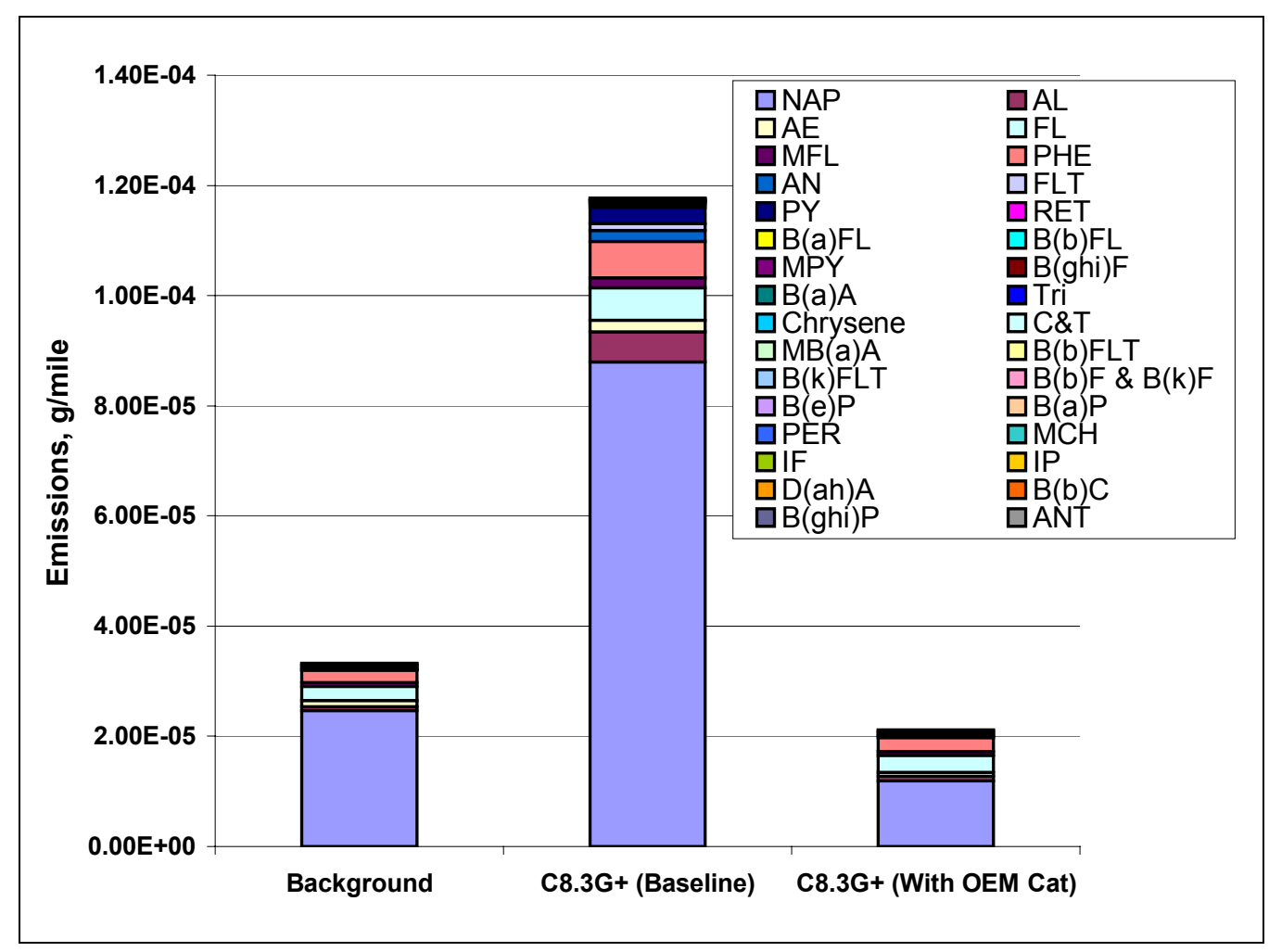

Figure F.1 PAH Results With Background Values

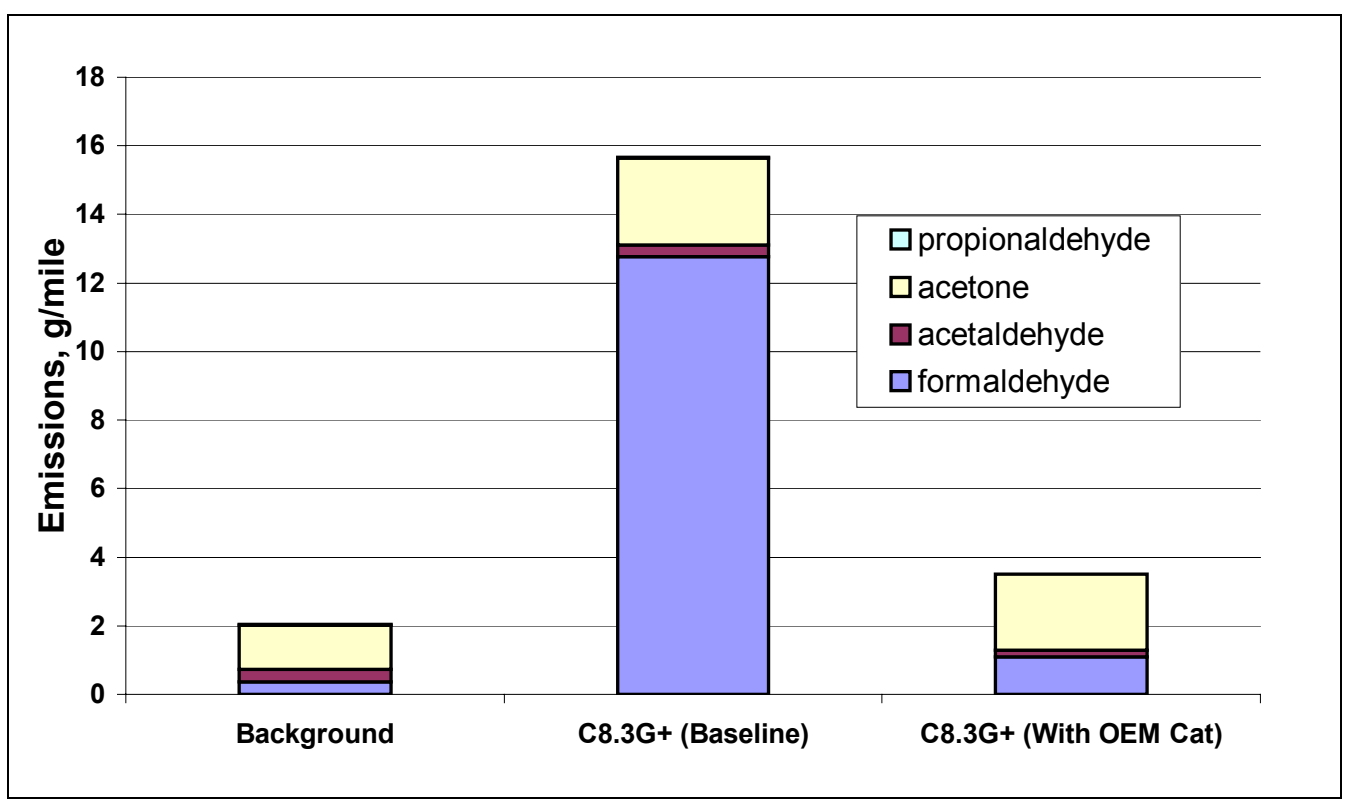

Figure F.2 Carbonyl Results With Background Values 


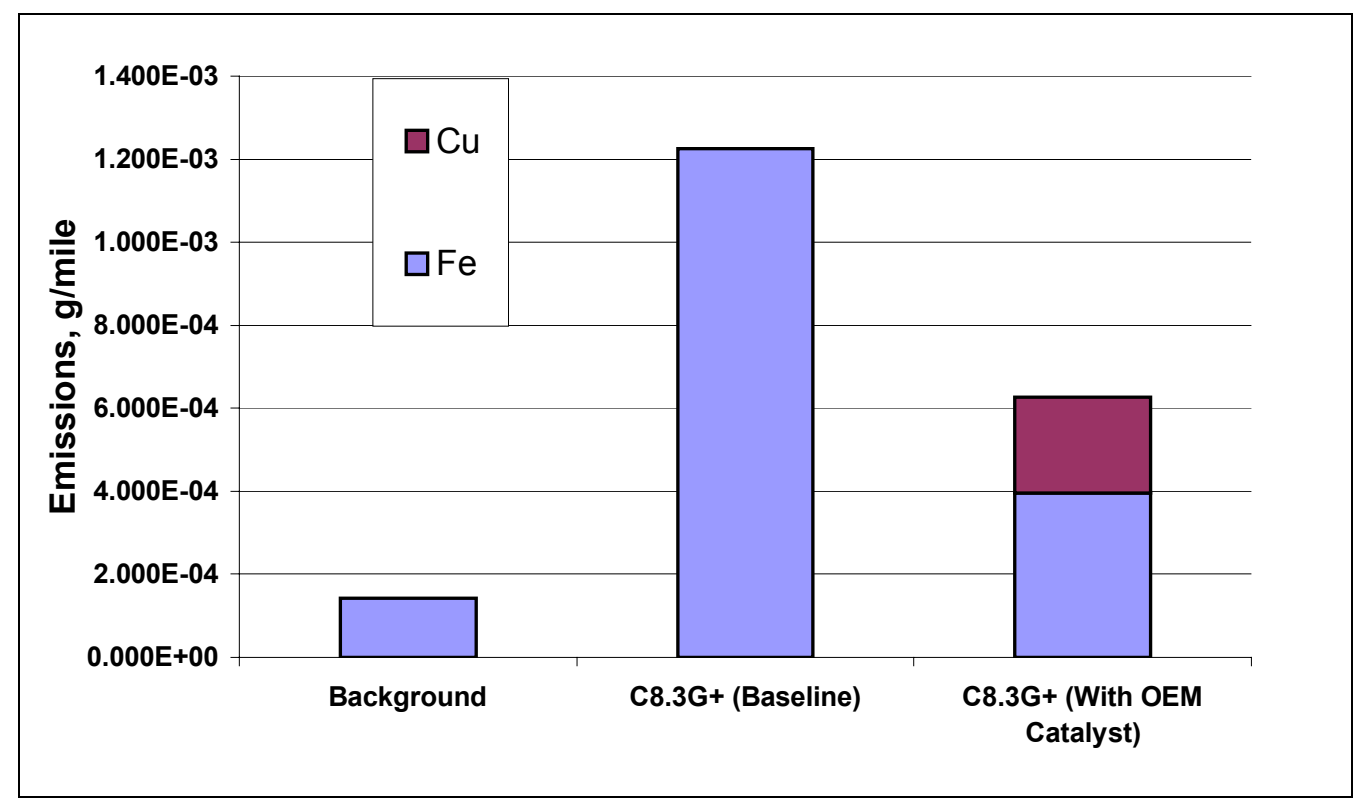

Figure F.3 Engine Wear Metal Results With Background Values

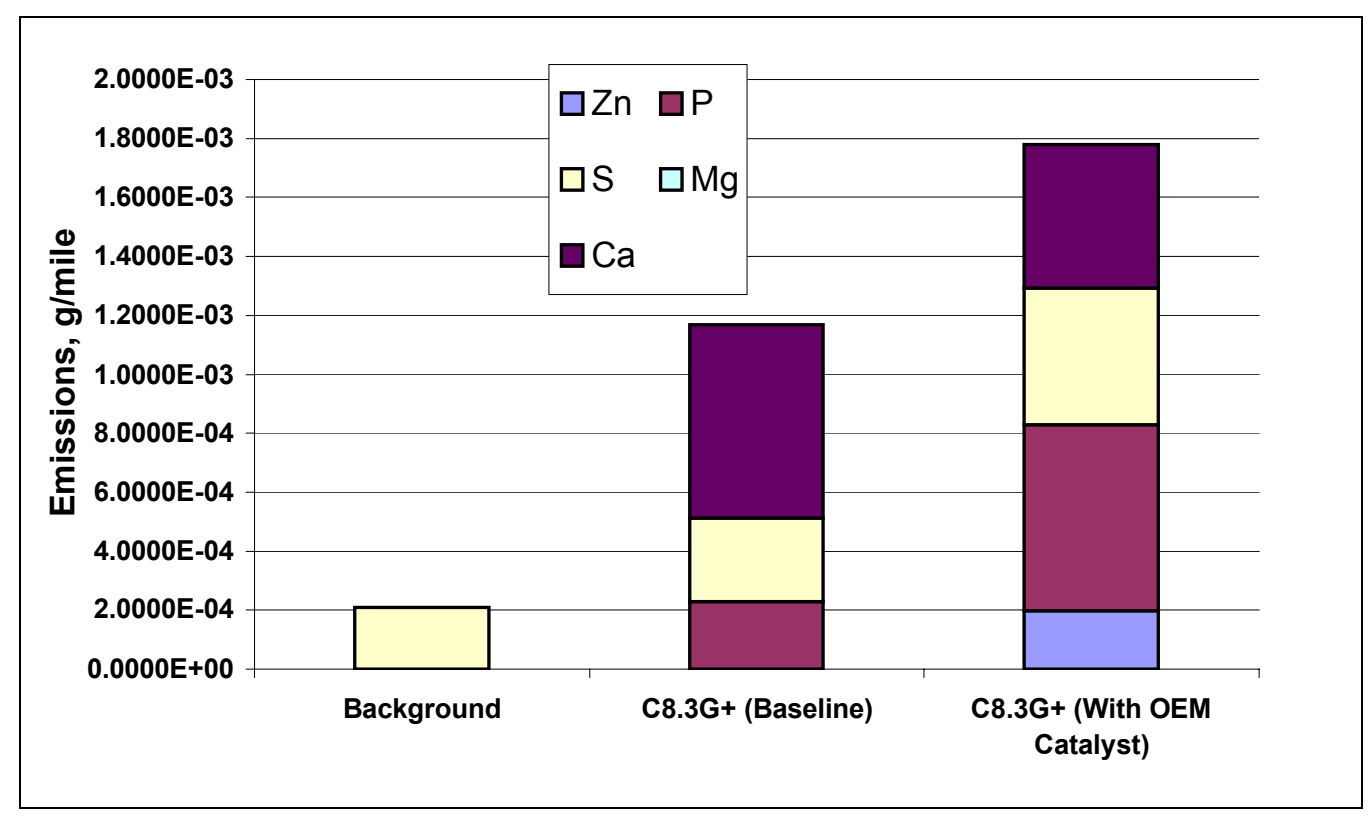

Figure F.4 Lubrication Oil Results With Background Values 


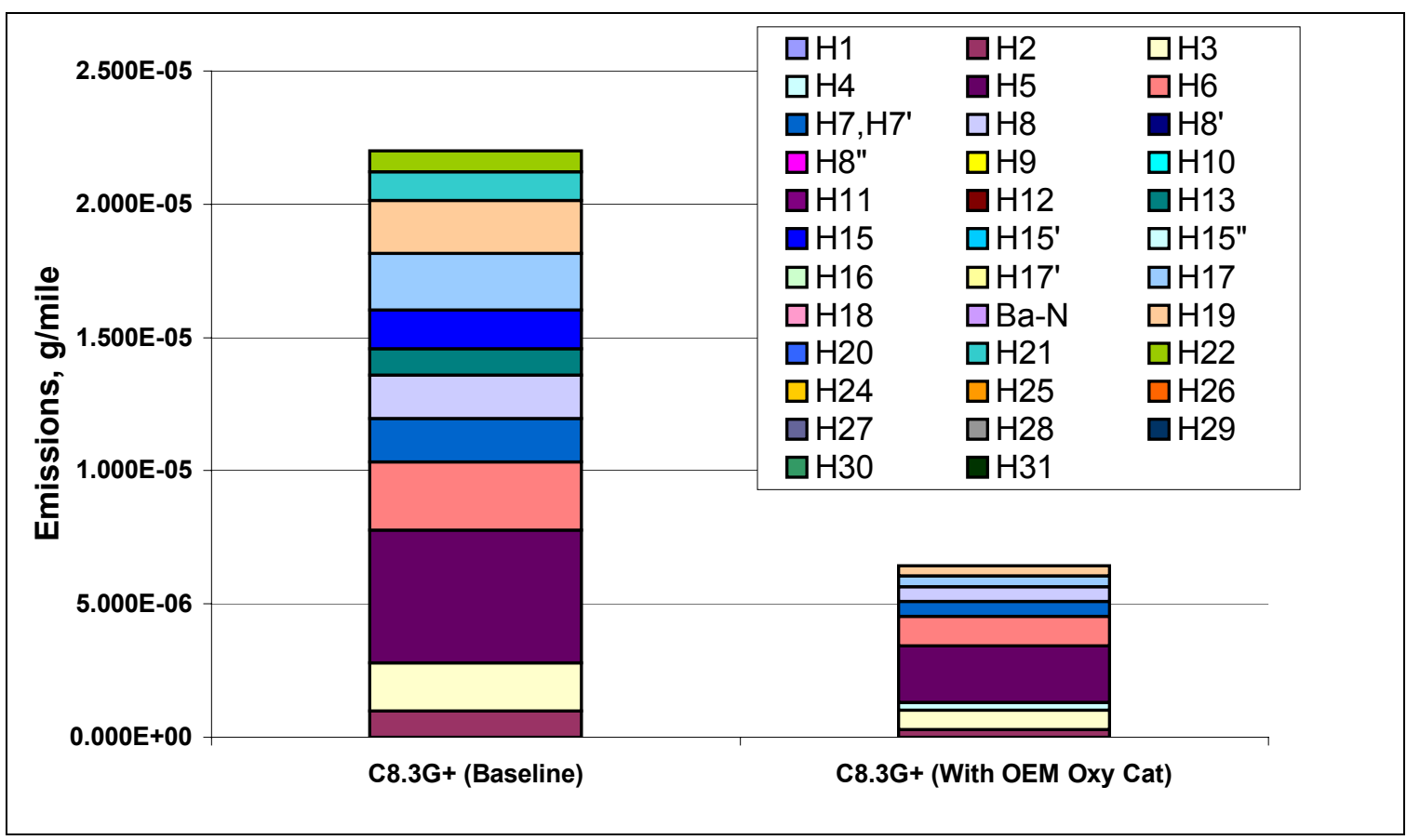

Figure F.5 Hopane Results

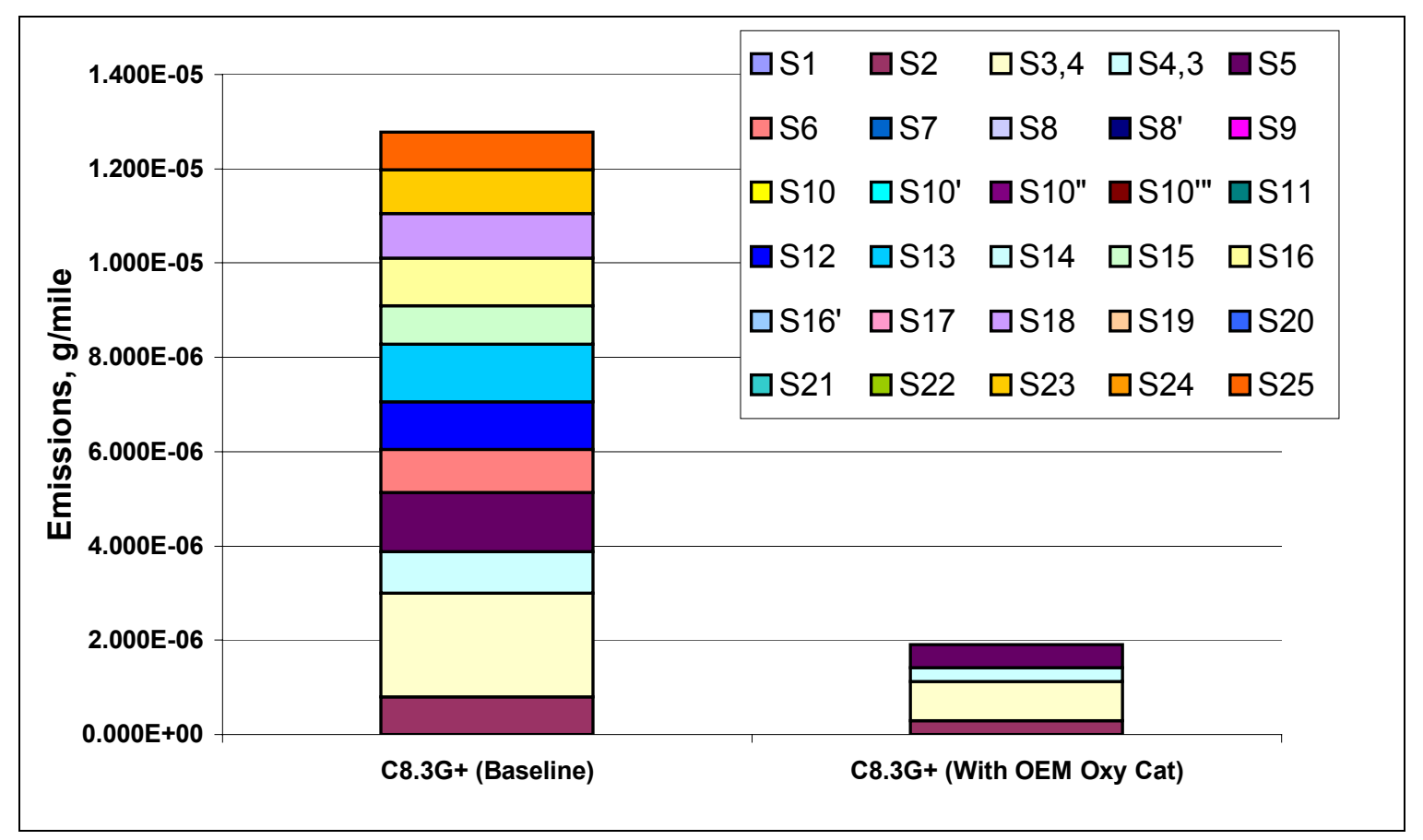

Figure F.6 Sterane Results 


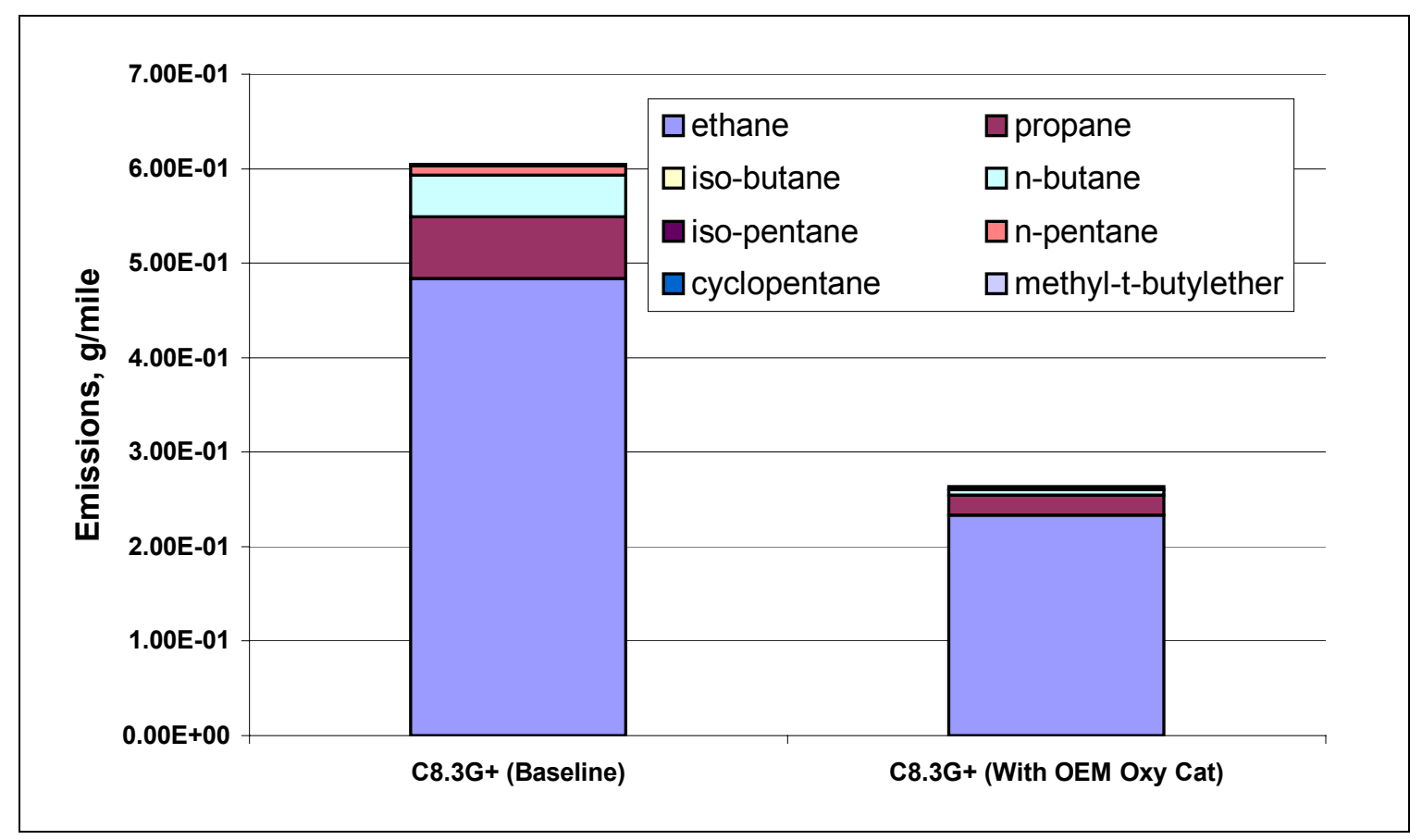

Figure F.7 Alkane Results

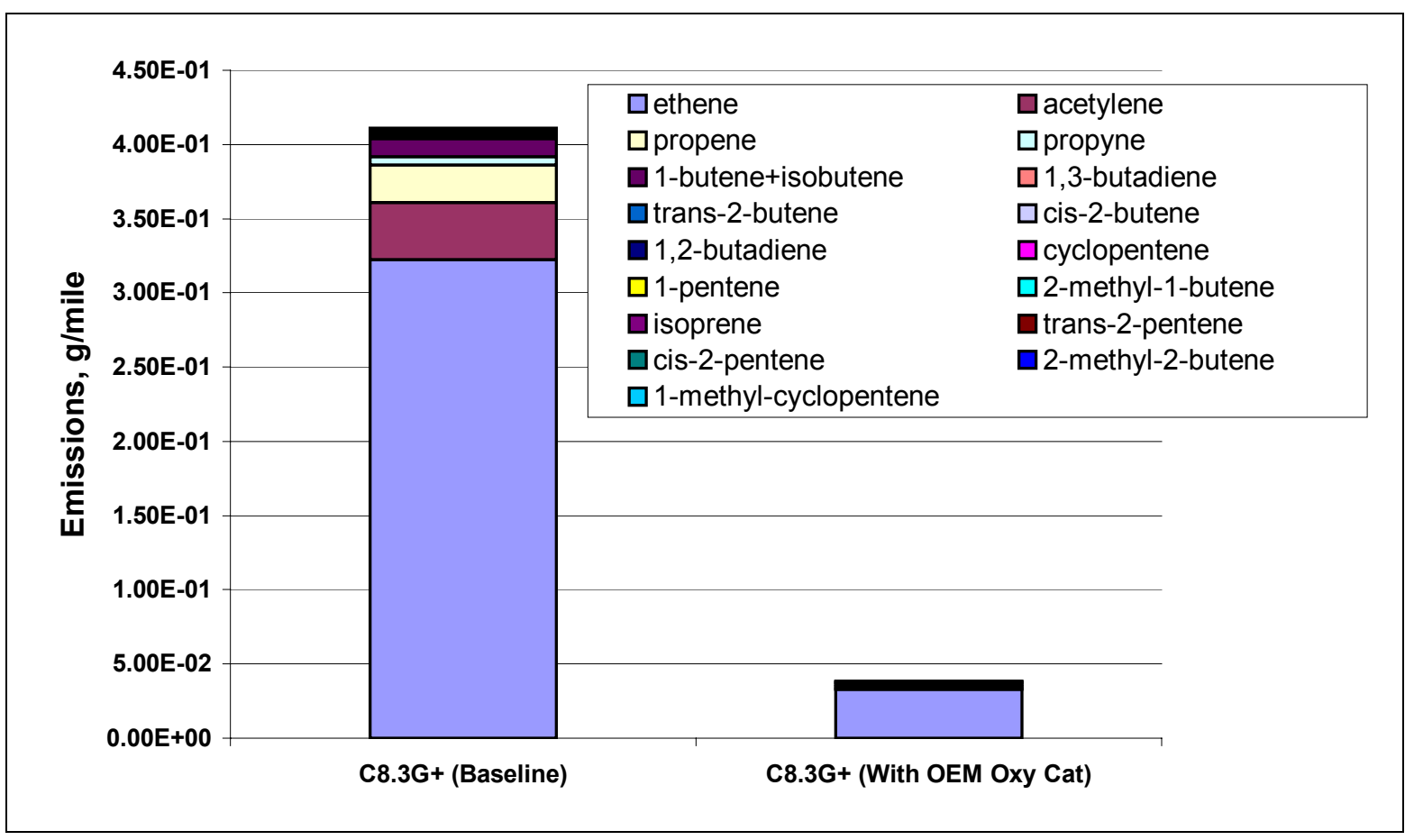

Figure F.8 Olefin Results 


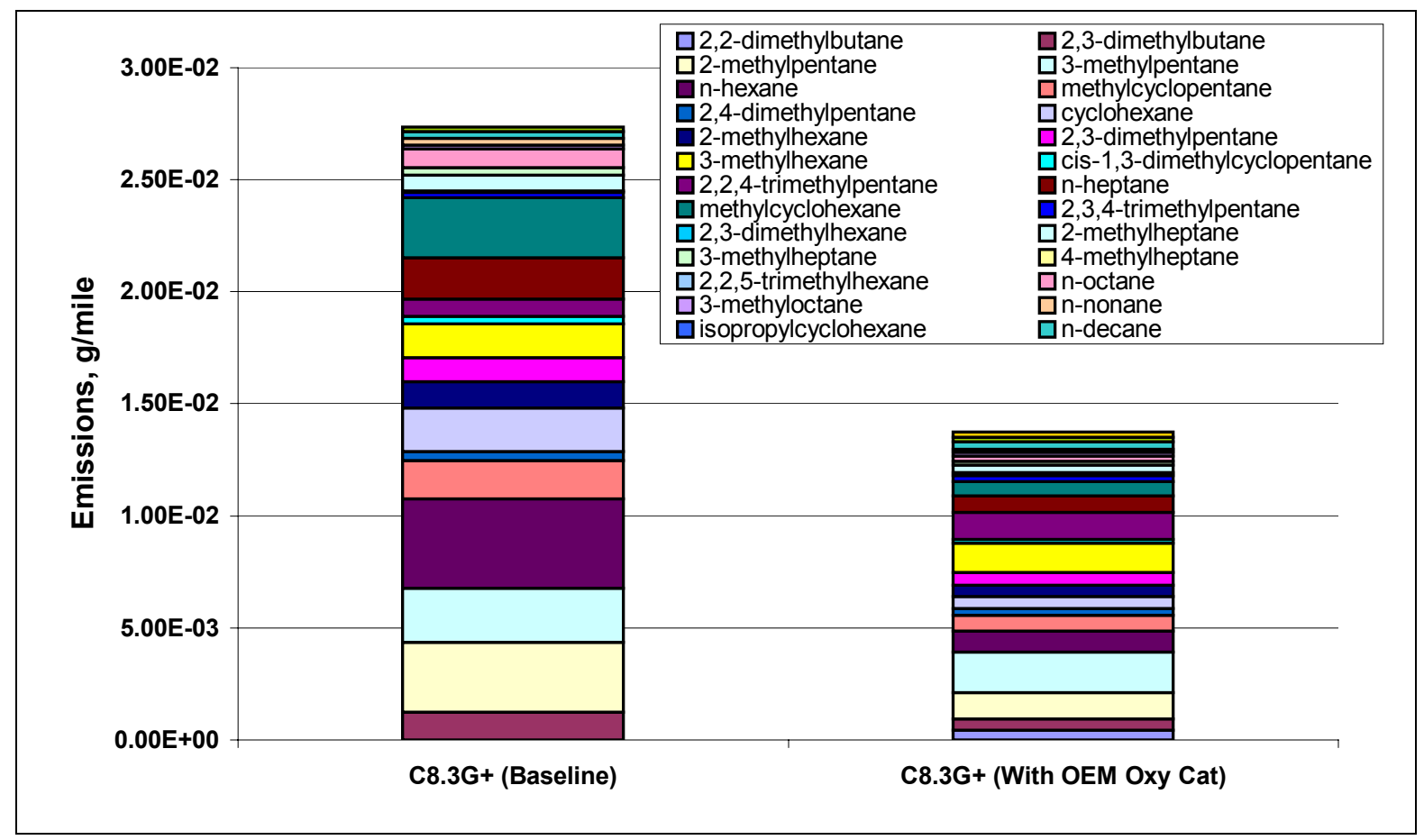

Figure F.9 C6 and Heavier Alkanes

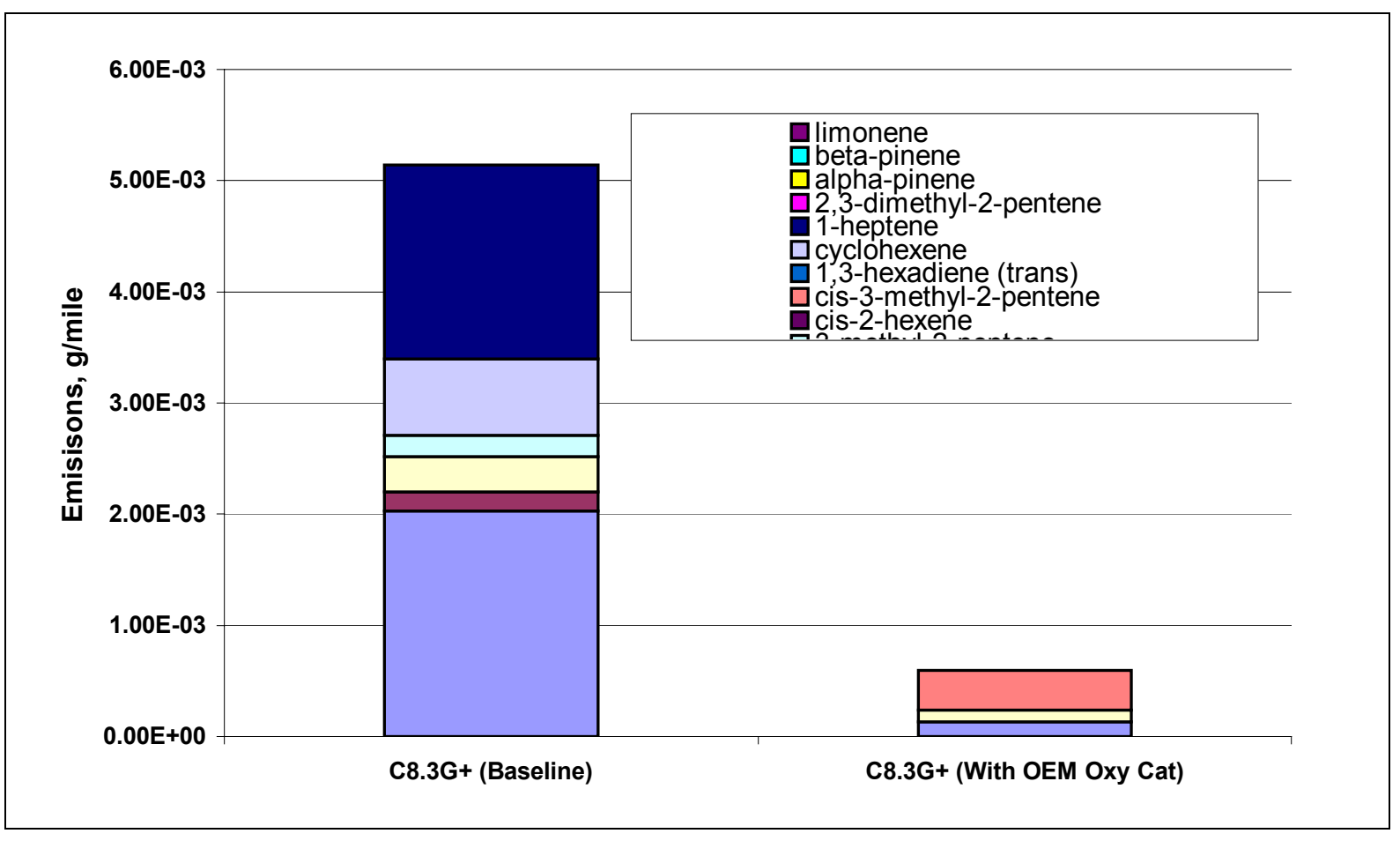

Figure F.10 C6 and Heavier Olefins 


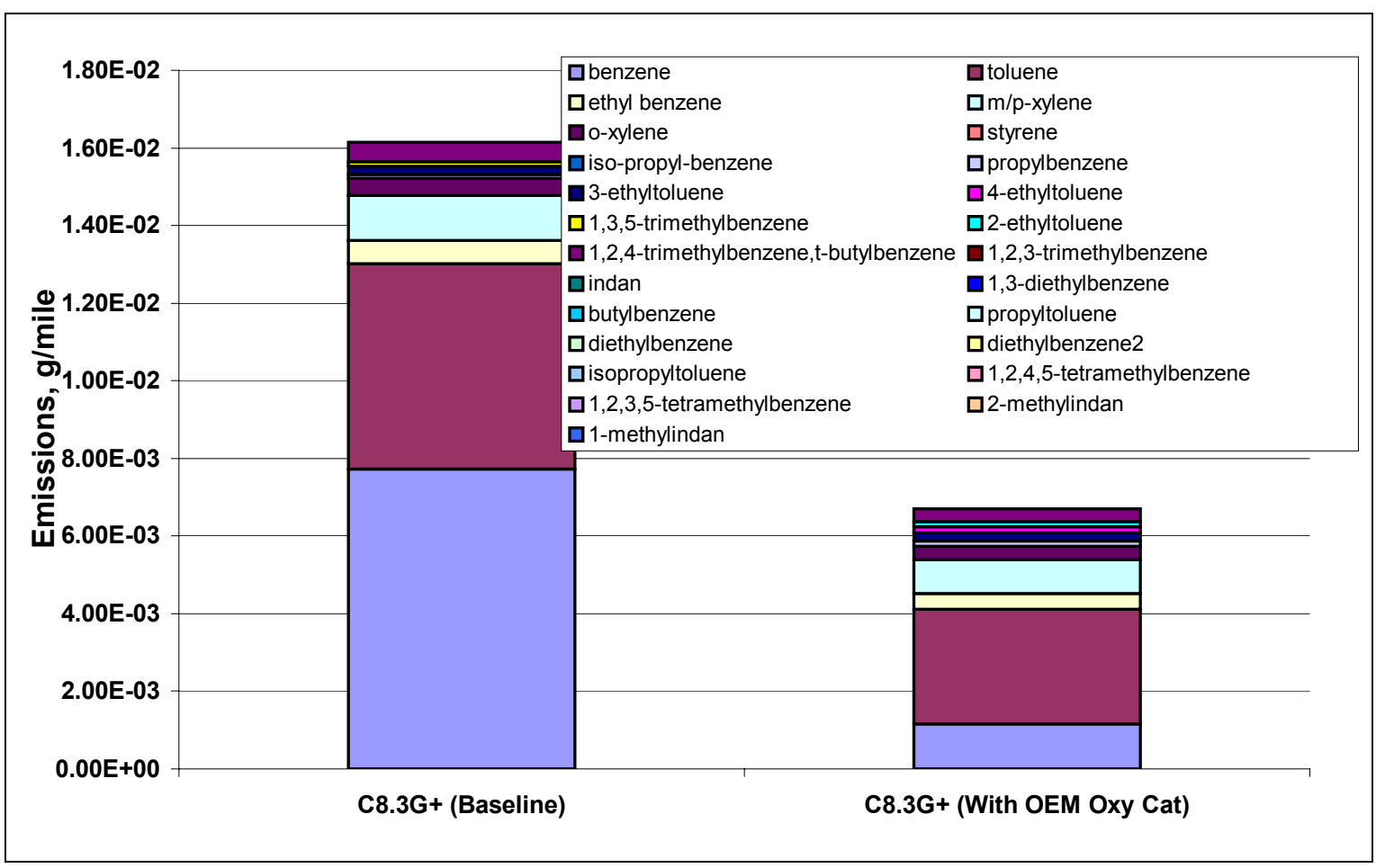

Figure F.11 Aromatic Results

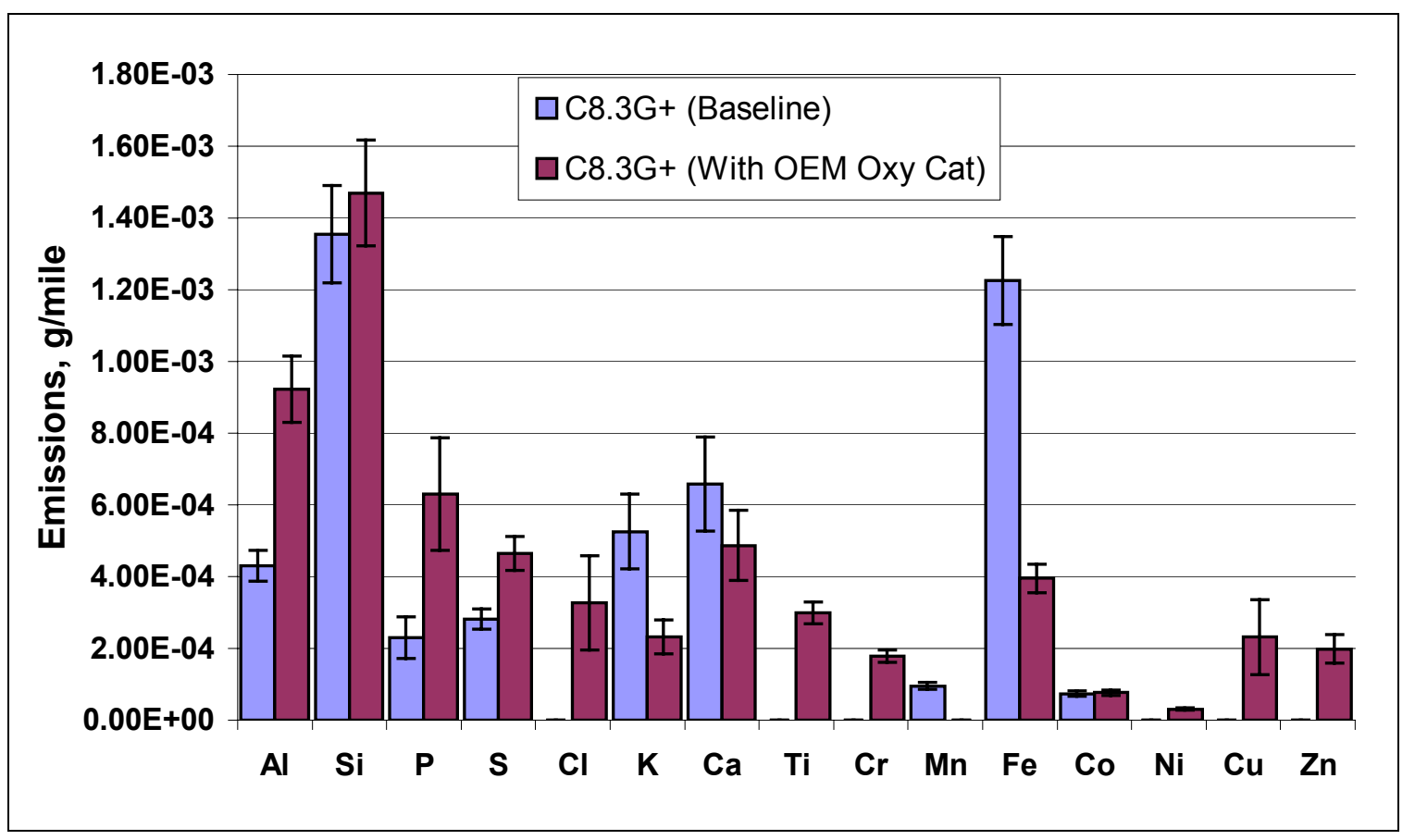

Figure F.12 Elemental Metal Analysis with Uncertainty 


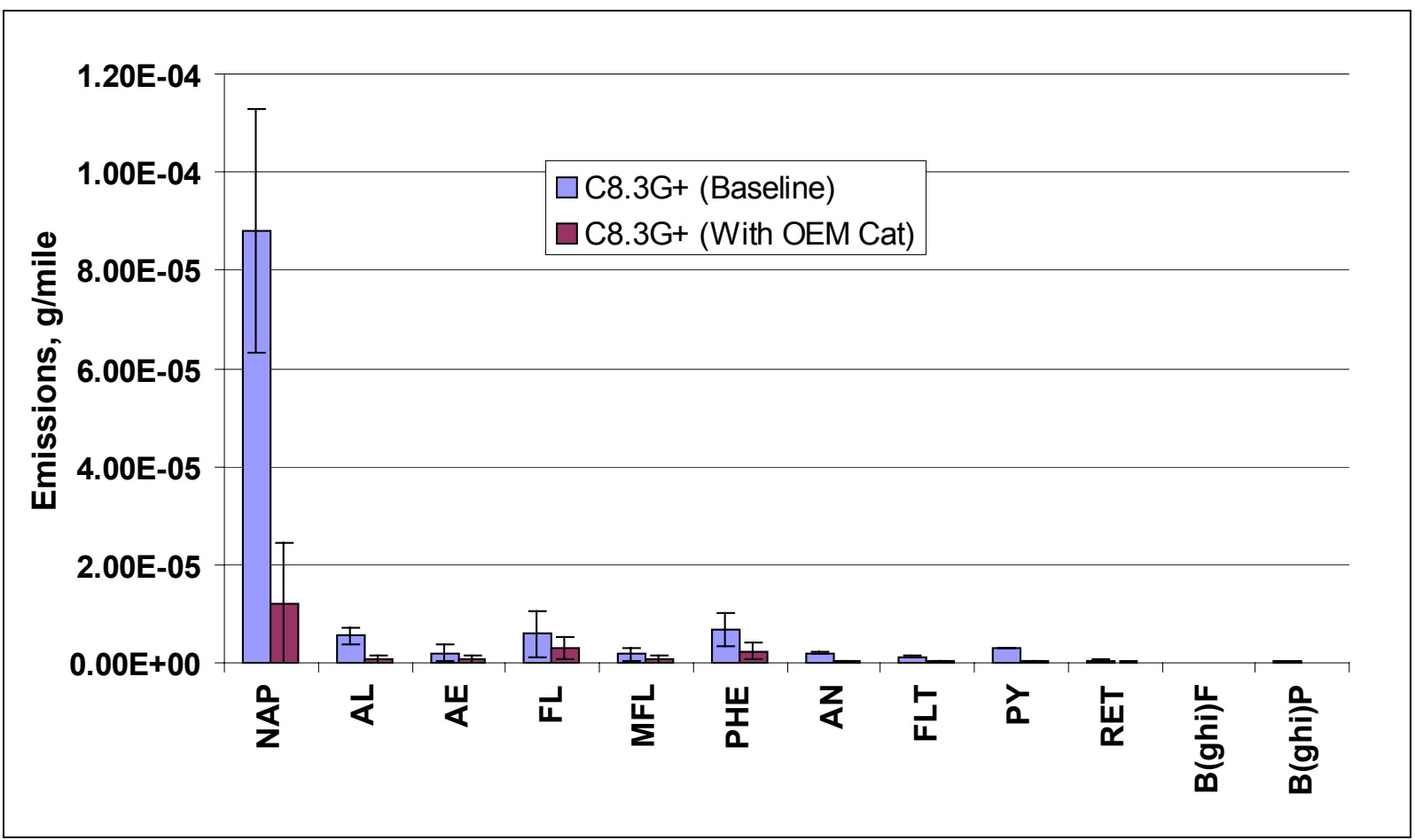

Figure F.13 PAH Results with Uncertainty

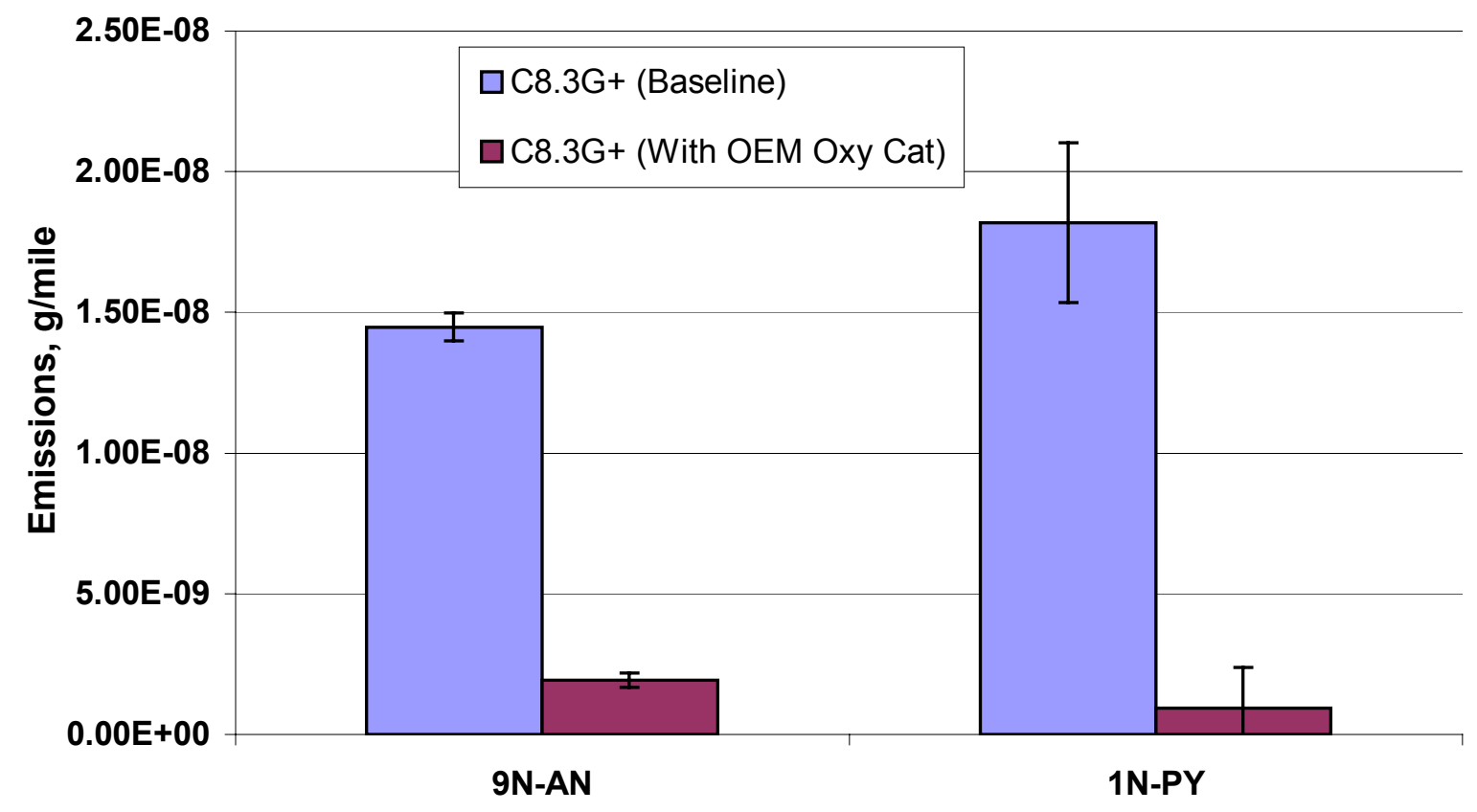

Figure F.14 Nitro-PAH with Uncertainty 